NASA/TM—2009-215486

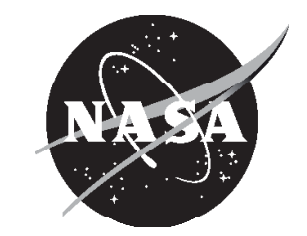

Numerical Study of Outlet Boundary Conditions for Unsteady Turbulent Internal Flows Using the NCC

Tsan-Hsing Shih

Ohio Aerospace Institute, Brook Park, Ohio

Nan-Suey Liu

Glenn Research Center, Cleveland, Ohio 


\section{NASA STI Program . . . in Profile}

Since its founding, NASA has been dedicated to the advancement of aeronautics and space science. The NASA Scientific and Technical Information (STI) program plays a key part in helping NASA maintain this important role.

The NASA STI Program operates under the auspices of the Agency Chief Information Officer. It collects, organizes, provides for archiving, and disseminates NASA's STI. The NASA STI program provides access to the NASA Aeronautics and Space Database and its public interface, the NASA Technical Reports Server, thus providing one of the largest collections of aeronautical and space science STI in the world. Results are published in both non-NASA channels and by NASA in the NASA STI Report Series, which includes the following report types:

- TECHNICAL PUBLICATION. Reports of completed research or a major significant phase of research that present the results of NASA programs and include extensive data or theoretical analysis. Includes compilations of significant scientific and technical data and information deemed to be of continuing reference value. NASA counterpart of peer-reviewed formal professional papers but has less stringent limitations on manuscript length and extent of graphic presentations.

- TECHNICAL MEMORANDUM. Scientific and technical findings that are preliminary or of specialized interest, e.g., quick release reports, working papers, and bibliographies that contain minimal annotation. Does not contain extensive analysis.

- CONTRACTOR REPORT. Scientific and technical findings by NASA-sponsored contractors and grantees.

- CONFERENCE PUBLICATION. Collected papers from scientific and technical conferences, symposia, seminars, or other meetings sponsored or cosponsored by NASA.

- SPECIAL PUBLICATION. Scientific, technical, or historical information from NASA programs, projects, and missions, often concerned with subjects having substantial public interest.

- TECHNICAL TRANSLATION. Englishlanguage translations of foreign scientific and technical material pertinent to NASA's mission.

Specialized services also include creating custom thesauri, building customized databases, organizing and publishing research results.

For more information about the NASA STI program, see the following:

- Access the NASA STI program home page at http://www.sti.nasa.gov

- E-mail your question via the Internet to help@ sti.nasa.gov

- Fax your question to the NASA STI Help Desk at 301-621-0134

- Telephone the NASA STI Help Desk at 301-621-0390

- Write to: NASA Center for AeroSpace Information (CASI) 7115 Standard Drive Hanover, MD 21076-1320 
NASA/TM—2009-215486

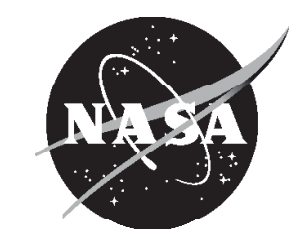

\section{Numerical Study of Outlet Boundary Conditions for Unsteady Turbulent Internal Flows Using the NCC}

Tsan-Hsing Shih

Ohio Aerospace Institute, Brook Park, Ohio

Nan-Suey Liu

Glenn Research Center, Cleveland, Ohio

National Aeronautics and

Space Administration

Glenn Research Center

Cleveland, Ohio 44135 


\section{Acknowledgments}

This work is supported by the NASA Fundamental Aeronautics Program. The authors would like to thank Dr. Jeffrey P. Moder for his useful comments and suggestions on the implementation of the outlet boundary condition.

This report is a formal draft or working paper, intended to solicit comments and ideas from a technical peer group.

This report contains preliminary findings, subject to revision as analysis proceeds.

Trade names and trademarks are used in this report for identification only. Their usage does not constitute an official endorsement, either expressed or implied, by the National Aeronautics and Space Administration.

This work was sponsored by the Fundamental Aeronautics Program at the NASA Glenn Research Center.

Level of Review: This material has been technically reviewed by technical management.

Available from

NASA Center for Aerospace Information 7115 Standard Drive

Hanover, MD 21076-1320
National Technical Information Service 5285 Port Royal Road Springfield, VA 22161 


\section{Contents}

Abstract fon

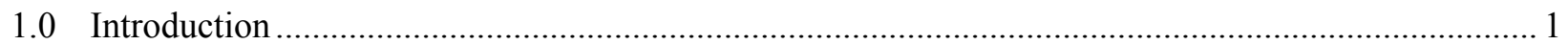

2.0 Unsteady Outlet Boundary Conditions....................................................................... 2

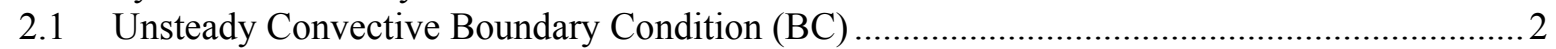

2.2 Implementation of Unsteady Convective BC in the NCC ............................................... 3

2.3 Extrapolation Boundary Condition......................................................................... 3

3.0 PRNS/VLES of LM6000 Single Injector Flame Tube .............................................................. 3

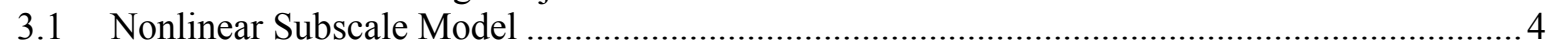

3.1.1 Results Using Unsteady Convective BC for Pressure Only ..................................... 4

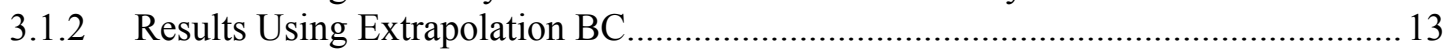

3.1.3 Results Using Fixed Pressure at the Outlet .......................................................... 17

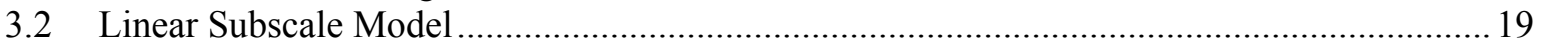

3.2.1 Results Using Unsteady Convective BC for Pressure Only …............................... 19

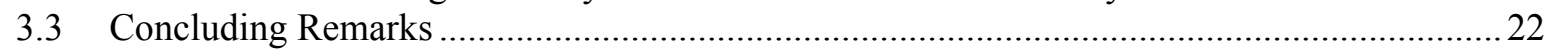

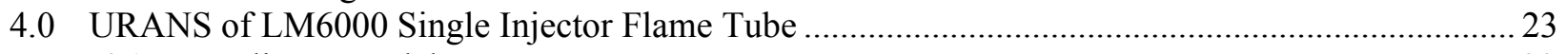

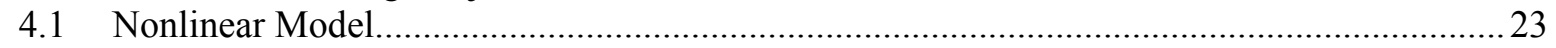

4.1.1 Results Using Unsteady Convective BC for Pressure Only ….................................23

4.1.2 Results Using Fixed Pressure at the Outlet ............................................................ 32

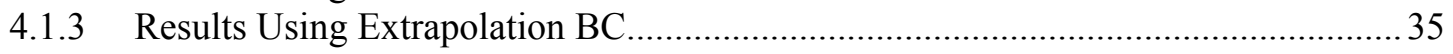

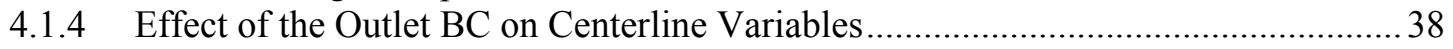

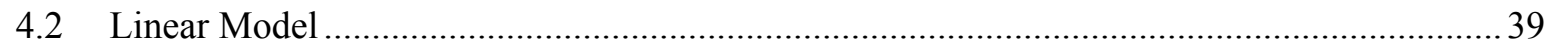

4.2.1 Results Using Unsteady Convective BC for Pressure Only …….............................. 39

4.3 Comparison of Centerline Variables Between Linear and Nonlinear Models ....................... 40

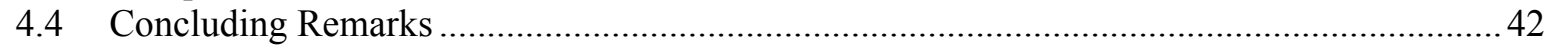

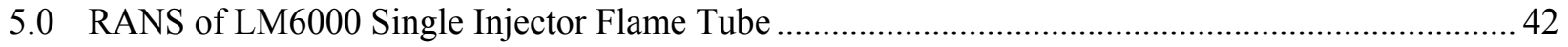

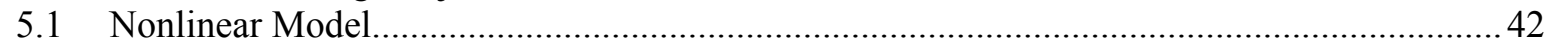

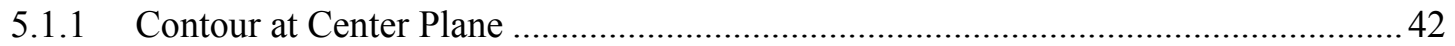

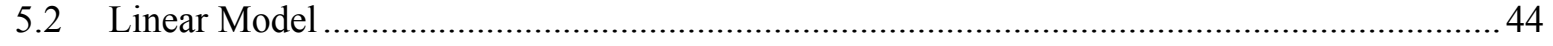

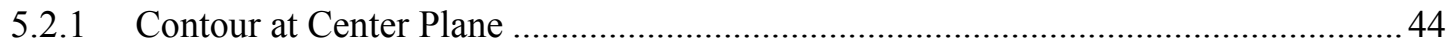

5.3 Comparison of Centerline Variables Between Nonlinear and Linear Models ....................... 45

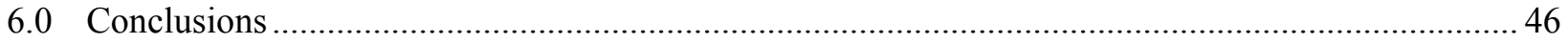

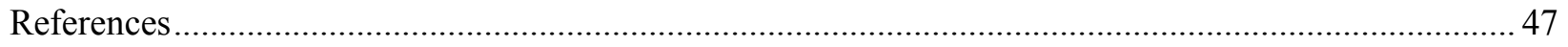





\title{
Numerical Study of Outlet Boundary Conditions for Unsteady Turbulent Internal Flows Using the NCC
}

\author{
Tsan-Hsing Shih \\ Ohio Aerospace Institute \\ Brook Park, Ohio 44142 \\ Nan-Suey Liu \\ National Aeronautics and Space Administration \\ Glenn Research Center \\ Cleveland, Ohio 44135
}

\begin{abstract}
This paper presents the results of studies on the outlet boundary conditions for turbulent internal flow simulations. Several outlet boundary conditions have been investigated by applying the National Combustion Code (NCC) to the configuration of a LM6000 single injector flame tube. First of all, very large eddy simulations (VLES) have been performed using the partially resolved numerical simulation (PRNS) approach, in which both the nonlinear and linear dynamic subscale models were employed. Secondly, unsteady Reynolds averaged Navier-Stokes (URANS) simulations have also been performed for the same configuration to investigate the effects of different outlet boundary conditions in the context of URANS. Thirdly, the possible role of the initial condition is inspected by using three different initial flow fields for both the PRNS/VLES simulation and the URANS simulation. The same grid is used for all the simulations and the number of mesh element is about 0.5 million.

The main purpose of this study is to examine the long-time behavior of the solution as determined by the imposed outlet boundary conditions. For a particular simulation to be considered as successful under the given initial and boundary conditions, the solution must be sustainable in a physically meaningful manner over a sufficiently long period of time.

The commonly used outlet boundary condition for steady Reynolds averaged Navier-Stokes (RANS) simulation is a fixed pressure at the outlet with all the other dependent variables being extrapolated from the interior. The results of the present study suggest that this is also workable for the URANS simulation of the LM6000 injector flame tube. However, it does not work for the PRNS/VLES simulation due to the unphysical reflections of the pressure disturbances at the outlet boundary. This undesirable situation can be practically alleviated by applying a simple unsteady convection equation for the pressure disturbances at the outlet boundary. The numerical results presented in this paper suggest that this unsteady convection of pressure disturbances at the outlet works very well for all the unsteady simulations (both PRNS/VLES and URANS) of the LM6000 single injector flame tube.
\end{abstract}

\subsection{Introduction}

Large eddy simulation (LES) and very large eddy simulation (VLES) of reacting turbulent internal flows are critically important for the accurate modeling of the mixing and combustion processes occurring in the combustors. Recently, we have developed an approach, called the partially resolved numerical simulation (PRNS), which aims at bringing out the dynamically important unsteady large and very large scale turbulent structures in the numerical simulation, but only using computer resources typically required by the unsteady Reynolds averaged Navier-Stoke approach (URANS). As a result, the PRNS/VLES approach is quite practical for engineering application. Its physical fidelity is higher than that of the RANS, while its demand on the computing resources is significantly lower than the demand by the LES. 
In our previous efforts (Refs. 1 to 4), either the periodic boundary condition or the extrapolation boundary condition was imposed at the outlet of the computational domain; mainly for the purpose of assessing the fundamentals and/or demonstrating the short-time solution of the PRNS/VLES approach. However, it is well known that the outlet boundary condition is critically important to the long-time solution of numerical simulation of turbulent flows (Refs. 5 to 6). The goal of the present effort is to identify a workable but simple outlet boundary condition (BC) for the long-time PRNS/VLES solution of turbulent internal flows. Our criteria for a workable boundary condition are set as follows: It must lead to a physically meaningful numerical solution; and this meaningful solution must be sustainable over a sufficiently long period of time.

In the current assessment effort, we have chosen the convective type of boundary condition (Ref. 7) as our baseline. Other types of outlet boundary conditions such as the extrapolation boundary condition and the fixed pressure boundary condition are also used for comparison. The numerical simulations were performed using the configuration of a LM6000 single injector flame tube, as its characteristic flow features are representative of the flow features typically occurring in the practical combustors. The same grid of about 0.5 million elements was used in all of the calculations.

Both PRNS/VLES and URANS numerical simulations were carried out. Two subscale models (nonlinear and linear) of PRNS/VLES were applied. Two Reynolds stress models (nonlinear and linear) of URANS were also used. For each type of simulation (PRNS/VLES or URANS), different outlet boundary conditions (i.e., the convective $\mathrm{BC}$, the extrapolated $\mathrm{BC}$, and the fixed pressure $\mathrm{BC}$ ) were applied for comparison. Furthermore, three different initial conditions (i.e., the nonlinear RANS solution, the linear RANS solution and the static flow field) were employed for each type of simulation to examine the effect of the initial conditions.

The numerical results are presented in terms of the time history of flow variables at four locations along the centerline of the flame tube; the instantaneous distribution of flow variables at a center plane, and the variation of flow variables along the centerline. The effects of the initial condition and the turbulence model are examined in the context of the imposed outlet boundary condition for either the PRNS/VLES or the URANS simulation.

\subsection{Unsteady Outlet Boundary Conditions}

A brief description of the unsteady outlet boundary condition and its implementation in the NCC will be given in this section.

\subsection{Unsteady Convective Boundary Condition (BC)}

The following unsteady convective boundary condition (Ref. 7) will be applied at the outlet boundary:

$$
\frac{\partial \phi_{\ell b}}{\partial t}+U\left(\frac{\partial \phi_{\ell}}{\partial n}\right)_{b}=0, \quad \phi_{\ell}=u, v, w, f_{k}, p, h, k, \varepsilon
$$

Where $\phi_{\ell}$ represents a dependent flow variable, for example, the velocity components $u, v, w$, the mass fraction of species $f_{k}$, the gauge pressure $p$ and the specific enthalpy $h$, the subscale turbulent kinetic energy and its dissipation rate $k$ and $\varepsilon$. The outlet boundary is indicated by the subscript $b$ and its unit outward normal is denoted by $n . U$ is a global "convective" velocity out of the boundary surface, and its magnitude is determined, at any instant, by the requirement of the global mass conservation of the entire computational domain. 


\subsection{Implementation of Unsteady Convective BC in the NCC}

Consistent with the solution algorithm for the interior flow field (Ref. 8), Eq. (1) is also solved in a time-accurate manner via the same dual time step scheme in which the convergence of the inner (or the pseudo time) loop is achieved through the application of a 4 stage Runge-Kutta scheme, i.e.,

$$
\begin{aligned}
& \phi_{\ell b}^{0}=\phi_{\ell b}^{n} \\
& \phi_{\ell b}^{1}=\phi_{\ell b}^{0}-\frac{\Delta \tau}{4} R\left(\phi_{\ell b}^{0}\right) /\left(1+\frac{\Delta \tau}{4} \frac{3 / 2}{\Delta t}\right) \\
& \phi_{\ell b}^{2}=\phi_{\ell b}^{0}-\frac{\Delta \tau}{3} R\left(\phi_{\ell b}^{1}\right) /\left(1+\frac{\Delta \tau}{3} \frac{3 / 2}{\Delta t}\right) \\
& \phi_{\ell b}^{3}=\phi_{\ell b}^{0}-\frac{\Delta \tau}{2} R\left(\phi_{\ell b}^{2}\right) /\left(1+\frac{\Delta \tau}{2} \frac{3 / 2}{\Delta t}\right) \\
& \phi_{\ell b}^{4}=\phi_{\ell b}^{0}-\frac{\Delta \tau}{1} R\left(\phi_{\ell b}^{3}\right) /\left(1+\frac{\Delta \tau}{1} \frac{3 / 2}{\Delta t}\right) \\
& \phi_{\ell b}^{n+1}=\phi_{\ell b}^{4}
\end{aligned}
$$

The residual is defined as

$$
R\left(\phi_{\ell b}^{m}\right)=\frac{1}{\Delta t}\left(\frac{3}{2} \phi_{\ell b}^{m}-2 \phi_{\ell b}^{p}+\frac{1}{2} \phi_{\ell b}^{p-1}\right)+U^{m} \frac{\partial \phi_{\ell b}^{m}}{\partial n}
$$

Here, $n$ represents the pseudo time. Within each pseudo time, $m(=0,1,2,3)$ is related to the stage number of the Runge-Kutta scheme, and $p$ denotes the real time. $\Delta \tau$ is the pseudo time step and $\Delta t$ is the real time step. At every real time $p$, Eq. (2) is executed for pseudo time $n(1 \rightarrow \infty)$ until the residual $R$ is reduced to a prescribed order of magnitude. This procedure at the boundary is synchronized with the solver for the interior field to provide the necessary boundary information at each and every Runge-Kutta stage.

\subsection{Extrapolation Boundary Condition}

The extrapolation $\mathrm{BC}$ has the following form:

$$
\left(\frac{\partial \phi_{\ell}}{\partial n}\right)_{b}=0
$$

\subsection{PRNS/VLES of LM6000 Single Injector Flame Tube}

LM6000 is a General Electric low NOx emission gas turbine combustor. We have performed several types of numerical simulations for a single injector flame tube to evaluate the effects of several outlet boundary conditions. A highly swirling jet (a lean methane-air mixture) is injected from a circular inlet into a rectangular duct. The inlet pressure and temperature are about 6 atmospheres and $644 \mathrm{~K}$. The inlet flow variables are specified by using the mean profiles from the experiment. The Reynolds number based on the inlet axial velocity and the inlet jet diameter is about 3,200,000. The following two figures depict the computational domain and the numerical grids on two perpendicular center planes. The total number of grid points is about 495,000, it is noted here that this same grid is used in this study for all simulations (PRNS/VLES, URANS and RANS). 

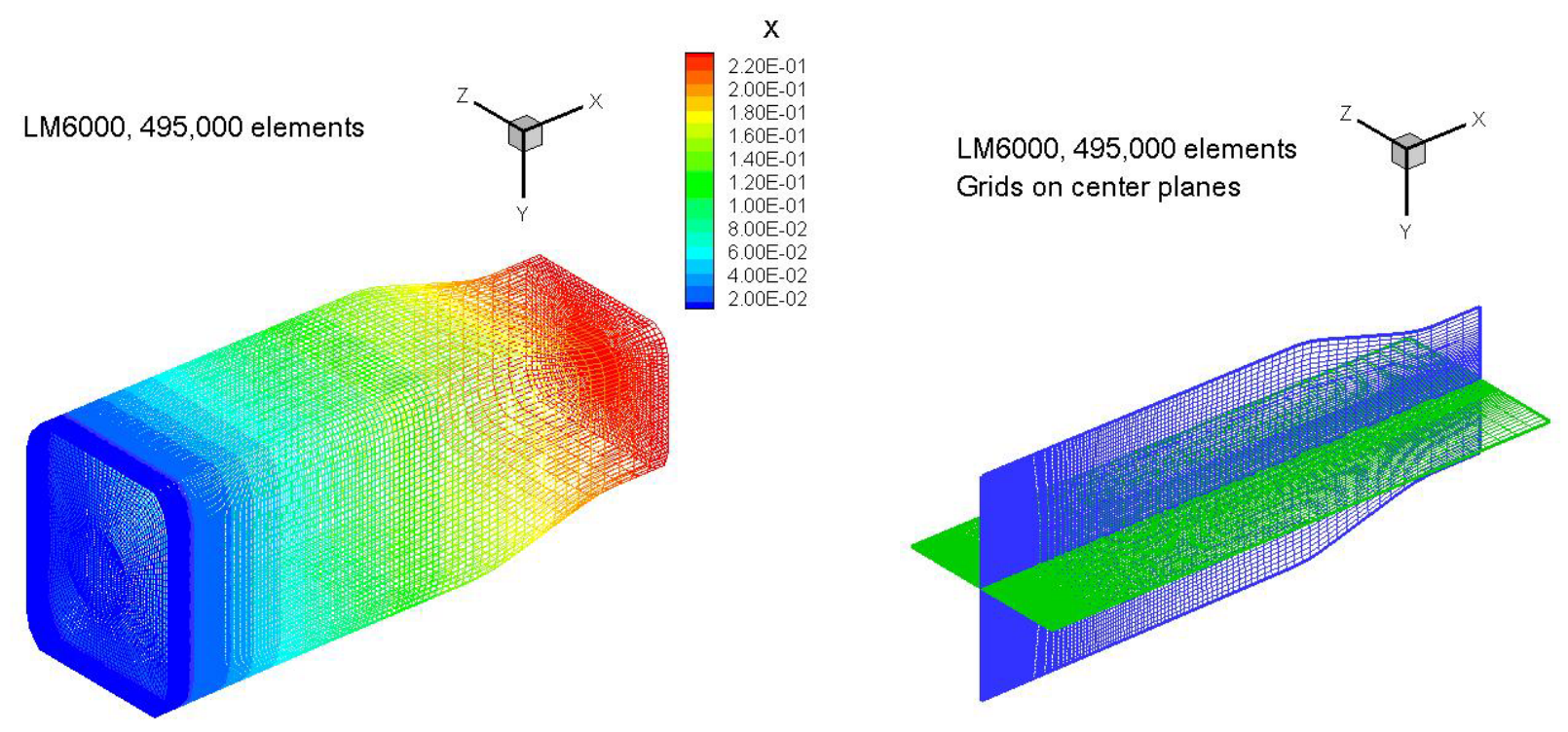

In this section, we will present the results from very large eddy simulation using the PRNS approach. The resolution control parameter (RCP) was set at a value of about 0.333 . Two subscale models (nonlinear and linear) were applied. Three outlet boundary conditions (i.e., the unsteady convective BC, the extrapolation BC and the fixed pressure BC) were tested. Furthermore, for a given outlet boundary condition, three different initial conditions (i.e., the nonlinear RANS solution, the linear RANS solution and the static flow field) were used in its assessment.

\subsection{Nonlinear Subscale Model}

PRNS with the nonlinear subscale model is fundamentally different from the traditional LES approach. Here, the interactions between the resolved large scale turbulence and the unresolved small scale turbulence are accounted for not just by the eddy viscosity, but also, explicitly in the filtered transport equations, by the turbulence source terms originated from the nonlinear part of the subscale model. So far, these additional turbulence source terms have not been considered in the existing LES approaches (see Ref. 1).

\subsubsection{Results Using Unsteady Convective BC for Pressure Only}

In this case, the unsteady convective outlet $\mathrm{BC}$ is only applied to the gauge pressure. The rest of the dependent flow variables at the outlet are determined by extrapolating from the interior point (i.e. extrapolation $\mathrm{BC}$ ). This is consistent with the observation that, for subsonic viscous internal flow simulation, the information on pressure at the outlet boundary is always needed for properly maintaining the global mass conservation.

The results are presented in three parts: the time history of velocity components and gauge pressure at four locations along the centerline; the instantaneous contour plots of flow variables at a center plane; and the instantaneous centerline flow variable profiles.

\subsubsection{Time History}

The time history of velocity components and gauge pressure were recorded at four centerline locations: $x=0.015,0.05,0.10$ and 0.2 . From which we may examine the development of turbulent fluctuations and perform further spectra analysis. The results are presented with respect to three different initial conditions: the nonlinear RANS solution, the linear RANS solution, and the static flow field. 


\section{Initial condition: Nonlinear RANS solution}
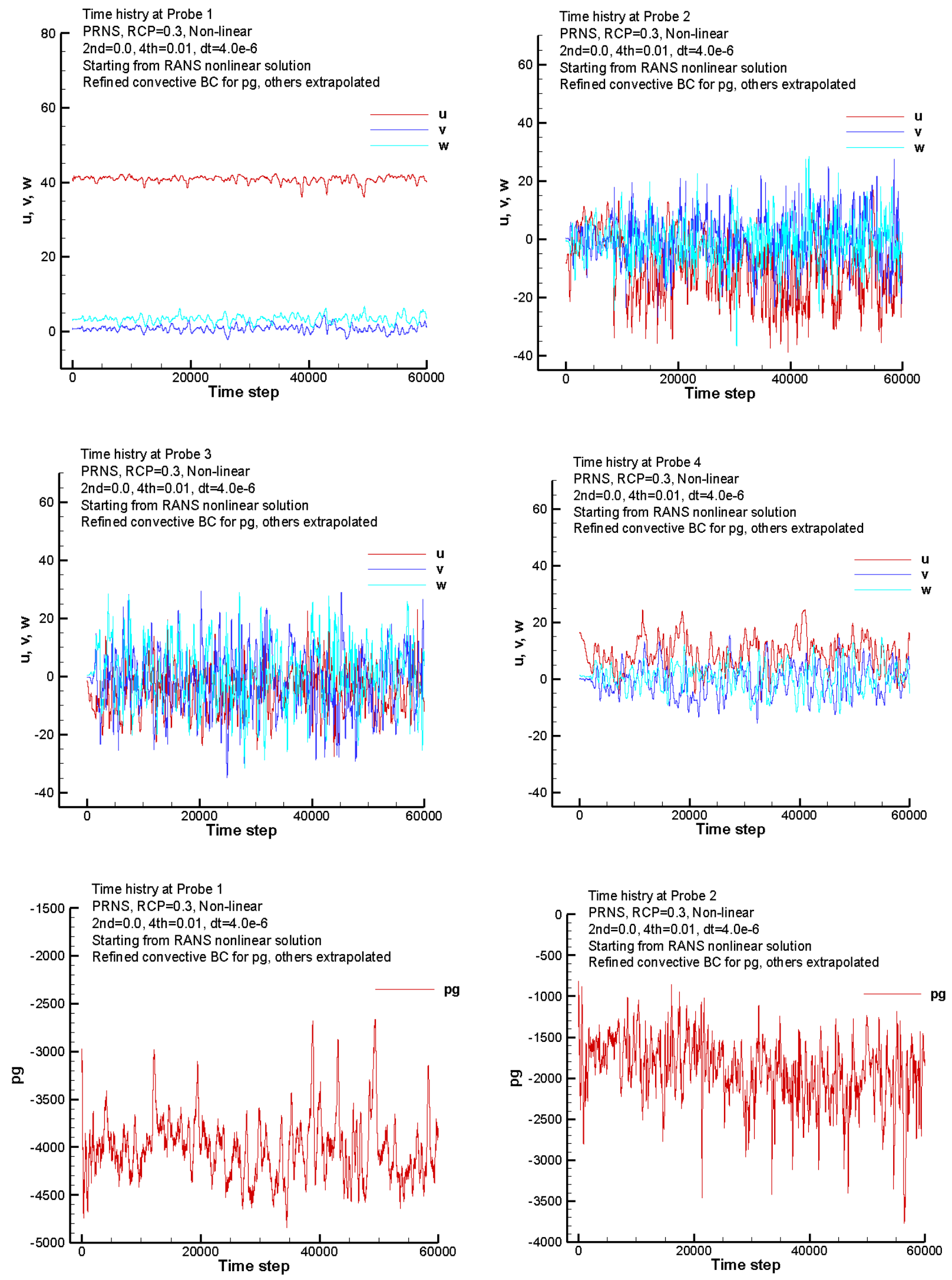

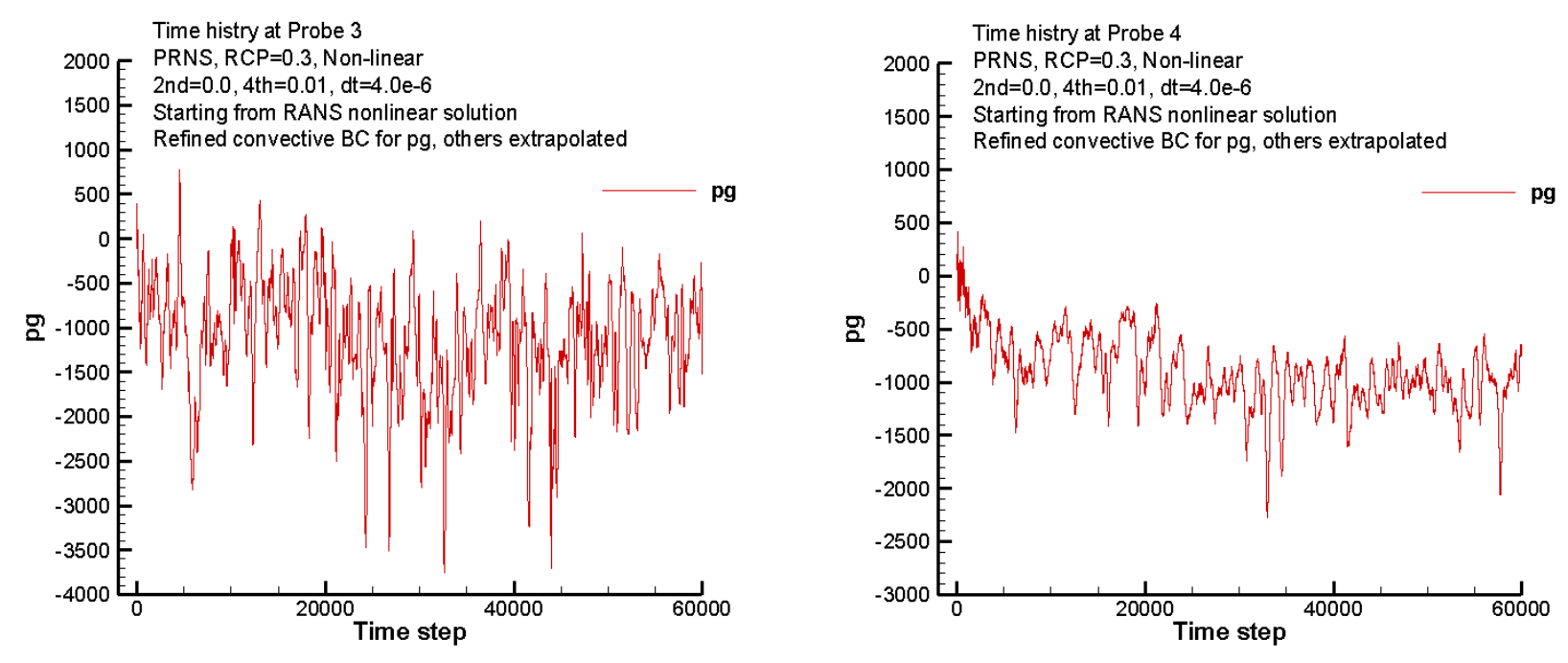

Initial condition: Linear RANS solution
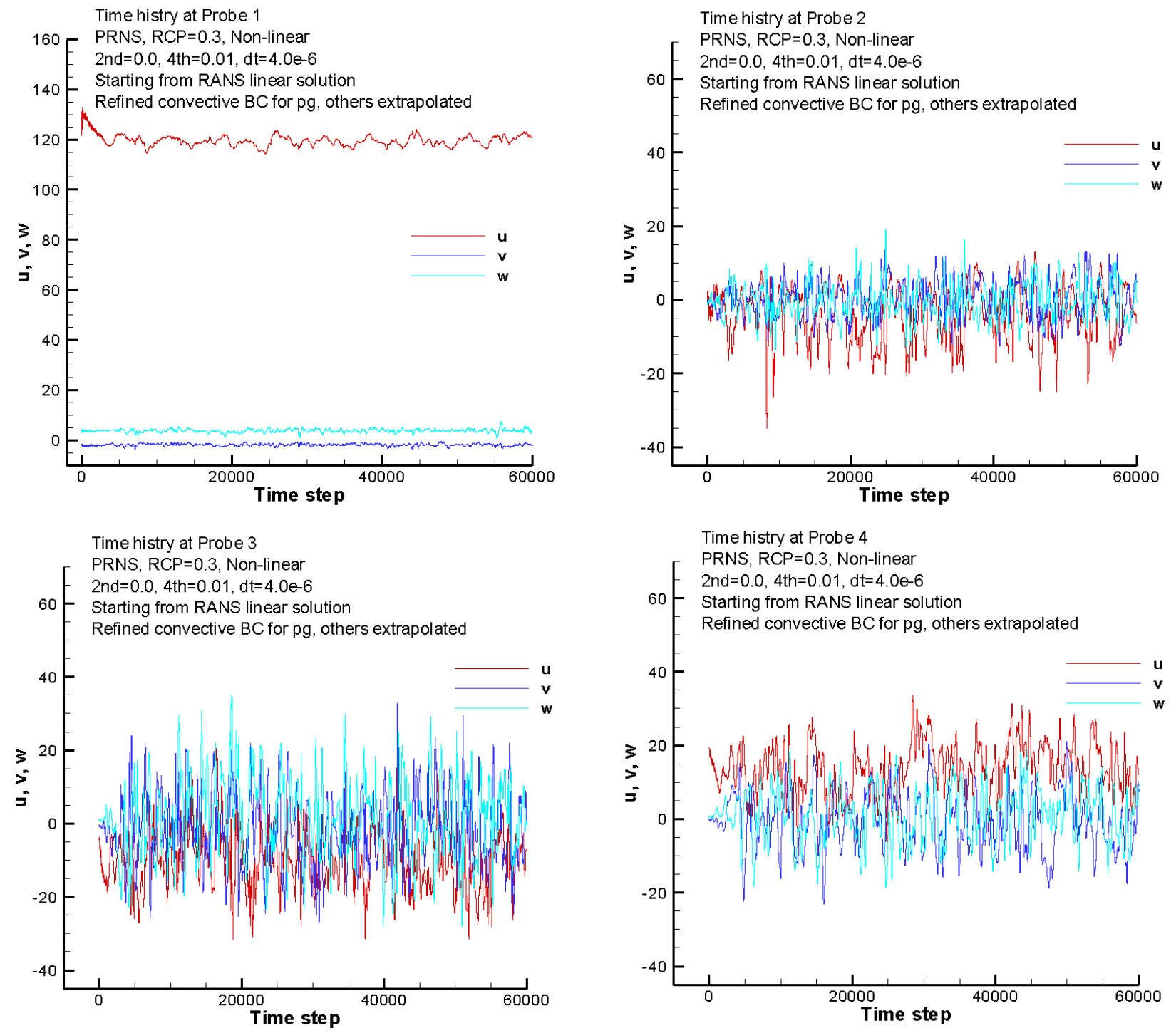
Time histry at Probe 1

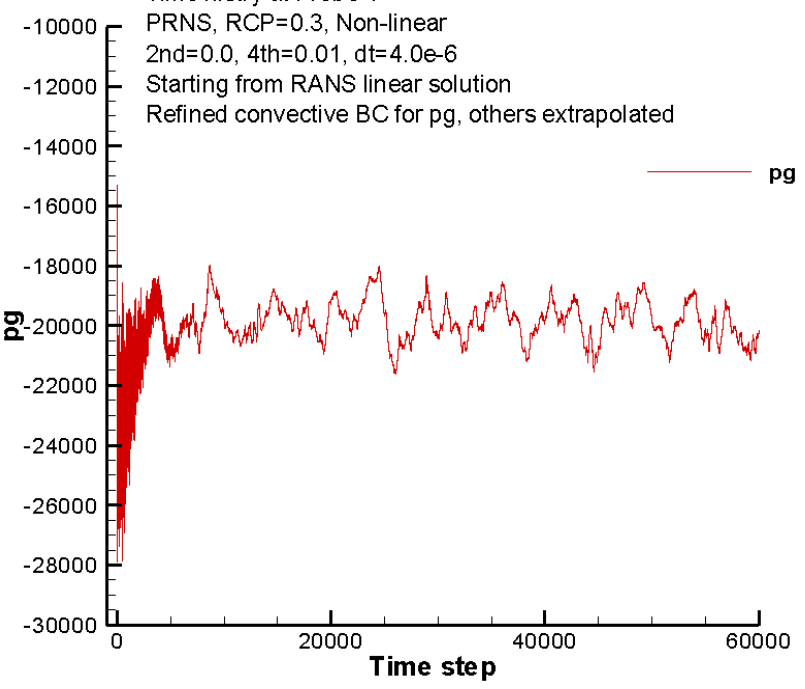

Time histry at Probe 3

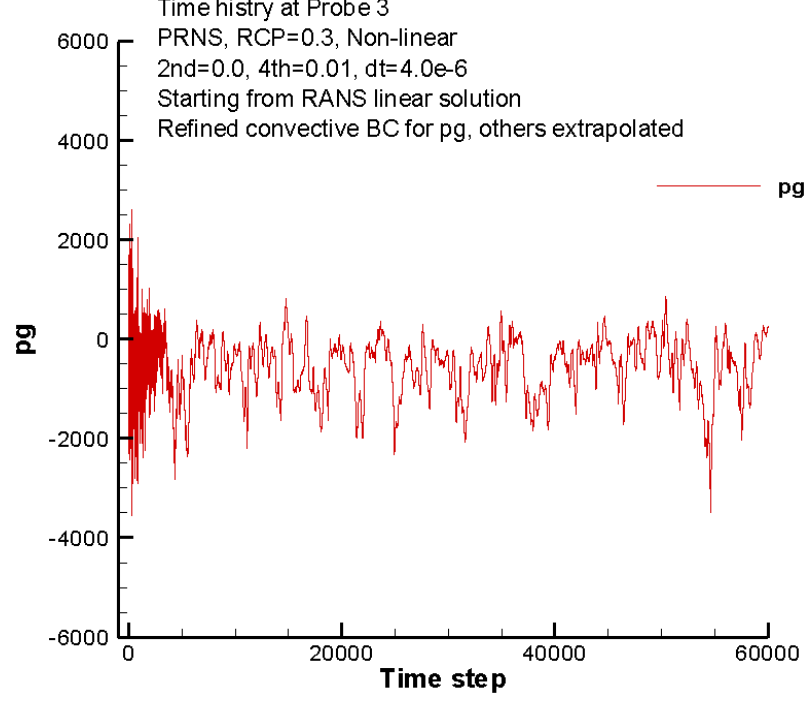

\section{Initial condition: Static flow field}

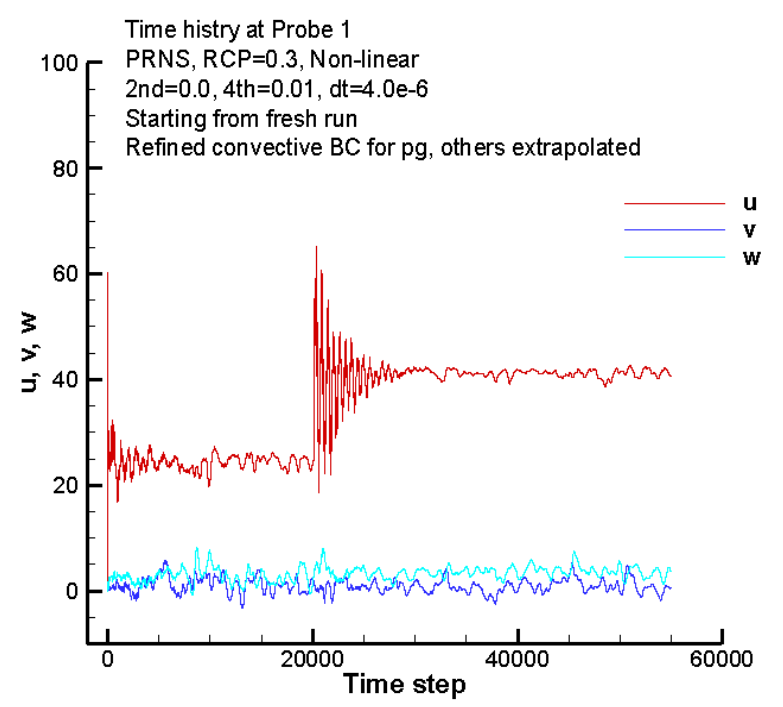

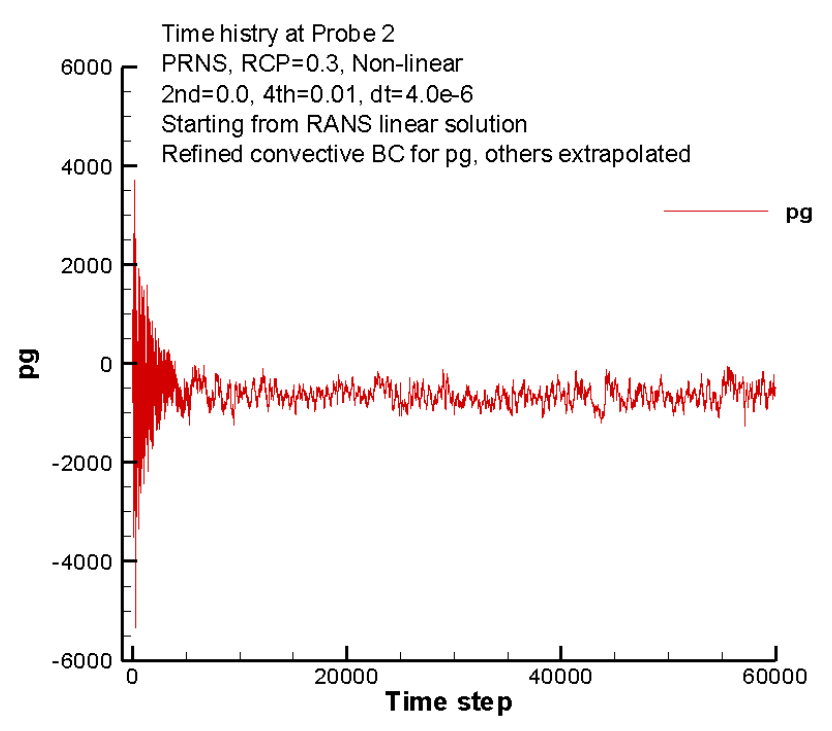
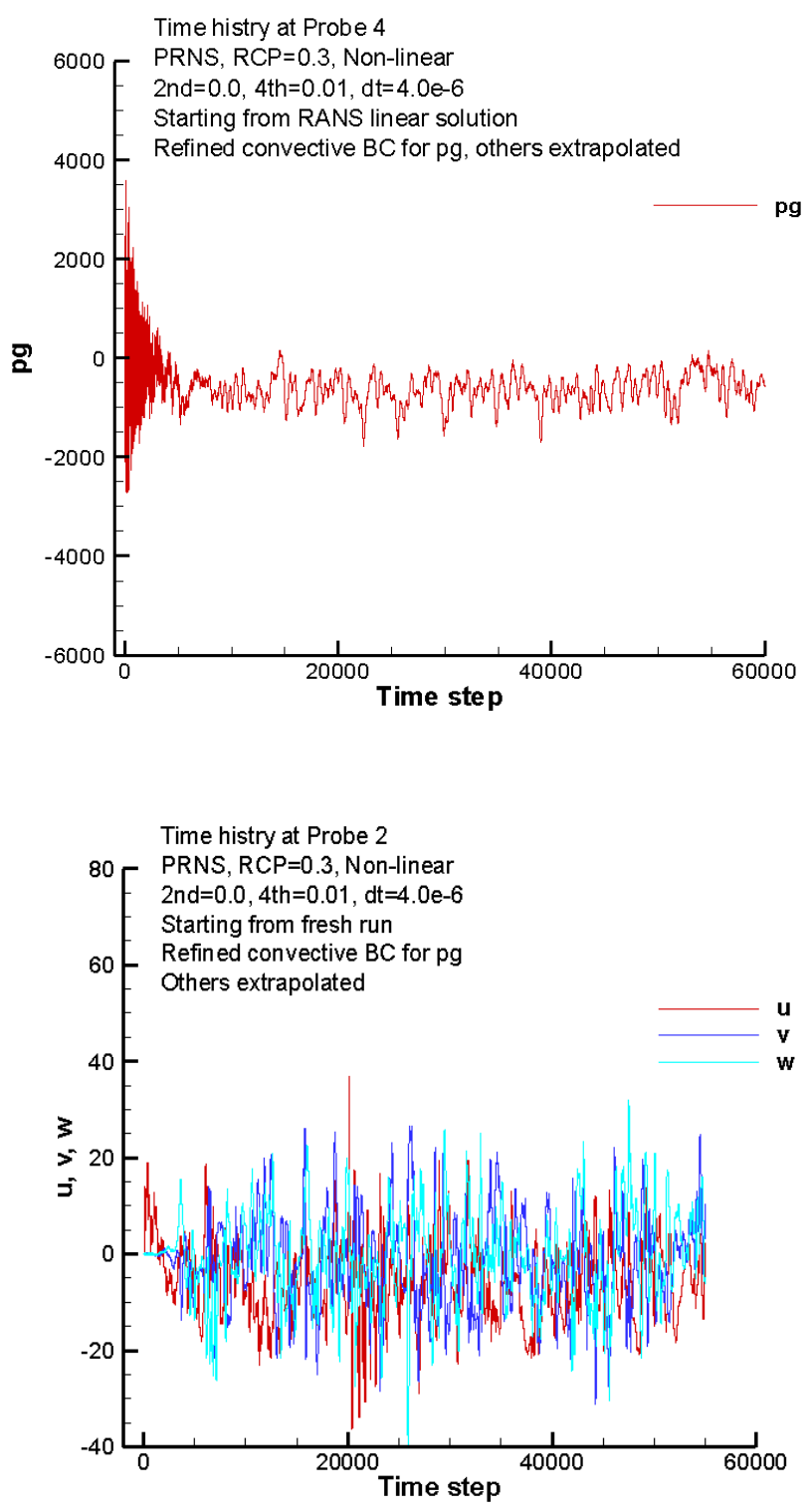

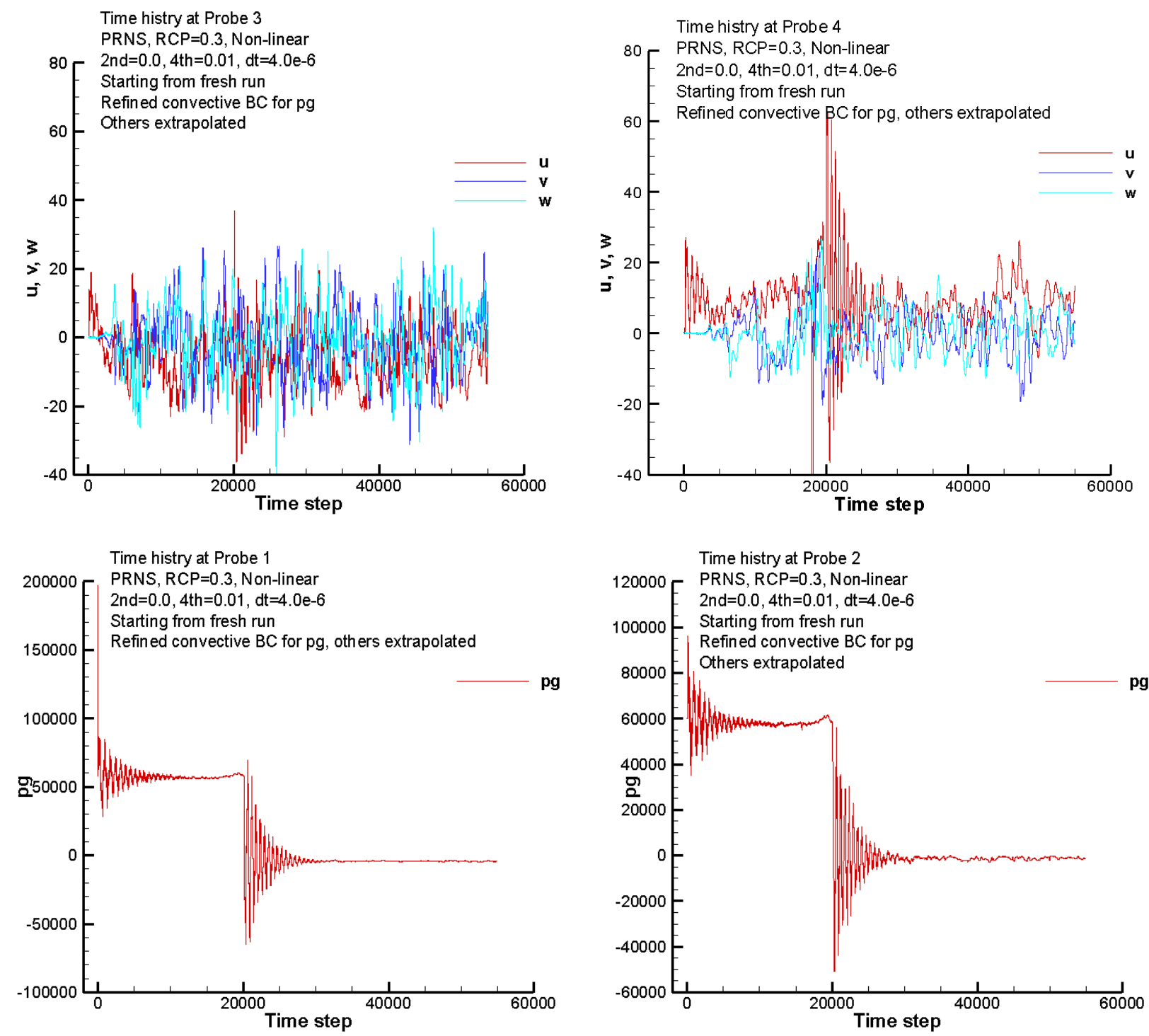

Time histry at Probe 2

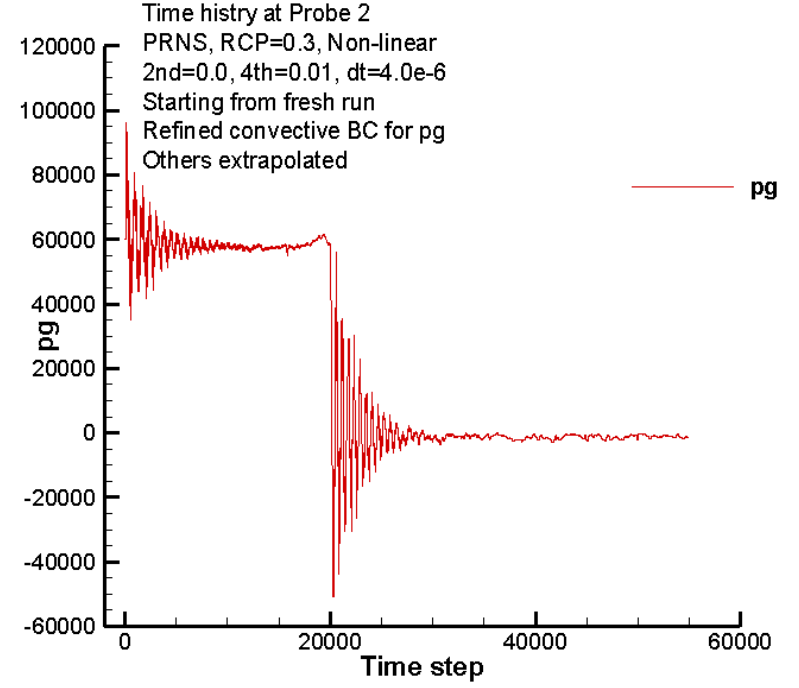

Time histry at Probe 3

PRNS, RCP $=0.3$, Non-linear

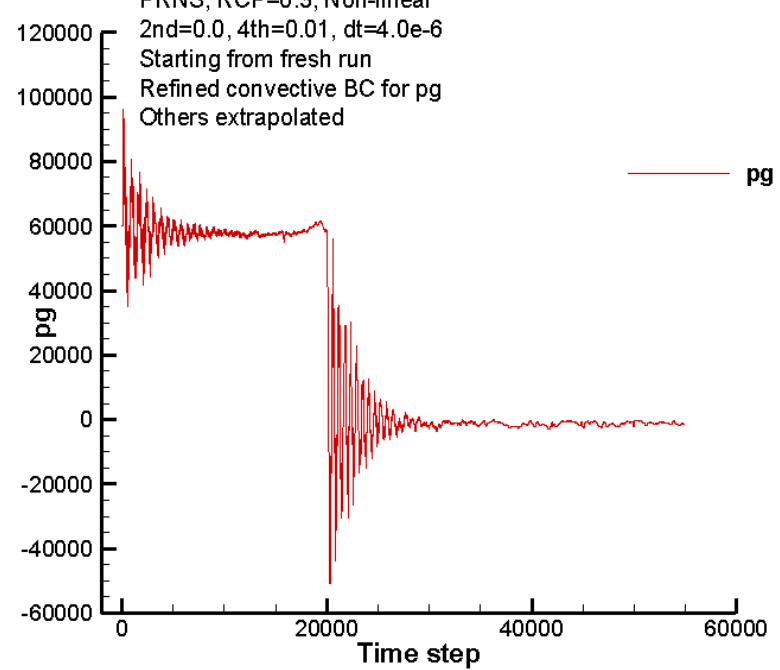

Time histry at Probe 4

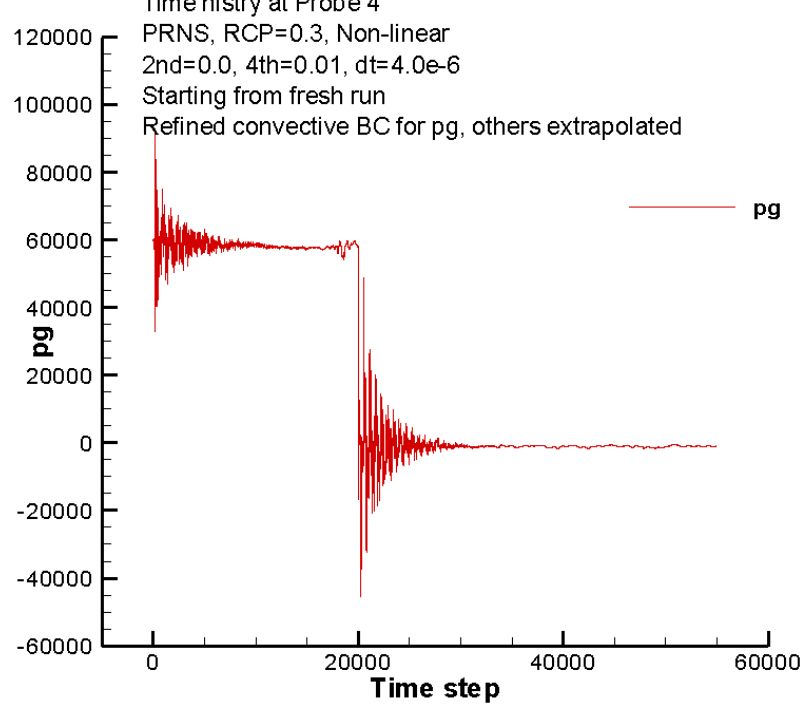




\subsubsection{Contour at Center Plane}

The snapshots of instantaneous flow field at a center plane are presented for the time step number 60,000 , which is about 100 flow-through time (defined as the ratio of the length of the combustor to the inlet centerline axial velocity). From which we may examine the flow structures. The results are presented with respect to three different initial conditions: the nonlinear RANS solution, the linear RANS solution, and the static flow field.

\section{Initial condition: Nonlinear RANS solution}

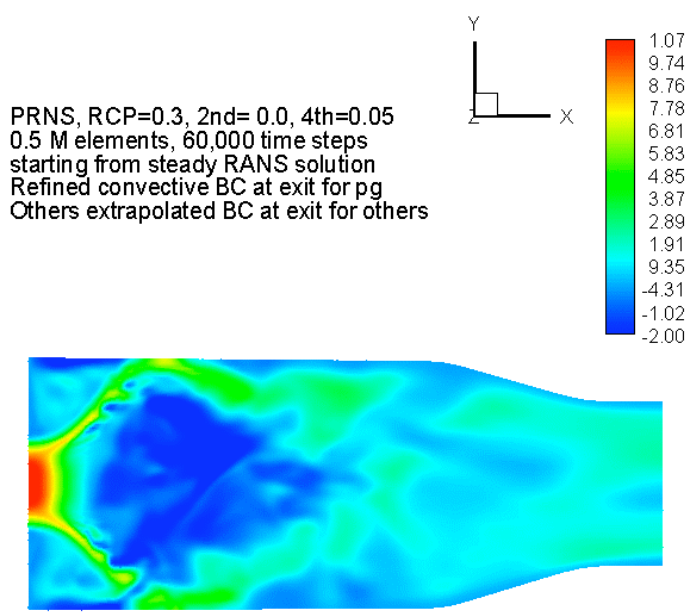

PRNS, RCP $=0.3,2 \mathrm{nd}=0.0,4$ th $=0.05$ $0.5 \mathrm{M}$ elements, 60,000 time steps starting from steady RANS solution Refined convective $B C$ at exit for $p g$ Others extrapolated $\mathrm{BC}$ at exit for others
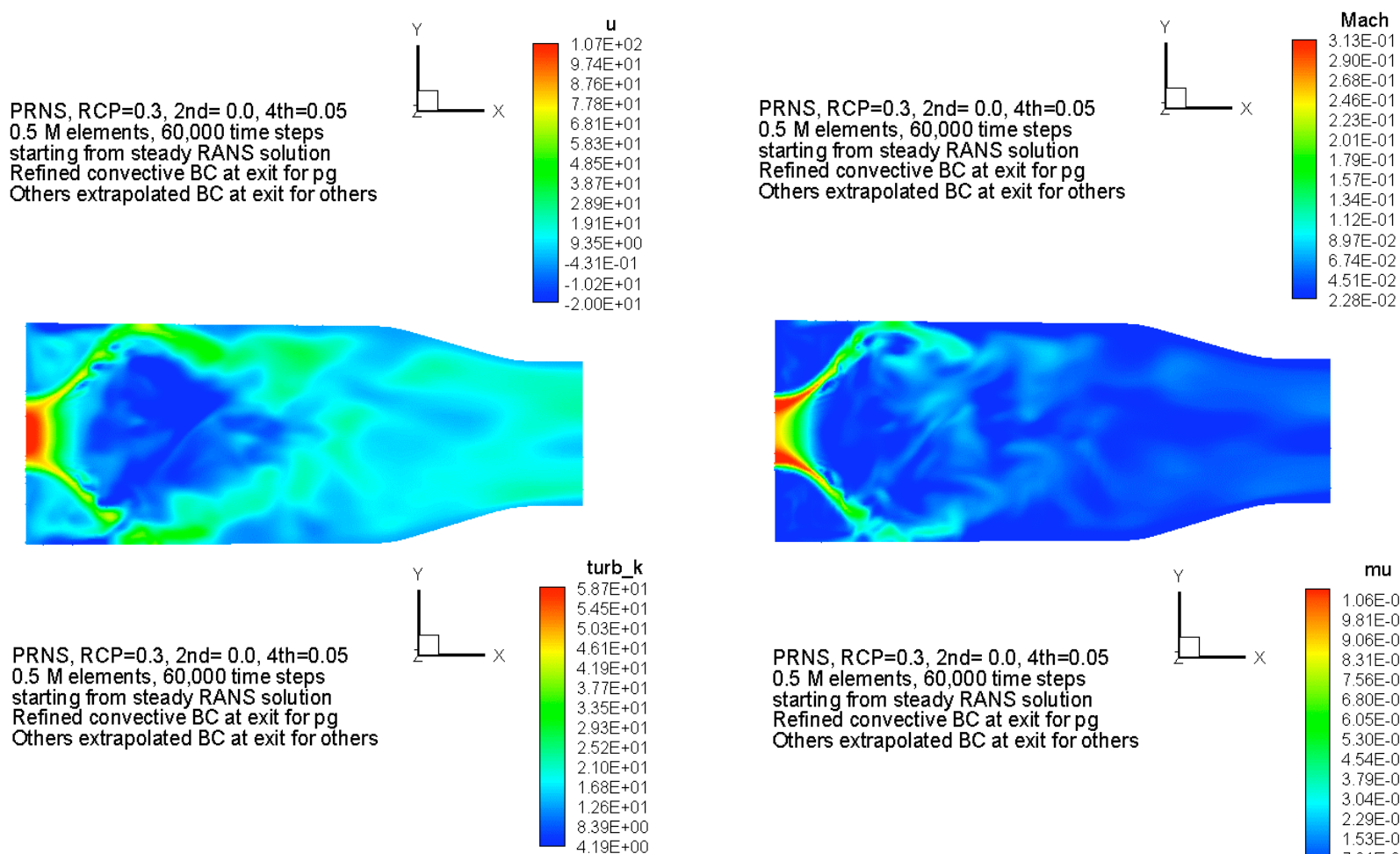

urb_k $87 \mathrm{E}+01$
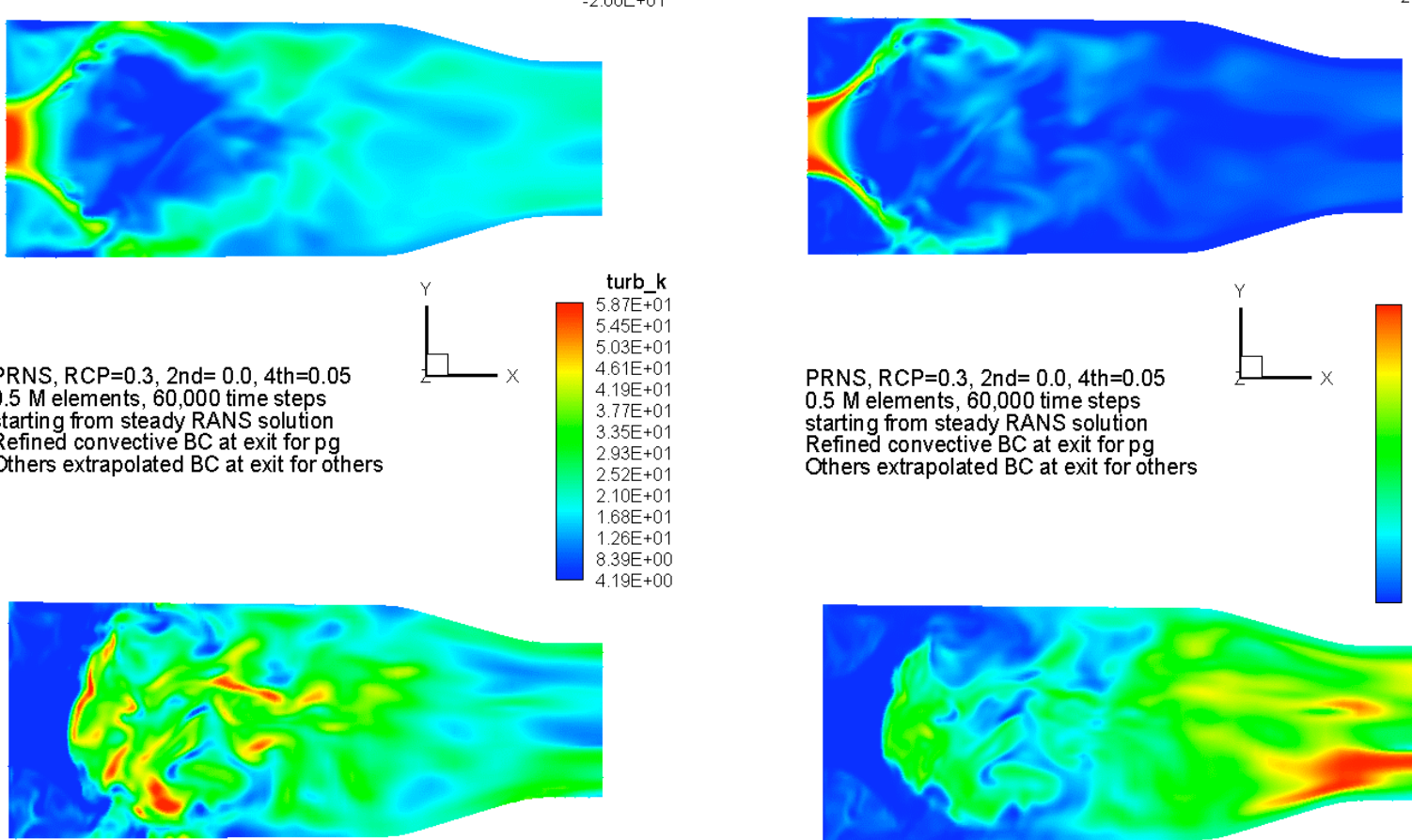

PRN, RCP $=0.3,2 \mathrm{nd}=0.0,4$ th $=0.05$ $0.5 \mathrm{M}$ elements, 60,000 time steps starting from steady RANS solution Refined convective $\mathrm{BC}$ at exit for $\mathrm{p}$ Others extrapolated $\mathrm{BC}$ at exit for others

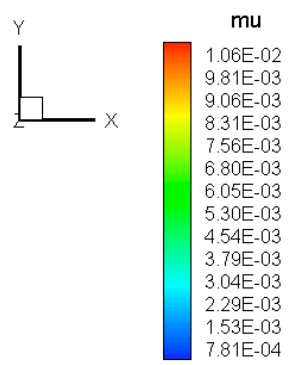

PRNS, RCP $=0.3,2 \mathrm{nd}=0.0,4$ th $=0.05$
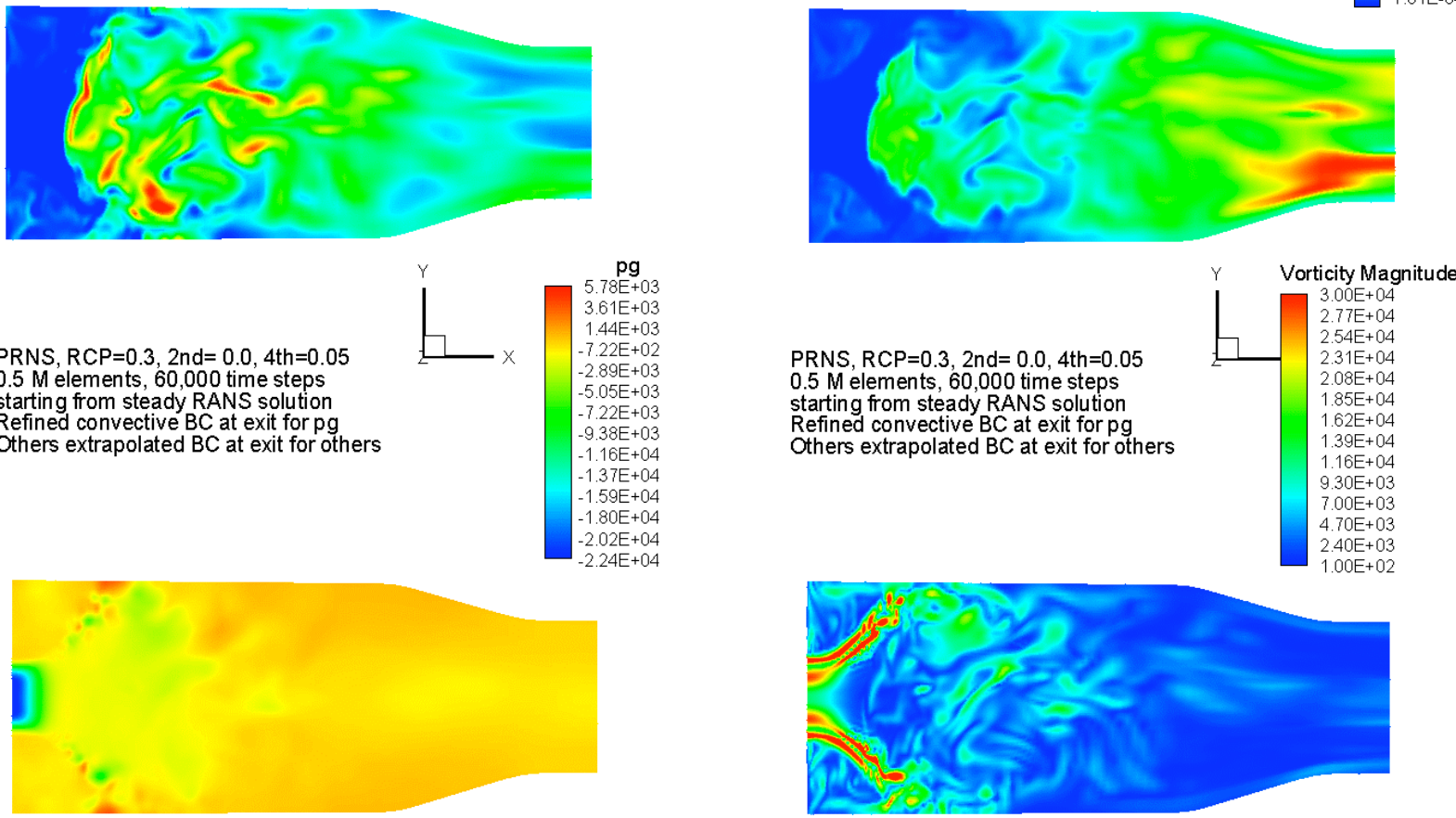
starting from starting from steady RANS solution Refined convective $\mathrm{BC}$ at exit for $\mathrm{pg}$ Others extrapolated $\mathrm{BC}$ at exit for others

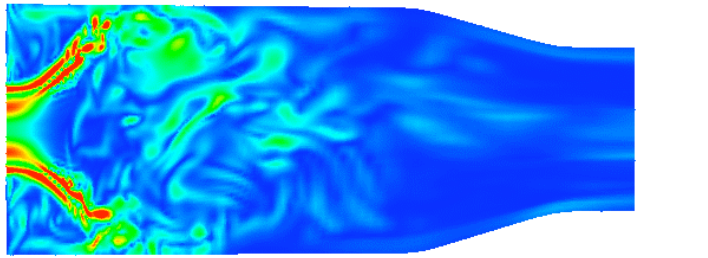




\section{Initial condition: Linear RANS solution}

PRNS, non-lineae, $\mathrm{RCP}=0.3$

2nd $=0.0,4$ th $=0.01, \mathrm{CFL}=1, \mathrm{dt}=4 \mathrm{e}-6$

$0.5 \mathrm{M}$ elements, 60,000 time steps

Starting from steady RANS (L) solution

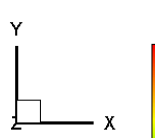

$\mathrm{U}$

$1.17 \mathrm{E}+02$

$1.17 \mathrm{E}+02$
$1.05 \mathrm{E}+02$

$1.05 \mathrm{E}+02$

9.38E+01

$7.10 \mathrm{E}+01$

$7.10 \mathrm{E}+01$

$5.97 E+01$

4.83E+01

$3.69 \mathrm{E}+01$

$2.55 \mathrm{E}+01$

$1.41 \mathrm{E}+01$

$2.76 \mathrm{E}+00$

$-8.62 \mathrm{E}+00$

$-2.00 \mathrm{E}+01$

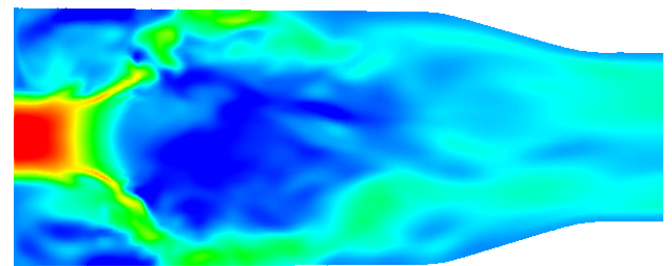

RNS non-lineae, $\mathrm{RCP}=0.3$

2nd $=0.0,4$ th $=0.01, \mathrm{CFL}=1, \mathrm{dt}=4 \mathrm{e}-6$

$0.5 \mathrm{M}$ elements, 60,000 time steps

Starting from steady RANS (L) solution

Refined convective $\mathrm{BC}$ at exit for $\mathrm{pg}$

Extrapolated $\mathrm{BC}$ at exit for others
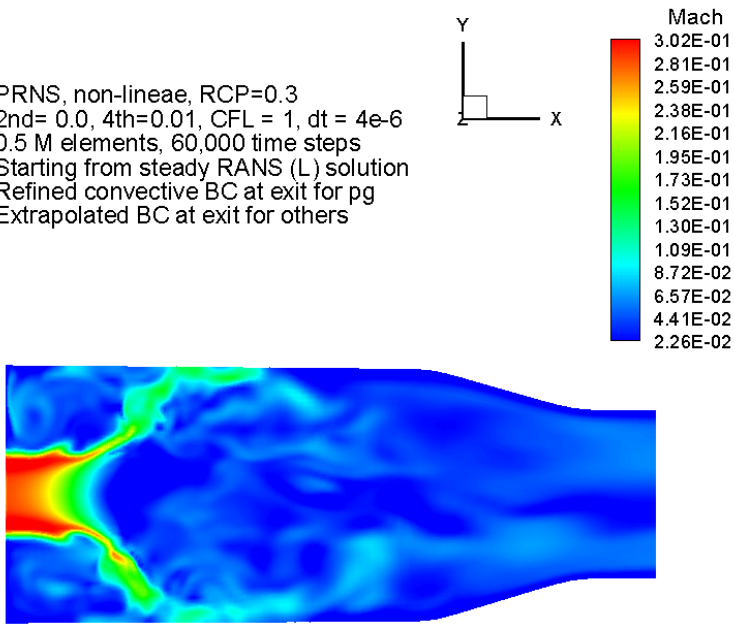

PRNS, non-lineae, $\mathrm{RCP}=0.3$

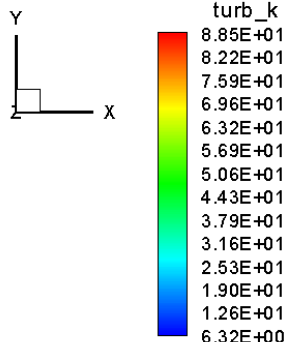

PRNS, non-lineae, $\mathrm{RCP}=0.3$

2nd $=0.0,4$ th $=0.01, \mathrm{CFL}=1, \mathrm{dt}=4 \mathrm{e}-6$

$0.5 \mathrm{M}$ elements, 60,000 time steps

Starting from steady RANS (L) solution

$0.5 \mathrm{M}$ elements, 60,000 time steps

Refined convective $\mathrm{BC}$ at exit for $\mathrm{pg}$

Extrapolated BC at exit for others
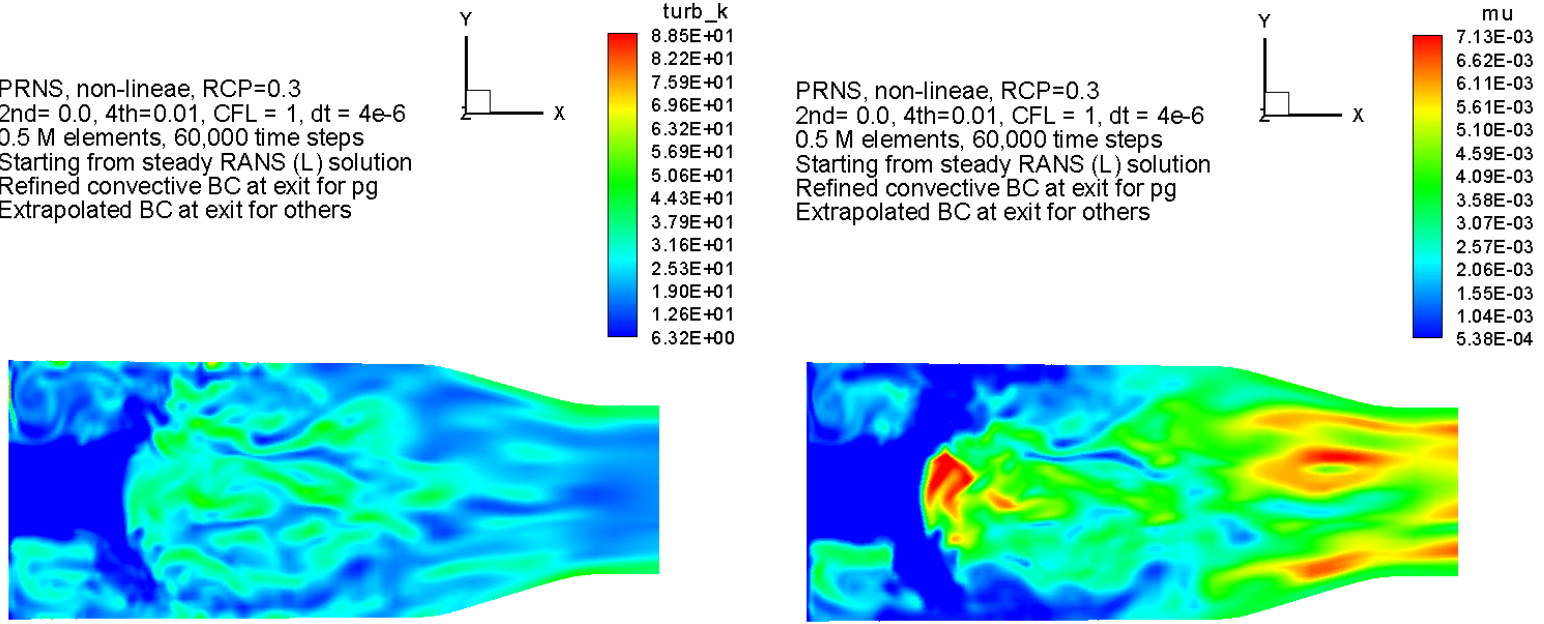

PRNS, non-lineae, $\mathrm{RCP}=0.3$

2nd $=0.0,4$ th $=0.01, \mathrm{CFL}=1, \mathrm{dt}=4 \mathrm{e}-6$

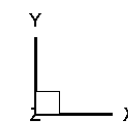

$\mathrm{pg}$
$9.14 \mathrm{E}+03$
$6.50 \mathrm{E}$

9.14E+03

$6.50 \mathrm{E}+03$

$3.86 \mathrm{E}+03$

$1.21 \mathrm{E}+03$
$-1.43 \mathrm{E}+03$
$-4.07 \mathrm{E}+03$

$-1.43 \mathrm{E}+03$

$0.5 \mathrm{M}$ elements, 60,000 time steps

$-4.07 \mathrm{E}+03$

$-9.35 \mathrm{E}+03$

$-1.20 \mathrm{E}+04$

Refined convective $B C$ at exit for pg

$-1.20 \mathrm{E}+04$

$-1.46 \mathrm{E}+04$

$1.73 E+04$

(.)

$-2.26 \mathrm{E}+04$

PRNS, non-lineae, $\mathrm{RCP}=0.3$

2nd $=0,0,4$ th $=0.01, C F L=1, d t=4 \mathrm{e}-6$

$0.5 \mathrm{M}$ elements, 60,000 time steps

Starting from steady RANS (L) solution

Refined convective $B C$ at exit for $p$

Y Vorticity Magnitude

Extrapolated $\mathrm{BC}$ at exit for others
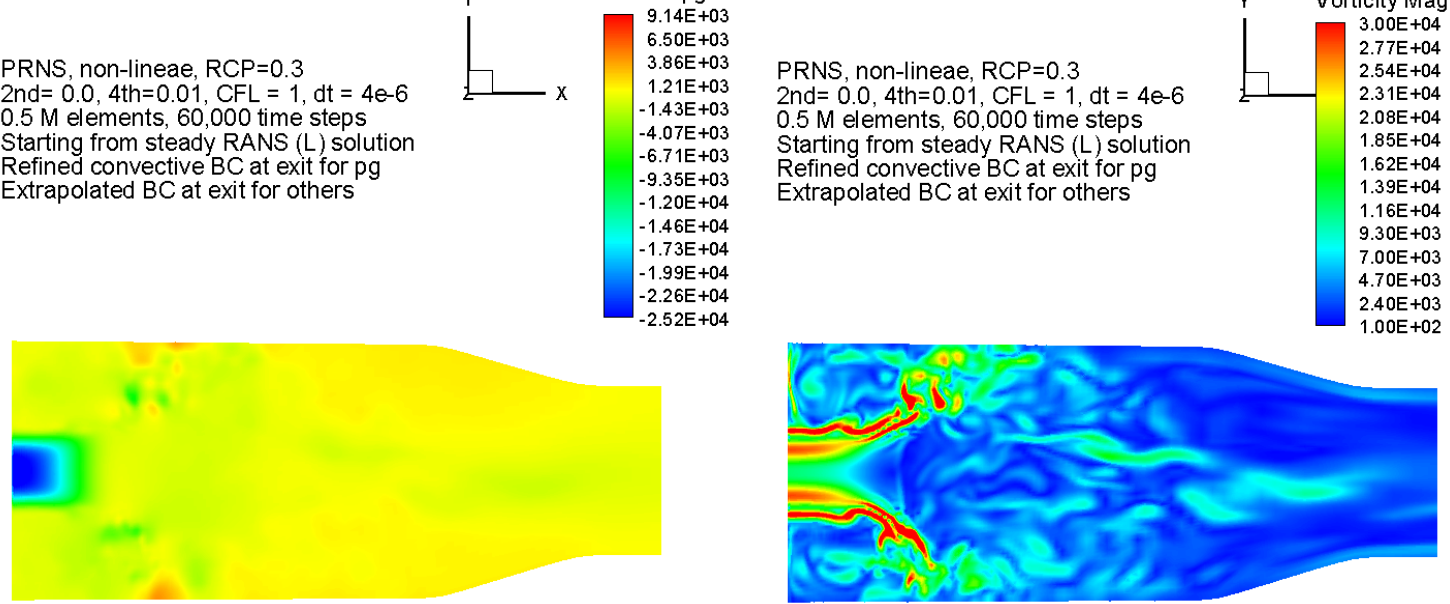
Initial condition: Static flow field

PRNS non-lineae $\mathrm{RCP}=0.3$ 2nd $=0.0,4 \mathrm{th}=0.01, \mathrm{CFL}=1, \mathrm{dt}=4 \mathrm{e}-6$ $0.5 \mathrm{M}$ elements, 70,000 time steps tarting from fresh run

Refined convective $\mathrm{BC}$ at exit for $\mathrm{pg}$ Extrapolated BC at exit for others

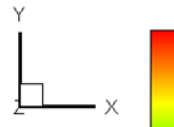
U $55 \mathrm{E}+01$ $8.59 \mathrm{E}+01$ $7.62 \mathrm{E}+01$ $6.66 \mathrm{E}+01$ $5.70 \mathrm{E}+01$ 4.74E+01 $3.77 \mathrm{E}+01$ $281 \mathrm{E}+01$ $1.85 \mathrm{E}+01$ (2) (1.84E $-1.04 \mathrm{E}+01$ $2.00 \mathrm{E}+01$

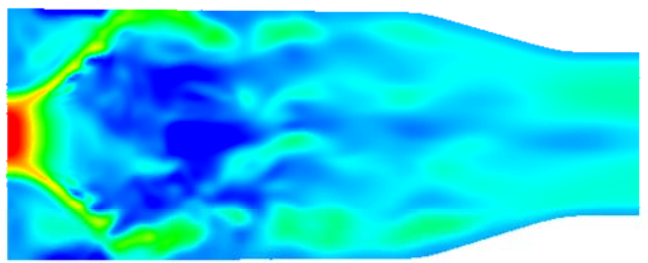

PRNS, non-lineae, RCP $=0.3$ 2nd $=0.0,4$ th $=0.01, C F L=1, d t=4 e-6$ $0.5 \mathrm{M}$ elements, 70,000 time steps

Refined convective $B C$ at exit for $\mathrm{pg}$ Extrapolated $\mathrm{BC}$ at exit for others
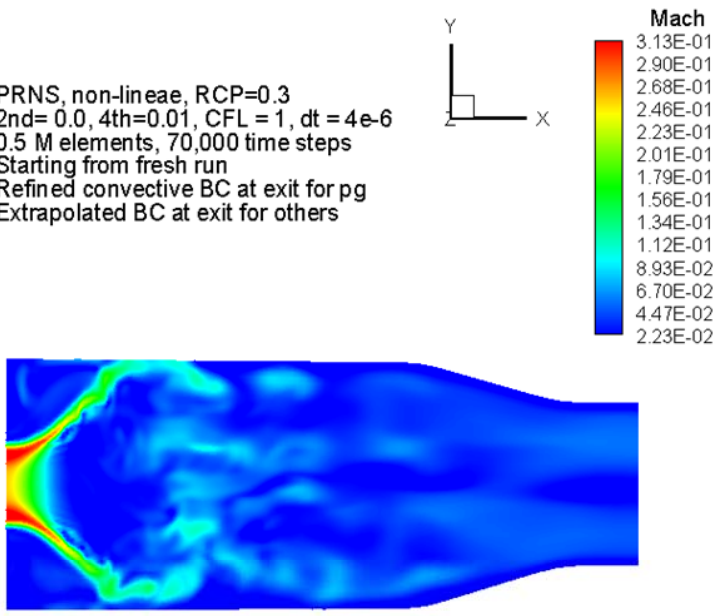

PRNS non-lineae $\mathrm{RCP}=0.3$

$2 \mathrm{nd}=0.0,4 \mathrm{th}=0.01, \mathrm{CFL}=1, \mathrm{dt}=4 \mathrm{e}-6$ $0.5 \mathrm{M}$ elements, 70,000 time steps Starting from fresh run

Refined convective $\mathrm{BC}$ at exit for $\mathrm{pg}$

Extrapolated $\mathrm{BC}$ at exit for others

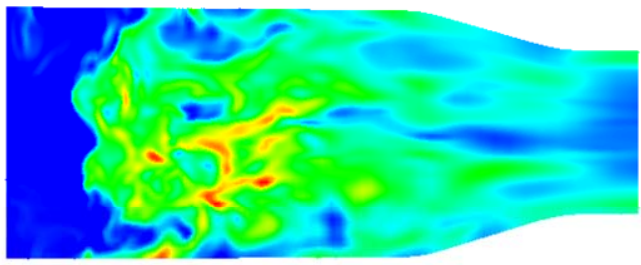

RNS, non-lineae, $\mathrm{RCP}=0.3$ nd $=0.0,4$ th $=0.01, \mathrm{CFL}=1, \mathrm{dt}=4 \mathrm{e}-6$

$0.5 \mathrm{M}$ elements, 70,000 time steps

Starting from fresh run

Refined convective $\mathrm{BC}$ at exit for $\mathrm{pg}$

Extrapolated $\mathrm{BC}$ at exit for others
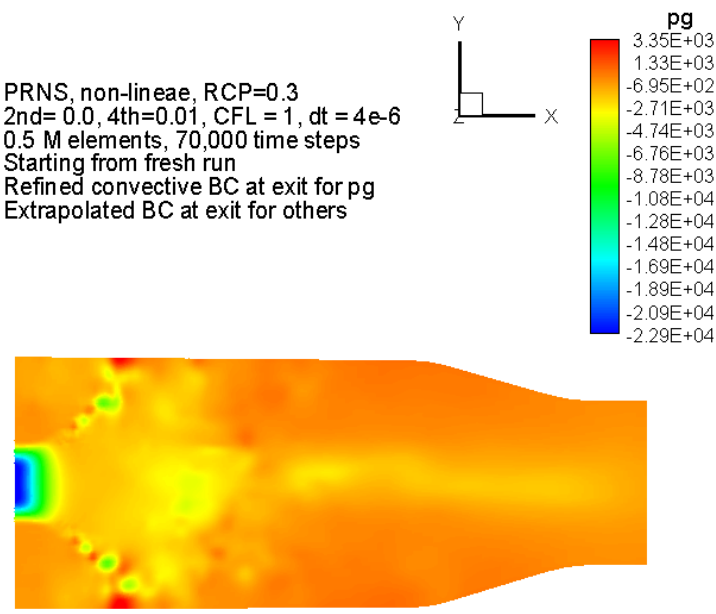

PRNS, non-lineae, $\mathrm{RCP}=0.3$

2nd $=0.0,4$ th $=0.01, C F L=1, d t=4 \mathrm{e}-6$

$0.5 \mathrm{M}$ elements, 70,000 time steps

Starting from fresh run

Refined convective $\mathrm{BC}$ at exit for pg

Extrapolated $\mathrm{BC}$ at exit for others
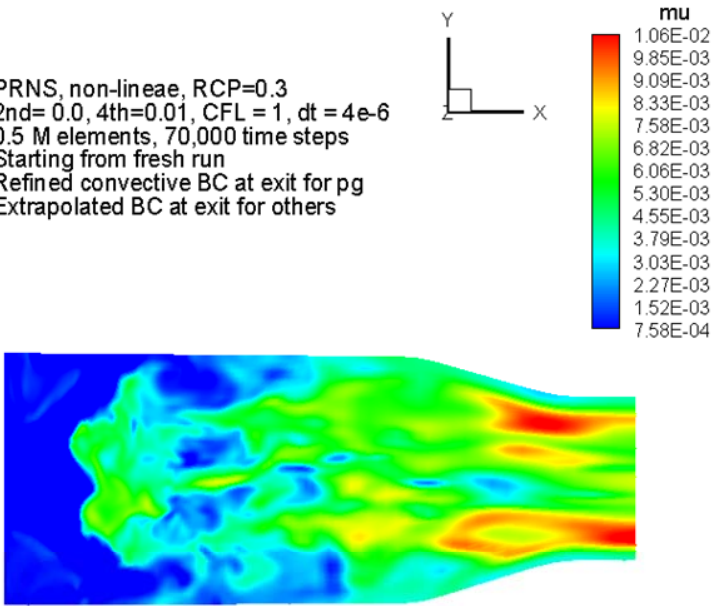

PRNS, non-lineae, $\mathrm{RCP}=0.3$ 2nd $=0.0,4$ th $=0.01, C F L=1, \mathrm{dt}=4 \mathrm{e}-6$ $0.5 \mathrm{M}$ elements, 70,000 time steps from fresh run

Refined convective $\mathrm{BC}$ at exit for $\mathrm{pg}$ Extrapolated $\mathrm{BC}$ at exit for others
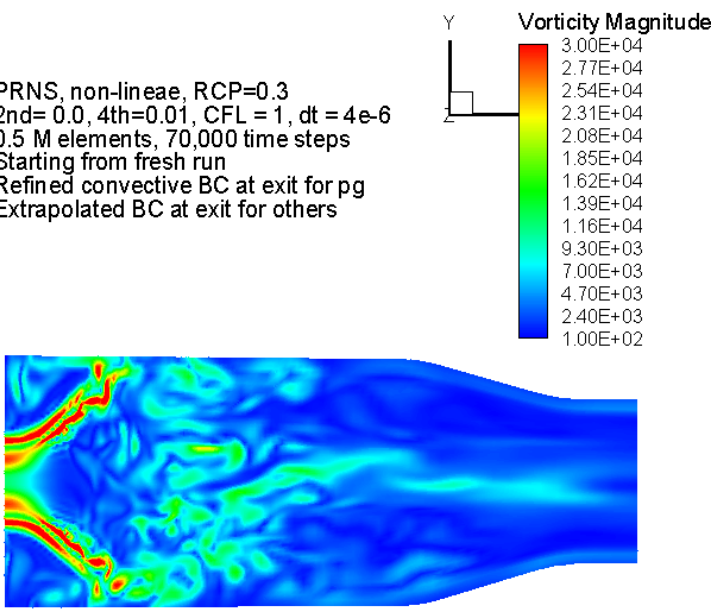


\subsubsection{Centerline Variables for Three Different Initial Conditions}

The instantaneous centerline flow variables (axial velocity $u$, Mach number, subscale turbulent kinetic energy $k$, effective viscosity $\mu_{T}$, gauge pressure and vorticity magnitude) at the time step 60,000 are presented here with three different initial conditions (the nonlinear RANS solution, the linear RANS solution, and the static flow field). From which we may examine the flow variation along the centerline.
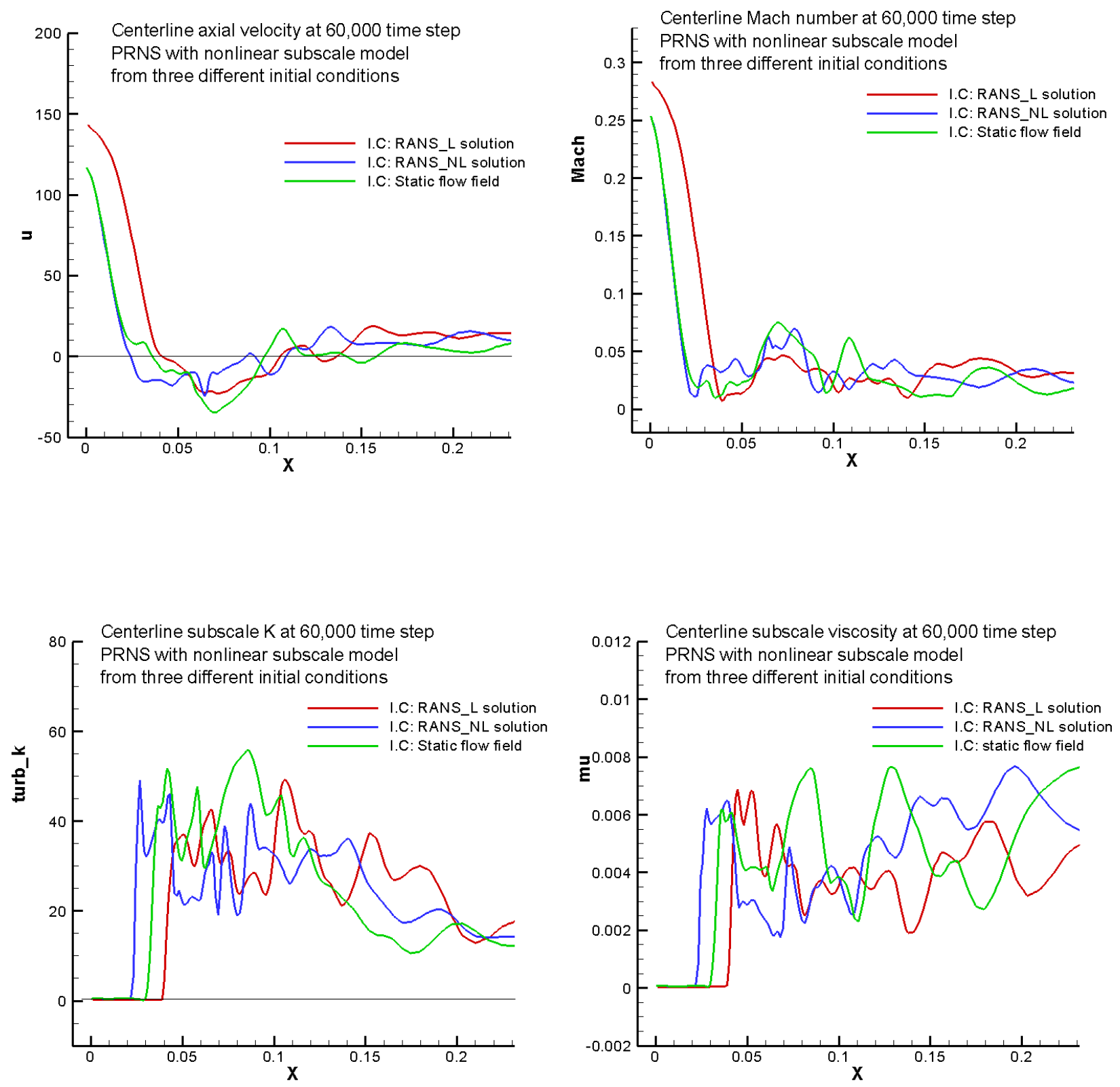

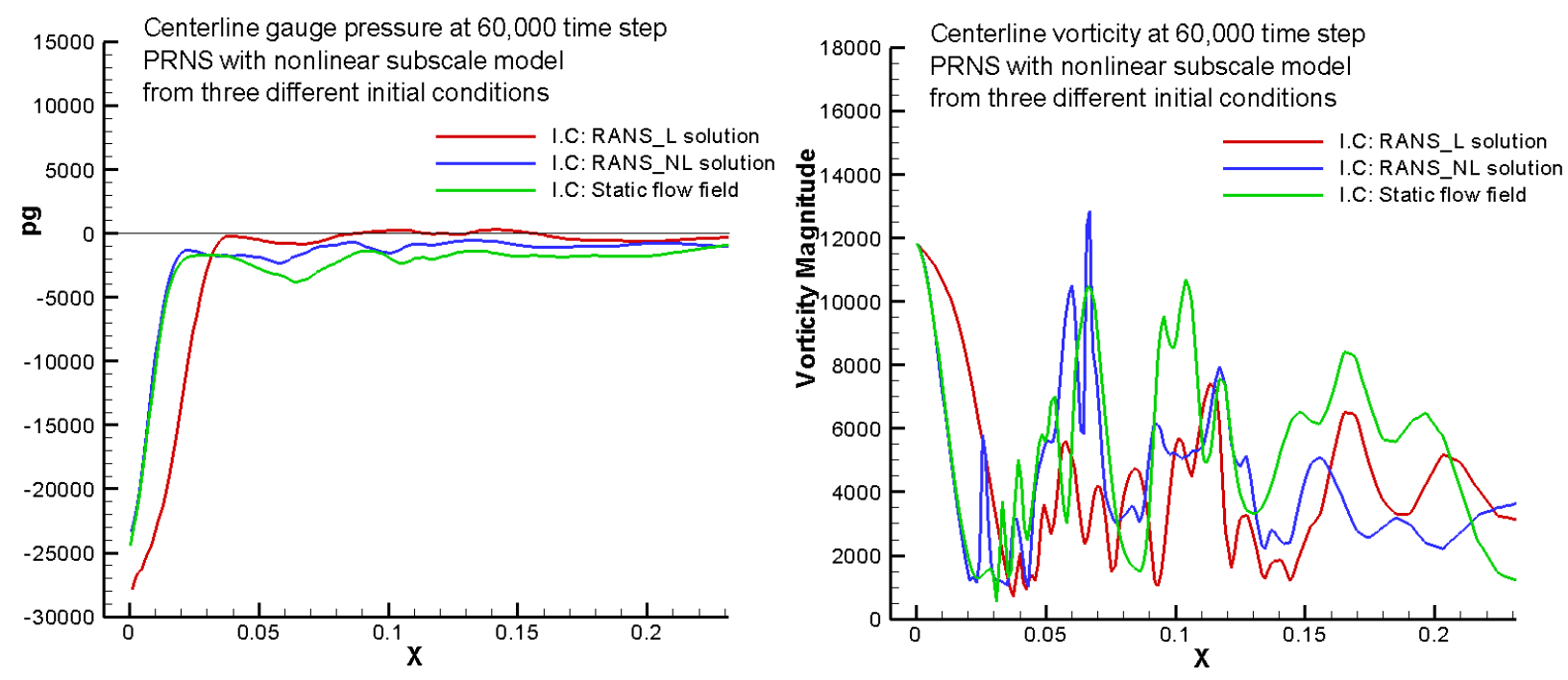

\subsubsection{Results Using Extrapolation BC}

In this case, all dependent flow variables at the outlet, including the gauge pressure, are extrapolated from the interior point. This is reminiscent of the so called perfectly non-reflecting boundary condition which might be used without significant numerical problem for short-time simulations (Ref. 6).

The results are presented in three parts: the time history of velocity components and gauge pressure at four locations along the centerline; the instantaneous contour plots of flow variables at a center plane; and the instantaneous centerline flow variable profiles.

\subsubsection{Time History}

The time history of velocity components and gauge pressure were recorded at four centerline locations: $x=0.015,0.05,0.10$ and 0.2 . From which we may examine the development of turbulent fluctuations and perform further spectra analysis. The simulations have been carried out using three different initial conditions: the nonlinear RANS solution, the linear RANS solution, and the static flow field. They all lead to the conclusion that, in the long run, the numerical solution can not be sustained in a physically meaningful manner. In the following, only the results using the linear RANS solution as the initial condition are presented to illustrate the development of the calculation.

The time histories at all four locations show that the flow variables are not approaching their statistically stationary mean values even after a long-time simulation.
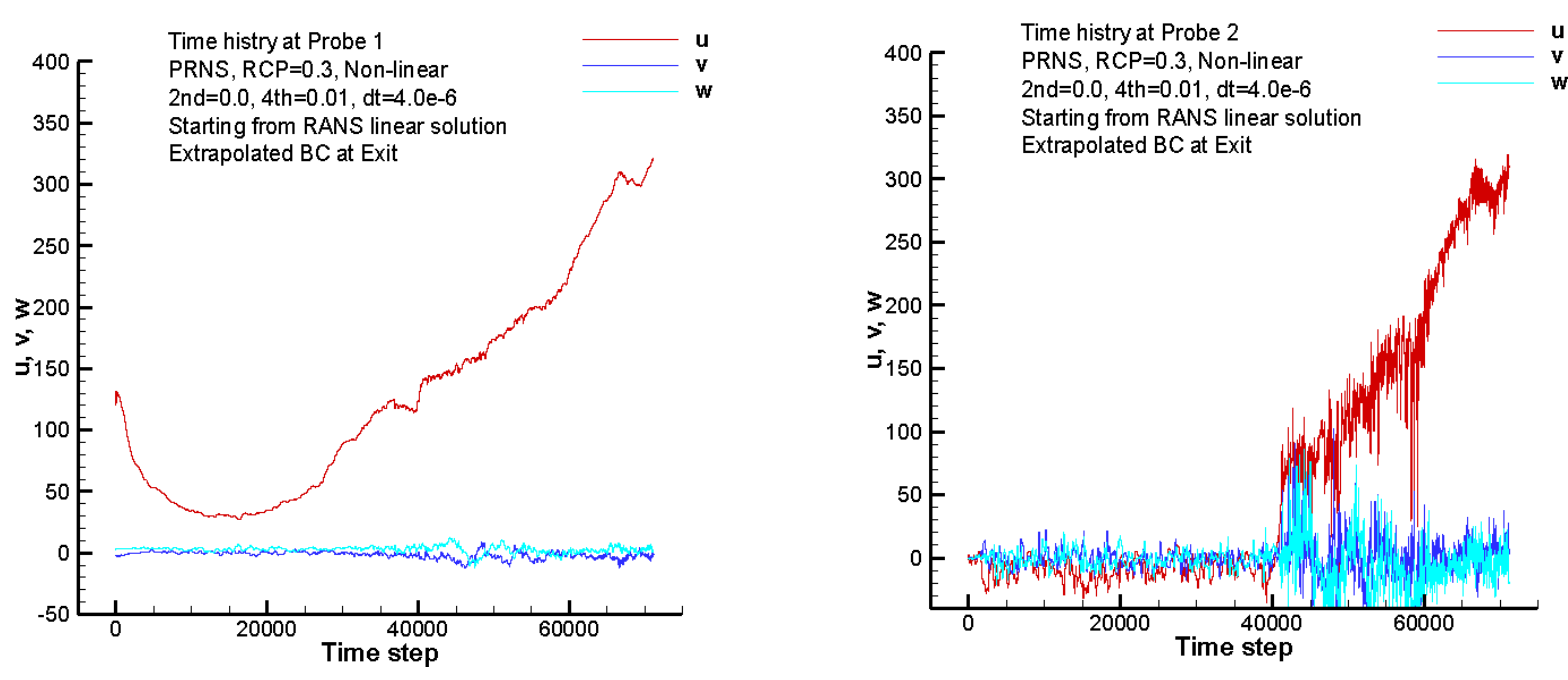

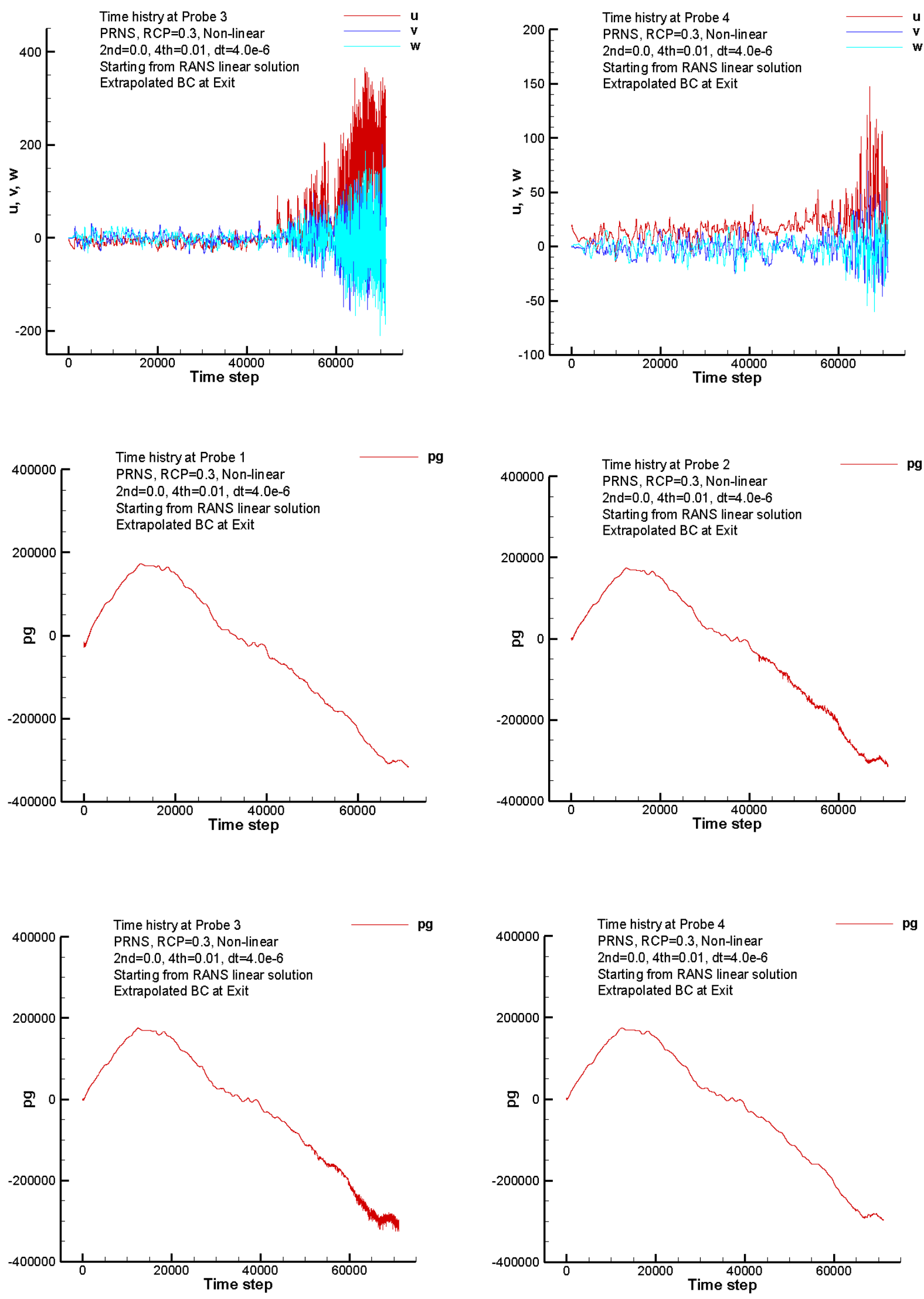


\subsubsection{Contour at Center Plane}

The snapshots of instantaneous contour of flow variables at a center plane are presented for two time instants, namely, the 20,000 and the 55,000 time steps. It is evident that the flow field has undergone a dramatic change over this period of time. We consider that the flow field at time step 20,000 is still reasonable, but, as time goes by, the dynamically important flow structures are not sustained, in fact, the solutions are becoming physically unreasonable.
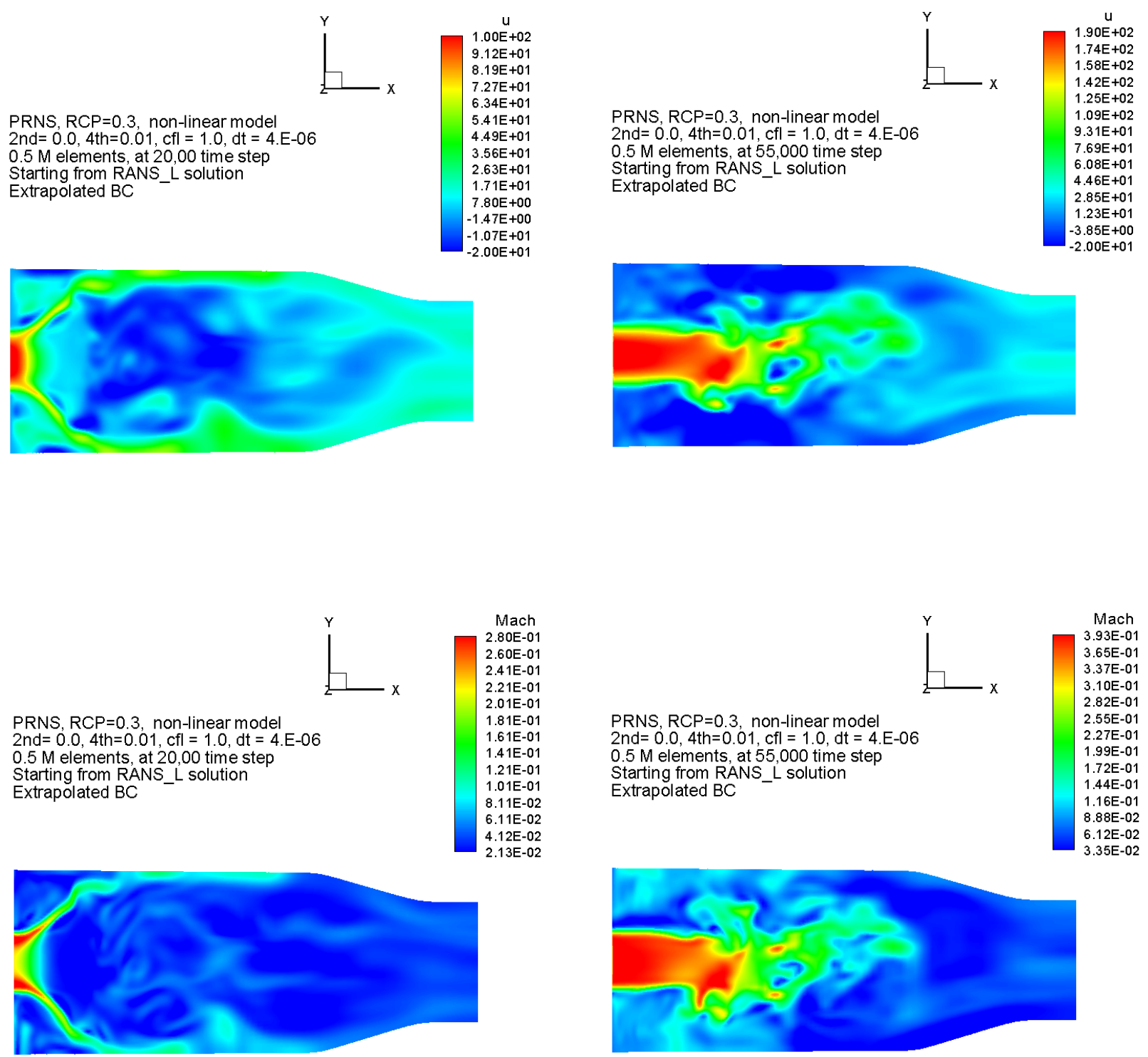
PRNS, RCP $=0.3$ non-linear model

2nd $=0.0,4$ th $=0.01, \mathrm{cfl}=1.0, \mathrm{dt}=4 . \mathrm{E}-06$

$0.5 \mathrm{M}$ elements, at 20,00 time step

Starting from RANS_L solution

Extrapolated BC

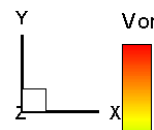

Magnitude

$3.00 \mathrm{E}+04$

$2.77 \mathrm{E}+04$

$2.54 \mathrm{E}+04$

2.08E+04

$1.85 \mathrm{E}+04$
$1.62 \mathrm{E}+04$

$1.62 \mathrm{E}+04$
$1.39 \mathrm{E}+04$

$1.16 \mathrm{E}+04$

$9.30 \mathrm{E}+03$

$7.00 \mathrm{E}+03$

$4.70 \mathrm{E}+03$

$2.40 \mathrm{E}+03$

$1.00 \mathrm{E}+02$

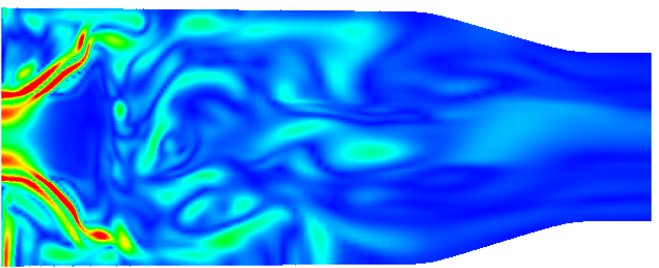

turb $k$

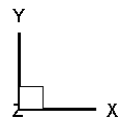

.

$3.31 \mathrm{E}+00$

$3.05 \mathrm{E}+00$ $2.80 \mathrm{E}+00$ $2.54 \mathrm{E}+00$ $2.29 \mathrm{E}+00$ $2.04 \mathrm{E}+00$

$.78 \mathrm{E}+00$

$1.53 \mathrm{E}+00$

$1.27 \mathrm{E}+00$

$1.02 \mathrm{E}+00$

$7.63 \mathrm{E}-01$

$5.09 \mathrm{E}-01$

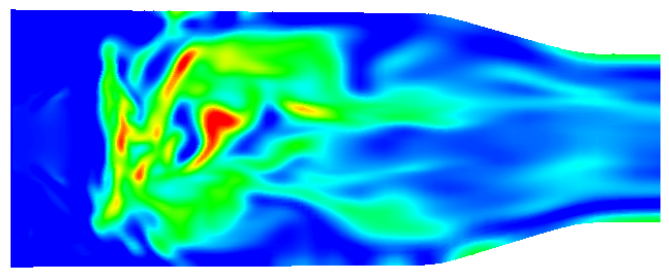

.

Extrapolated BC

$2.54 \mathrm{E}-01$

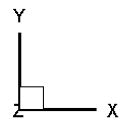

$\mathrm{mu}$

7.77E-04

$7.24 \mathrm{E}-04$
$6.71 \mathrm{E}-04$

$6.18 \mathrm{E}-04$

$6.18 \mathrm{E}-04$
$5.64 \mathrm{E}-04$

$5.64 \mathrm{E}-04$

PRNS, RCP $=0.3$, non-linear model

2nd $=0.0,4$ th $=0.01, \mathrm{cfl}=1.0, \mathrm{dt}=4 . \mathrm{E}-06$

$0.5 \mathrm{M}$ elements, at 20,00 time step

Starting from RANS L solution

Extrapolated BC 2nd $=0.0,4$ th $=0.01, \mathrm{cfl}=1.0, \mathrm{dt}=4 . \mathrm{E}-06$

$0.5 \mathrm{M}$ elements, at 55,000 time step

Starting from RANS_L solution

Extrapolated BC
PRNS, RCP $=0.3$, non-linear model

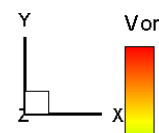

Magnitude

$3.00 \mathrm{E}+04$

$2.77 \mathrm{E}+04$

2.54

$2.08 \mathrm{E}+04$

.

1.85E+04

.62E+04

$.39 E+04$

$16 \mathrm{E}+04$

9.30E+03

$7.00 \mathrm{E}+03$

$4.70 \mathrm{E}+03$

$2.40 \mathrm{E}+03$

$1.00 \mathrm{E}+02$

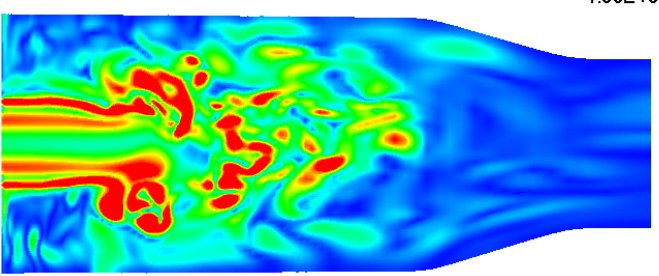

PRNS, RCP $=0.3$, non-linear model 2nd $=0.0,4$ th $=0.01, \mathrm{cfl}=1.0, \mathrm{dt}=4 . \mathrm{E}-06$

$0.5 \mathrm{M}$ elements, at 55,000 time step

Starting from RANS $L$ solution

Extrapolated BC

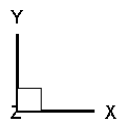

turb $k$

7.50E-01

$6.43 \mathrm{E}-01$

$5.89 \mathrm{E}-01$

$5.36 \mathrm{E}-01$

$4.82 \mathrm{E}-0$

4.29E-0

$3.75 \mathrm{E}-01$

3.21E-01

2.68E-01

2.14E-01

$1.61 \mathrm{E}-0$

.07E-0

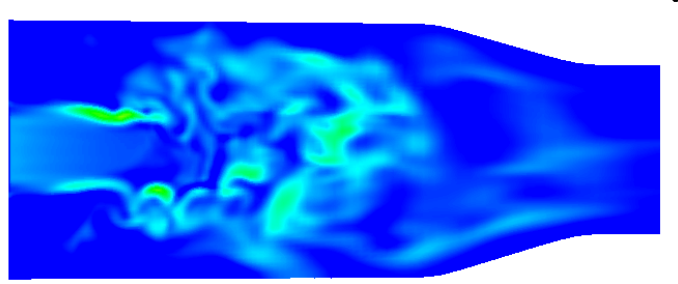

PRNS RCP $=0.3$ non-linear model

2nd $=0.0,4$ th $=0.01, \mathrm{cfl}=1.0, \mathrm{dt}=4 . \mathrm{E}-06$

$0.5 \mathrm{M}$ elements, at 55,000 time step

Starting from RANS_L solution

$3.71 \mathrm{E}-05$

Extrapolated BC
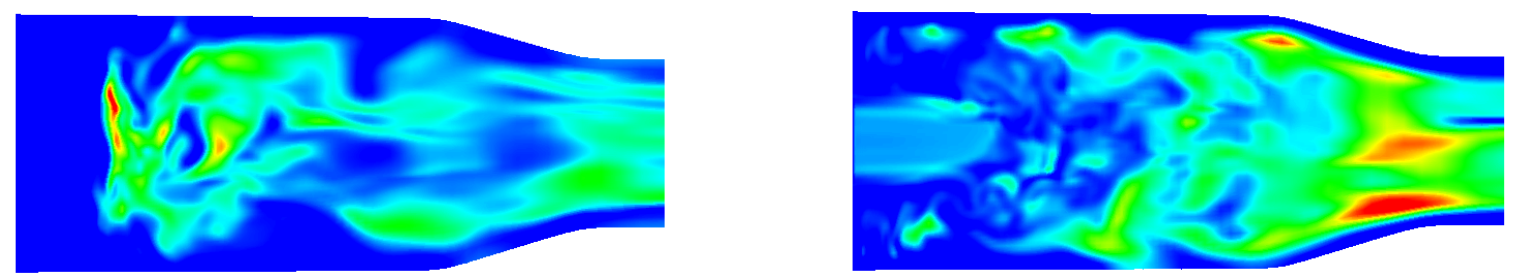

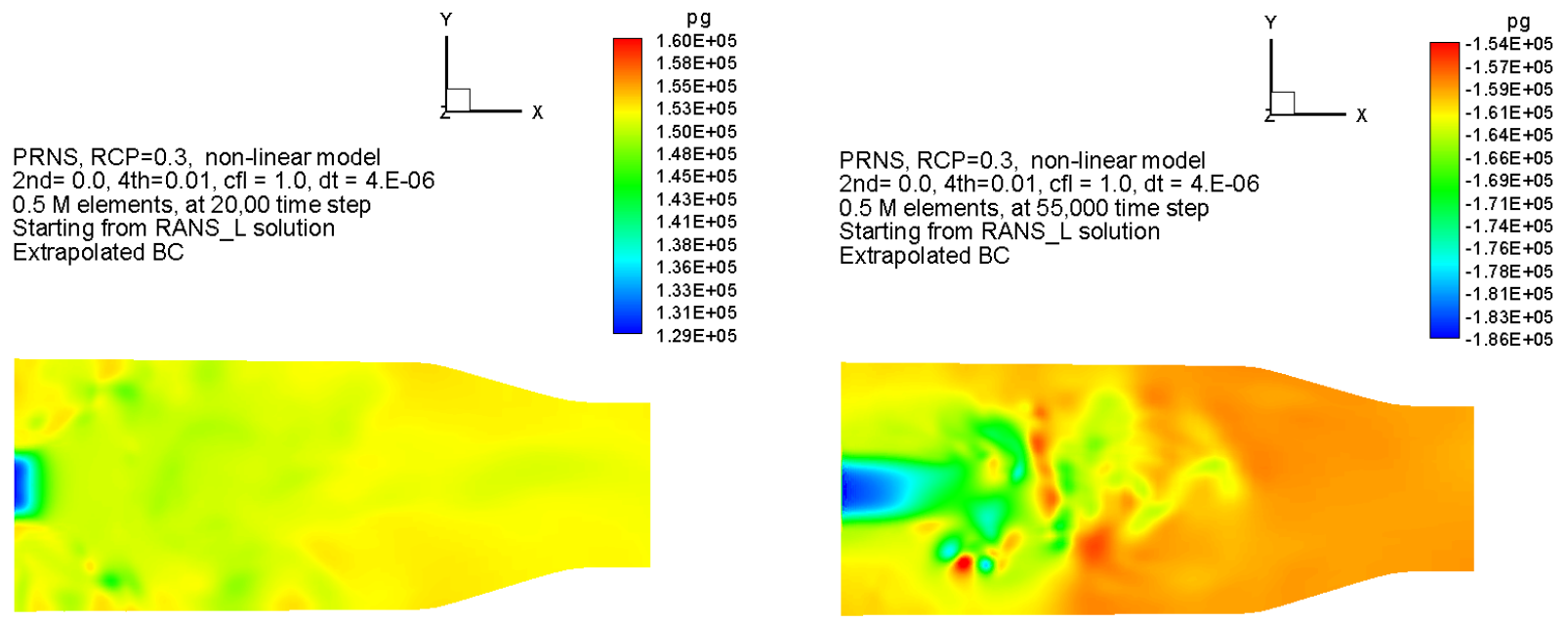

\subsubsection{Results Using Fixed Pressure at the Outlet}

In this case, fixed gauge pressure is imposed at the outlet while the rest of the variables are extrapolated from the interior point. The nonlinear RANS solution is used as the initial condition.

The calculation crashes after 7650 time step. Here we present the instantaneous contour of flow variables at the center planes for two time instants: 2550 time step and 7650 time step.

\subsubsection{Contour at Center Planes}

Snapshots of flow variable contours are shown at tow perpendicular center planes. Figures below on the left side are the snapshots at the time step 2,550, and figures on the right side are the snapshots taken at the time step 7650, i.e., when the simulation is about to crash.

The results indicate that, although the fluctuating turbulent flow field can be established over a relatively short time period, eventually, it can not survive the impact of pressure disturbances reflected from the outlet boundary having a fixed pressure. Very large inflow appears in the outlet region and the corresponding Mach number can exceed 1.4. Obviously, the flow structures are totally unphysical right before the crash of the calculation.
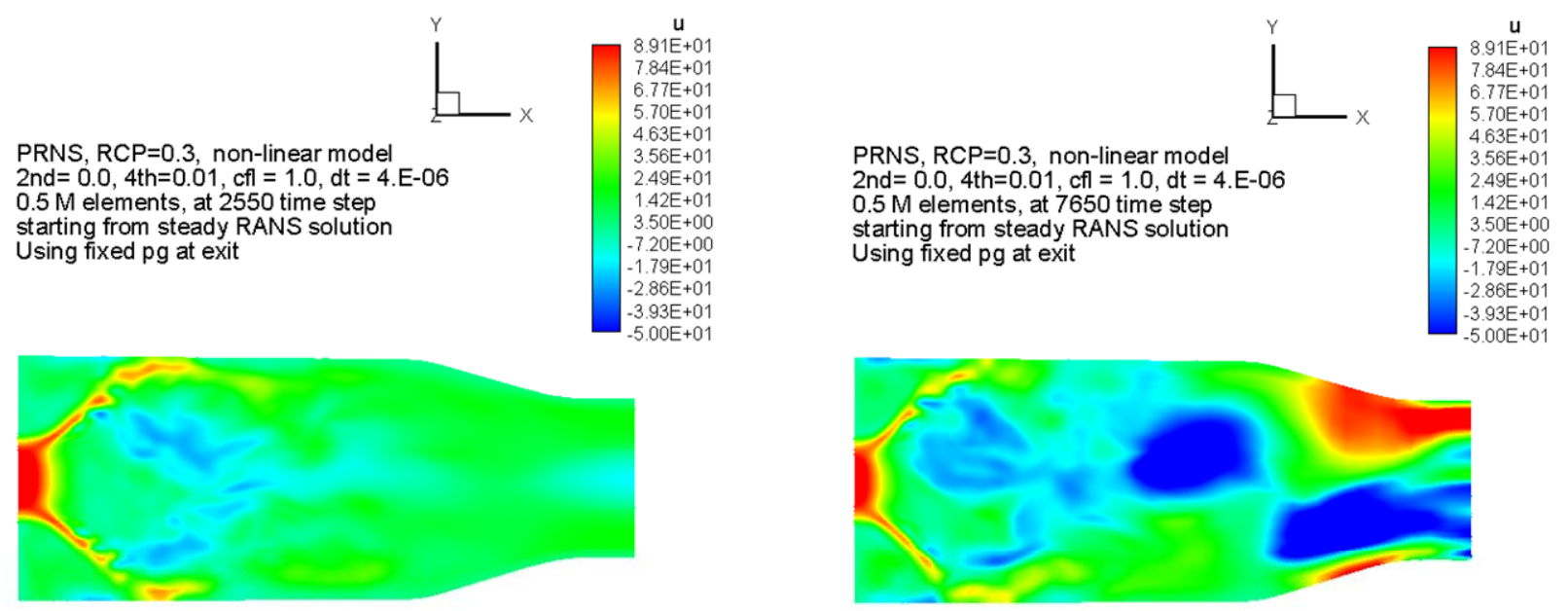

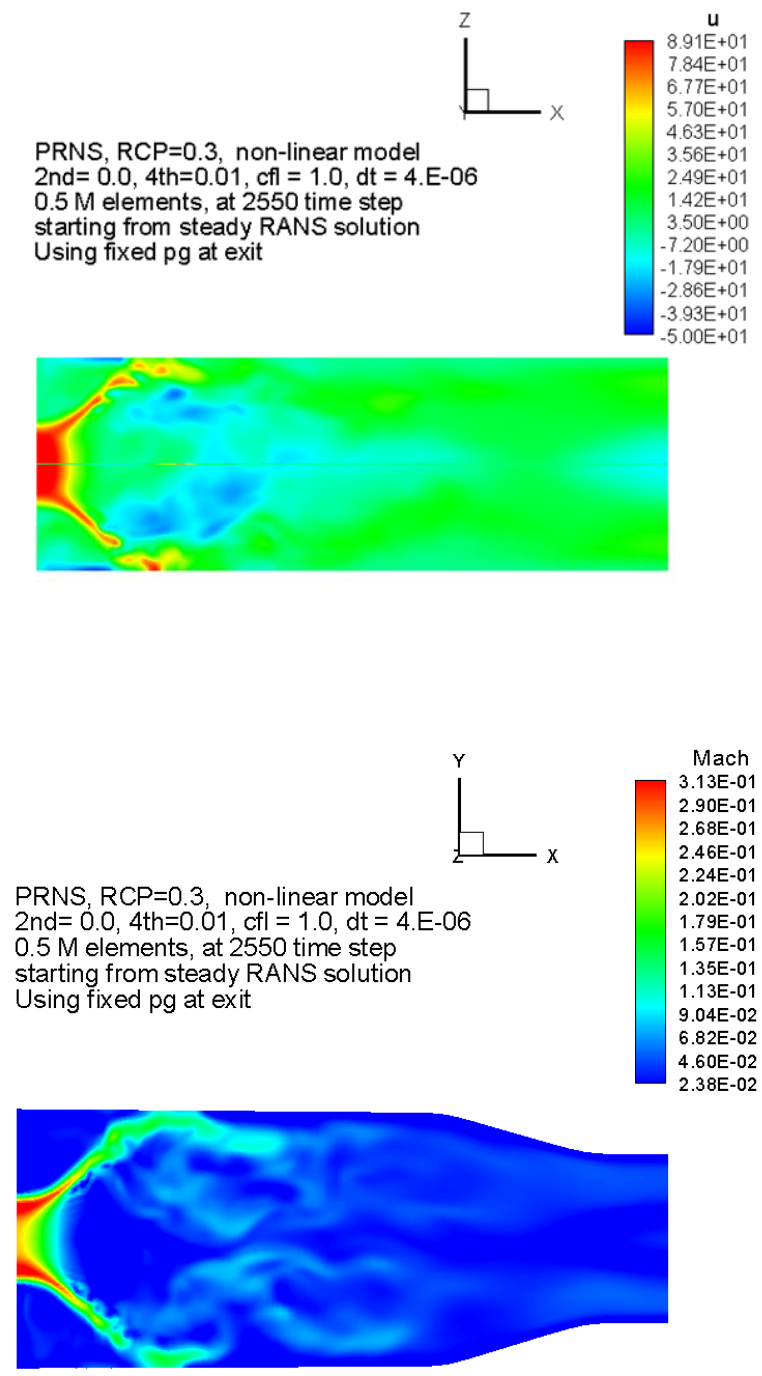

Mach

2.90E-01

$2.68 \mathrm{E}-01$
$2.46 \mathrm{E}-01$

2.24E-01

2.02E-01

$1.79 \mathrm{E}-01$

$1.57 \mathrm{E}-01$

$1.35 \mathrm{E}-01$

$1.13 \mathrm{E}-01$

$9.04 \mathrm{E}-02$

$6.82 \mathrm{E}-02$

$4.60 \mathrm{E}-02$

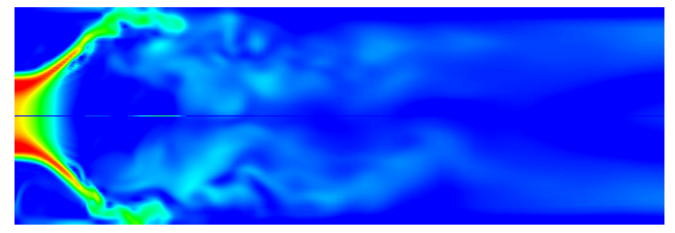

2nd $=0.0,4$ th=0.01, $\mathrm{cfl}=1.0, \mathrm{dt}=4 . \mathrm{E}-06$

$0.5 \mathrm{M}$ elements, at 2550 time step

starting from steady
Using fixed pg at exit
PRNS, RCP $=0.3$, non-linear model 2nd $=0.0,4$ th $=0.01, \mathrm{cfl}=1.0, \mathrm{dt}=4 . \mathrm{E}-06$

$0.5 \mathrm{M}$ elements, at 7650 time step

starting from steady RANS solution

Using fixed $\mathrm{pg}$ at exit

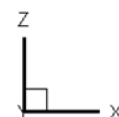

u $84 \mathrm{E}+0$

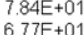
$6.77 \mathrm{E}+01$
$5.70 \mathrm{E}+01$ $4.63 \mathrm{E}+01$ $3.56 \mathrm{E}+01$ $249 \mathrm{E}+0$ $42 \mathrm{E}+01$ 20

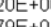
.79E+0 (2.8) $-3.93 \mathrm{E}+0$

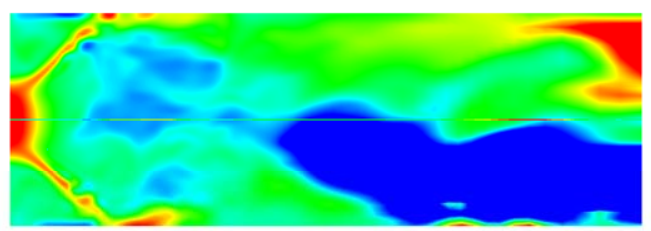

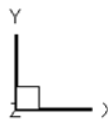

PRNS, RCP $=0.3$, non-linear model

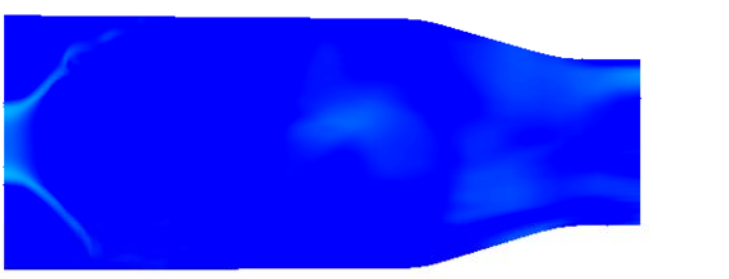

PRNS, RCP $=0.3$, non-linear model 2nd $=0.0,4$ th $=0.01, \mathrm{cfl}=1.0, \mathrm{dt}=4 . \mathrm{E}-06$

$0.5 \mathrm{M}$ elements, at 7650 time step

starting from steady RANS solution

Using fixed pg at exit

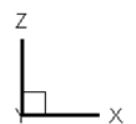

Mach

$1.39 \mathrm{E}+00$

$1.30 \mathrm{E}+00$

$1.20 \mathrm{E}+00$
$1.10 \mathrm{E}+00$

9.97E-01

8.97E-01

$7.98 \mathrm{E}-01$

6.98E-01

5.99E-01

4.99E-01

4.00E-01

3.00E-01

2.00E-01

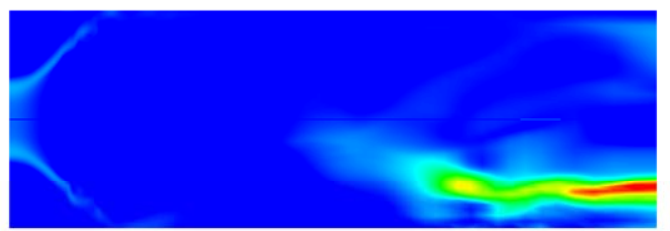



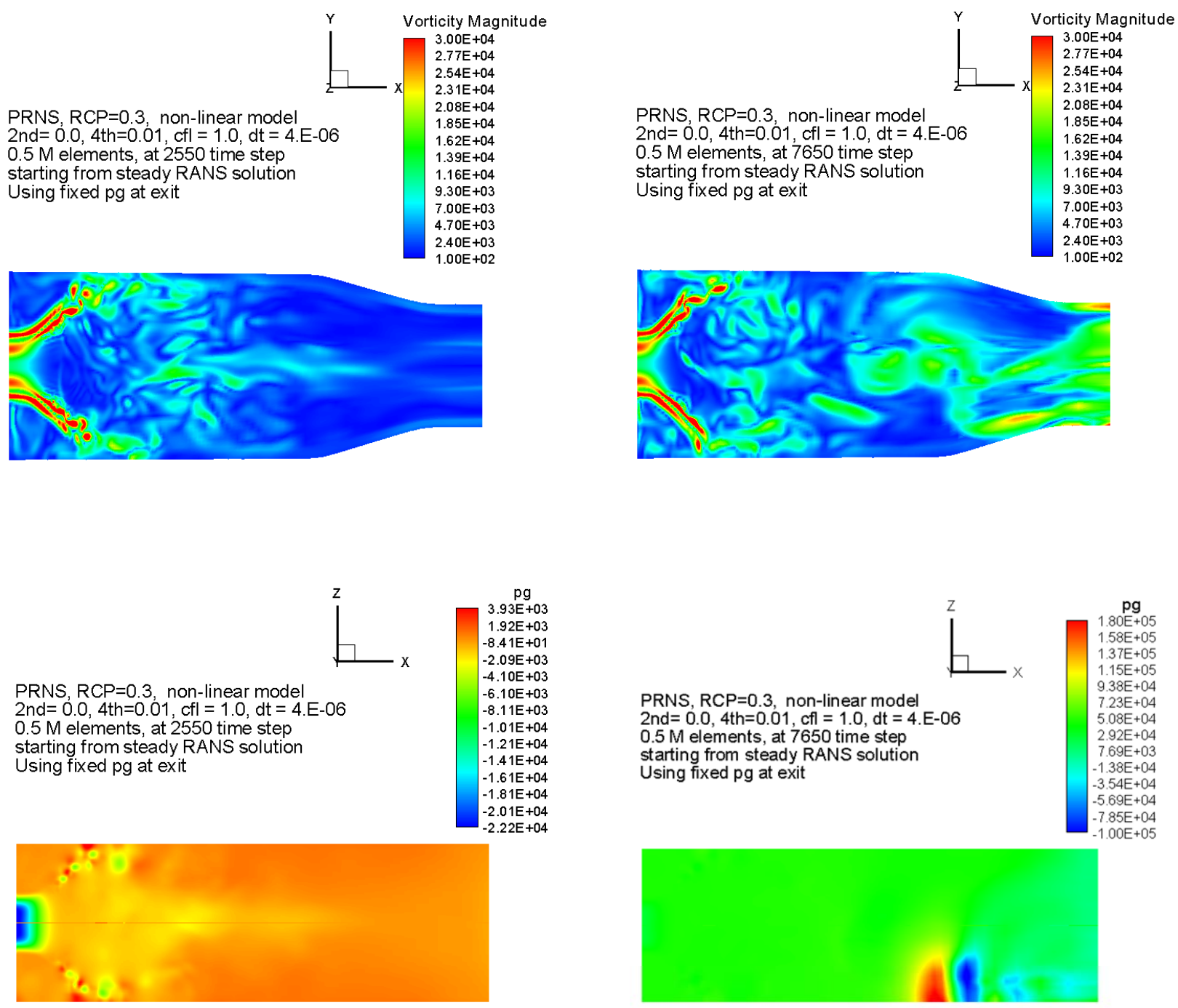

\subsection{Linear Subscale Model}

By now, it is clear that PRNS with the nonlinear subscale model and using the unsteady convective outlet boundary condition for the gauge pressure can successfully simulate the flow in a LM6000 single injector fame tube starting from different initial conditions. In the following, we turn our attention to PRNS with the linear subscale model.

A linear subscale model is a pure eddy viscosity model that is used in all the existing LES type of simulation, in which the effects of the unresolved small scale turbulence on the resolved large scale turbulence are solely accounted for via the eddy viscosity. In our previous assessment effort focusing on the fully developed turbulent pipe flows (Ref. 1), it has been demonstrated that the linear subscale model is not adequate for simulations of low Reynolds number turbulent pipe flows, because the turbulent fluctuations can not be sustained in the simulation over a long period of time.

\subsubsection{Results Using Unsteady Convective BC for Pressure Only}

Here, we present the results using the linear subscale model for the simulation of a LM6000 single injector flame tube. Both of the initial and the outlet boundary condition are the same as that applied in a case of using the nonlinear subscale model. That is, we apply the unsteady convective BC for the gauge 
pressure while the rest of the dependent variables are extrapolated from the interior; and the initial condition is the nonlinear RANS solution.

The results indicate that, although the short-time solution looks reasonable, this simulation does not provide the long-time solution, more specifically, the calculation crashes after 18,000 time steps.

\subsubsection{Contour at Center Plane}

Snapshots of flow variable contours are shown at a center plane for two instances: the time step 10,000 (figures on the left below) and the time step 18,000 (figures on the right below). At time step 10,000 (about 20 flow-through time), the flow structures appear to be reasonable, but the subscale turbulent kinetic energy $\mathrm{k}$ and eddy viscosity $\mu_{T}$ are too small, they are about two orders-of-magnitude smaller than their counterparts when using the nonlinear subscale model. At time step 18,000 (about 36 flow-through time), the flow structures near the outlet become unphysical, namely, large amount of flow rushing into the domain, with its corresponding Mach number approaching one. The calculation crashes soon after. We attribute the failure of the liner subscale model in this case to the fact that, by its nature, it can not account for the rotational and anisotropy effects. Hence, it is not adequate to use the linear subscale model for simulating the high swirling flow occurring in this LM6000 single injector flame tube.
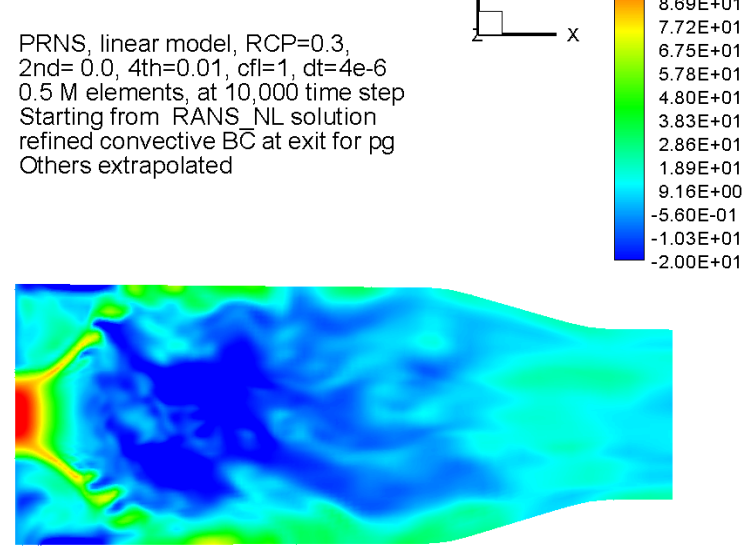

PRNS, linear model $\mathrm{RCP}=0.3$ 2nd=0.0, 4 th $=0.01, \mathrm{cfl}=1, \mathrm{dt}=4 \mathrm{e}-6$ $2 \mathrm{nd}=0.0,4$ th $=0.01, \mathrm{cfl}=1, \mathrm{dt}=4 \mathrm{e}-6$
$0.5 \mathrm{M}$ elements, at 10,000 time step Starting from RANS NL solution refined convective $B \bar{C}$ at exit for $p g$ Others extrapolated
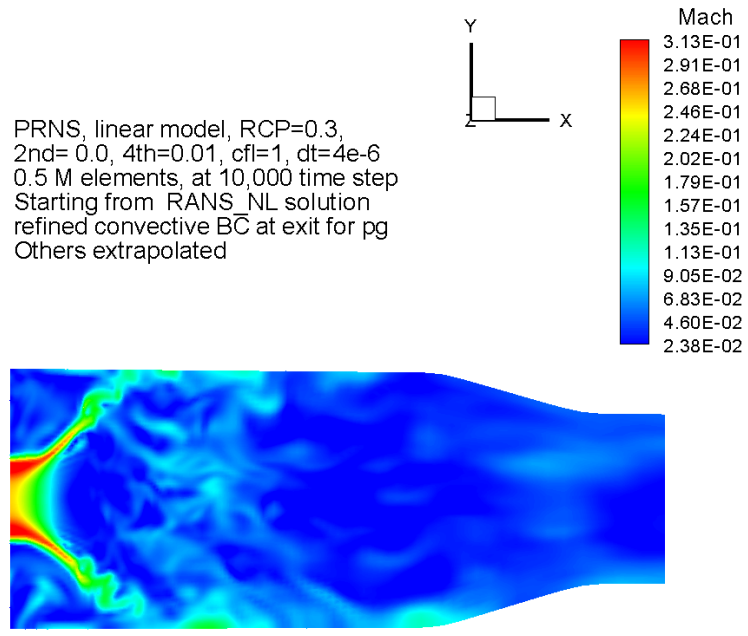

PRNS, linear model, $\mathrm{RCP}=0.3$ 2nd=0.0, 4th=0.01, cfl=1, dt=4e-6 $0.5 \mathrm{M}$ elements, at 18,000 time step Starting from RANS NL solution refined convective $B \bar{C}$ at exit for $p g$ Others extrapolated
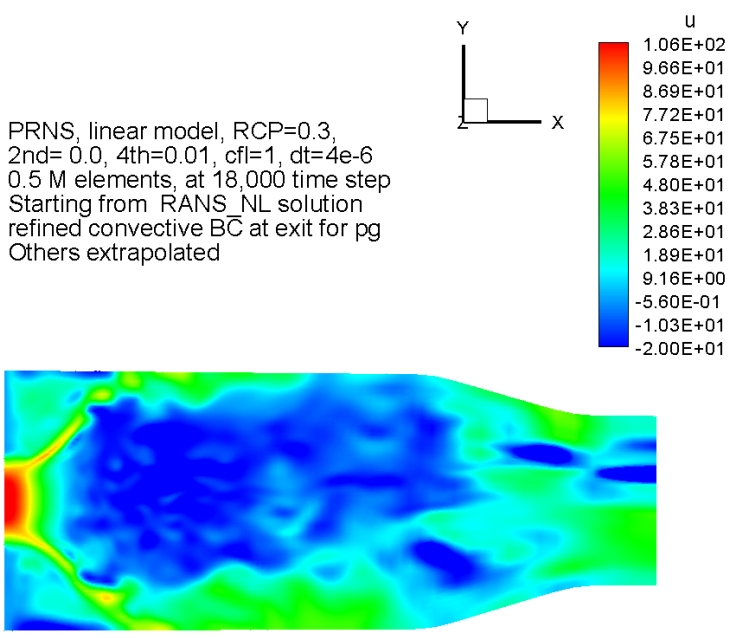

PRNS linear model, $\mathrm{RCP}=03$ 2nd=0.0, 4th=0.01, cfl=1, dt=4e-6 $2 \mathrm{nd}=0.0,4 \mathrm{th}=0.01, \mathrm{cfl}=1, \mathrm{dt}=4 \mathrm{e}-6$
$0.5 \mathrm{M}$ elements, at 18,000 time step Starting from RANS NL solution refined convective $B \bar{C}$ at exit for $p g$ Others extrapolated
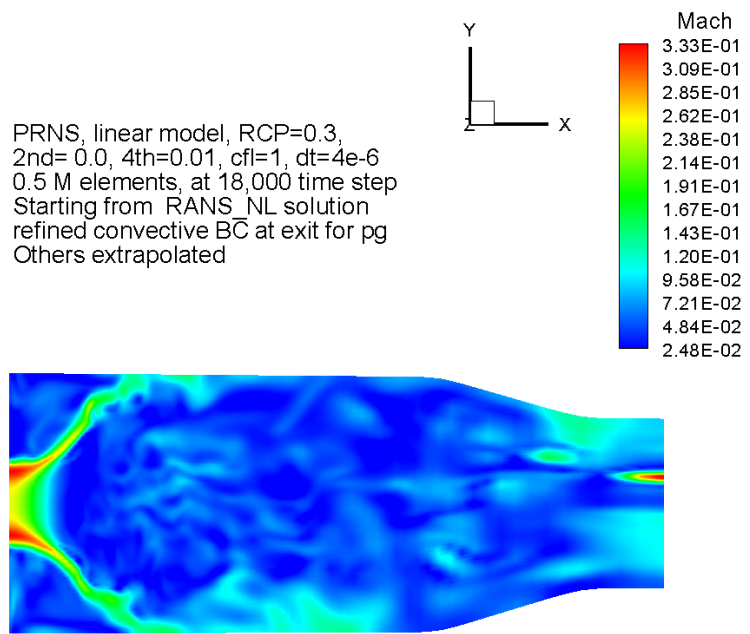
Mach contour at exit

PRNS, linear model, $\mathrm{RCP}=0.3$

2nd $=0.0,4 \mathrm{th}=0.01, \mathrm{cfl}=1, \mathrm{dt}=4 \mathrm{e}-6$

$0.5 \mathrm{M}$ elements, at 10,000 time step

Starting from RANS L solution

refined convective $B \bar{C}$ at exit for pg

Others extrapolated

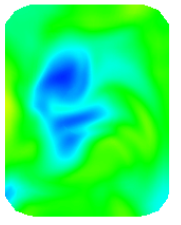

PRNS, linear model, $R C P=0.3$, 2nd $=0.0,4$ th $=0.01, \mathrm{cf}=1, \mathrm{dt}=4 \mathrm{e}-6$ $0.5 \mathrm{M}$ elements, at 10,000 time step Starting from RANS NL solution refined convective $B \bar{C}$ at exit for $p g$ Others extrapolated

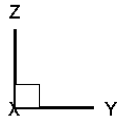

Mac

$1.0000 \mathrm{E}-01$

$9.2308 \mathrm{E}-02$

$8.4615 \mathrm{E}-02$

7.6923E-02

$6.9231 \mathrm{E}-02$

$6.1538 \mathrm{E}-02$

$6.1538 \mathrm{E}-02$

$5.3846 \mathrm{E}-02$
$4.6154 \mathrm{E}-02$

$4.6154 \mathrm{E}-02$
$3.8462 \mathrm{E}-02$

$3.8462 \mathrm{E}-02$
$3.0769 \mathrm{E}-02$

$2.3077 \mathrm{E}-02$

$1.5385 \mathrm{E}-02$

$7.6923 \mathrm{E}-03$

$0.0000 \mathrm{E}+00$
Mach contour at exit

PRNS, linear model, $R C P=0.3$

2nd $=0.0,4 \mathrm{th}=0.01, \mathrm{cfl}=1, \mathrm{dt}=4 \mathrm{e}-6$

$0.5 \mathrm{M}$ elements, at 18,000 time step Starting from RANS $\mathrm{L}$ solution

refined convective $B \bar{C}$ at exit for $p g$

Others extrapolated

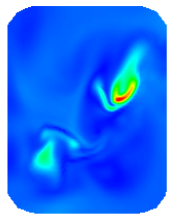

PRNS, linear model, $\mathrm{RCP}=0.3$, 2nd $=0.0,4$ th $=0.01, c f l=1, d t=4 e-6$ $0.5 \mathrm{M}$ elements, at 18,000 time step Starting from RANS NL solution refined convective $B \bar{C}$ at exit for $p g$ Others extrapolated

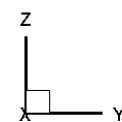

Mach

$9.1460 \mathrm{E}-01$

$8.4424 \mathrm{E}-01$

$7.7389 \mathrm{E}-01$

7.7389E-01

7.0354E-01

$6.3318 \mathrm{E}-01$

$5.6283 \mathrm{E}-01$

4.9248E-01

4.2212E-01

3.5177E-01

$2.8141 \mathrm{E}-01$

$2.1106 \mathrm{E}-01$

1.4071E-01

$7.0354 \mathrm{E}-02$
$0.0000 \mathrm{E}+00$

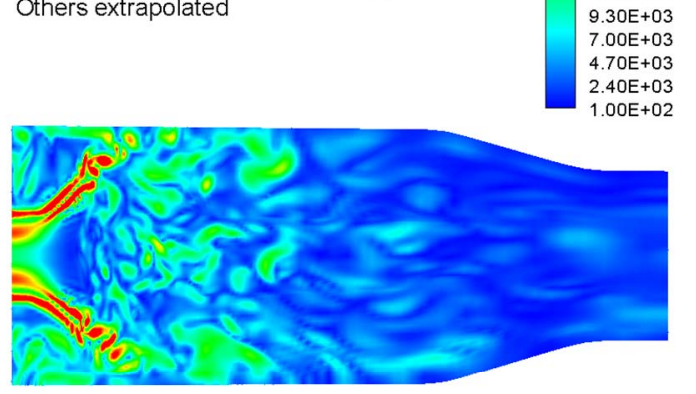

PRNS, linear model, $\mathrm{RCP}=0.3$,

Y Vorticity Magnitude

$3.00 \mathrm{E}+04$

$2.77 \mathrm{E}+04$

$2.54 \mathrm{E}+04$

$2.31 \mathrm{E}+04$

$1.85 \mathrm{E}+04$

$1.62 \mathrm{E}+04$

$1.39 \mathrm{E}+04$

$16 \mathrm{E}+04$

$2 \mathrm{nd}=0.0,4 \mathrm{th}=0.01, \mathrm{cf}=1, \mathrm{dt}=4 \mathrm{e}-6$

$0.5 \mathrm{M}$ elements, at 10,000 time step

Starting from RANS NL solution

refined convective $B \bar{C}$ at exit for $p g$

Others extrapolated
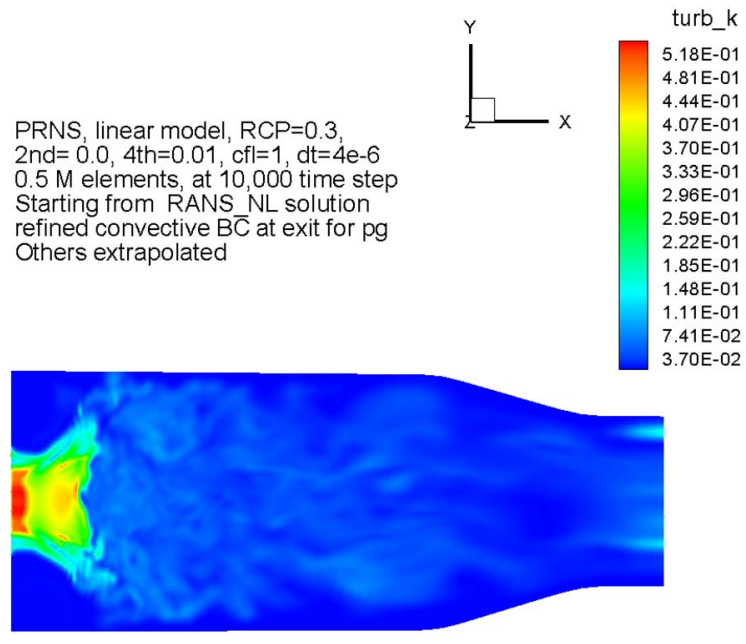

PRNS, linear model, RCP $=0.3$, $2 \mathrm{nd}=0.0,4 \mathrm{th}=0.01, \mathrm{cfl}=1, \mathrm{dt}=4 \mathrm{e}-6$ $0.5 \mathrm{M}$ elements, at 18,000 time step Starting from RANS NL solution refined convective $B \bar{C}$ at exit for pg Others extrapolated
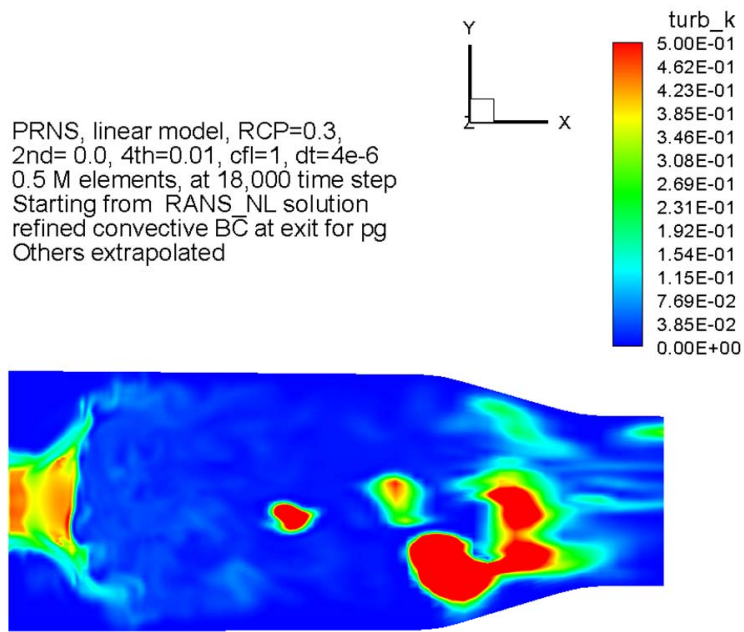
PRNS, linear model, $\mathrm{RCP}=0.3$, 2nd $=0.0,4$ th $=0.01, \mathrm{cfl}=1, \mathrm{dt}=4 \mathrm{e}-6$ $0.5 \mathrm{M}$ elements, at 10,000 time step Starting from RANS NL solution refined convective $B \bar{C}$ at exit for $p g$ Others extrapolated
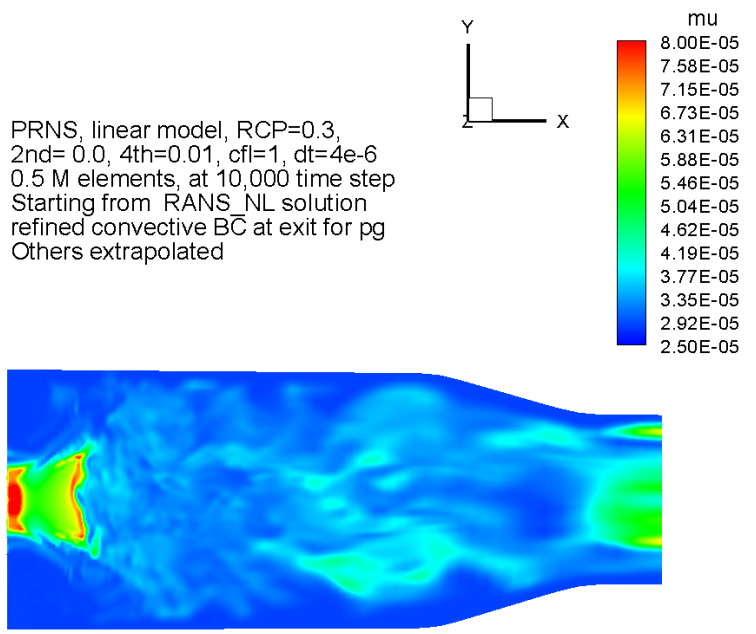

PRNS linear model, $\mathrm{RCP}=0.3$ $2 \mathrm{nd}=0.0,4 \mathrm{th}=0.01, \mathrm{cfl}=1, \mathrm{dt}=4 \mathrm{e}-6$ $0.5 \mathrm{M}$ elements, at 18,000 time step Starting from RANS NL solution Starting from RANS NL solution
refined convective $B \bar{C}$ at exit for $p g$ Others extrapolated
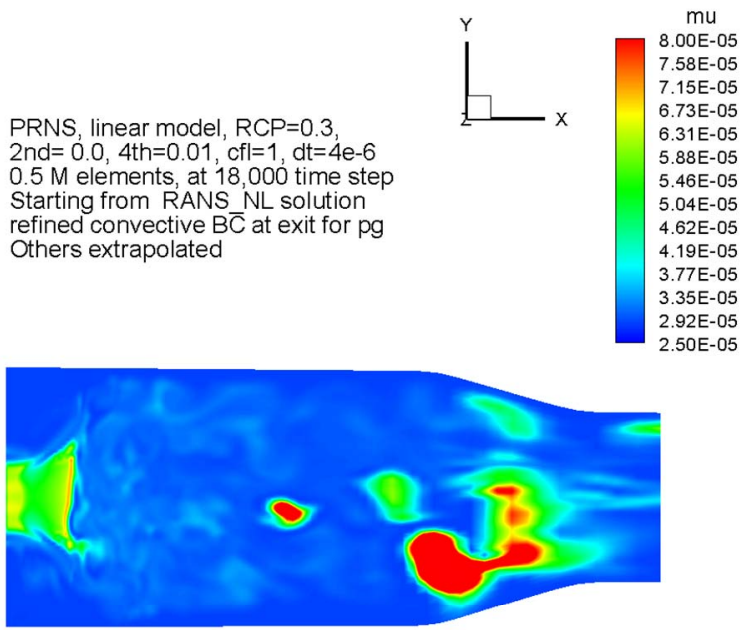

PRNS, linear model, $\mathrm{RCP}=0.3$, 2nd $=0.0,4 \mathrm{th}=0.01, \mathrm{cfl}=1, \mathrm{dt}=4 \mathrm{e}-6$ $0.5 \mathrm{M}$ elements, at 18,000 time step Starting from RANS NL solution 2nd $=0.0,4$ th $=0.01, \mathrm{cfl}=1, \mathrm{dt}=4 \mathrm{e}-$ $0.5 \mathrm{M}$ elements, at 10,000 time step Starting from RANS NL solution refined convective $\mathrm{B} \overline{\mathrm{C}}$ at exit for $\mathrm{pg}$

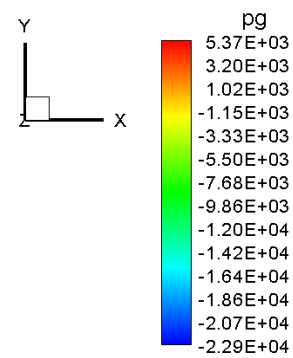
refined convective $\mathrm{B} \overline{\mathrm{C}}$ at exit for pg Others extrapolated
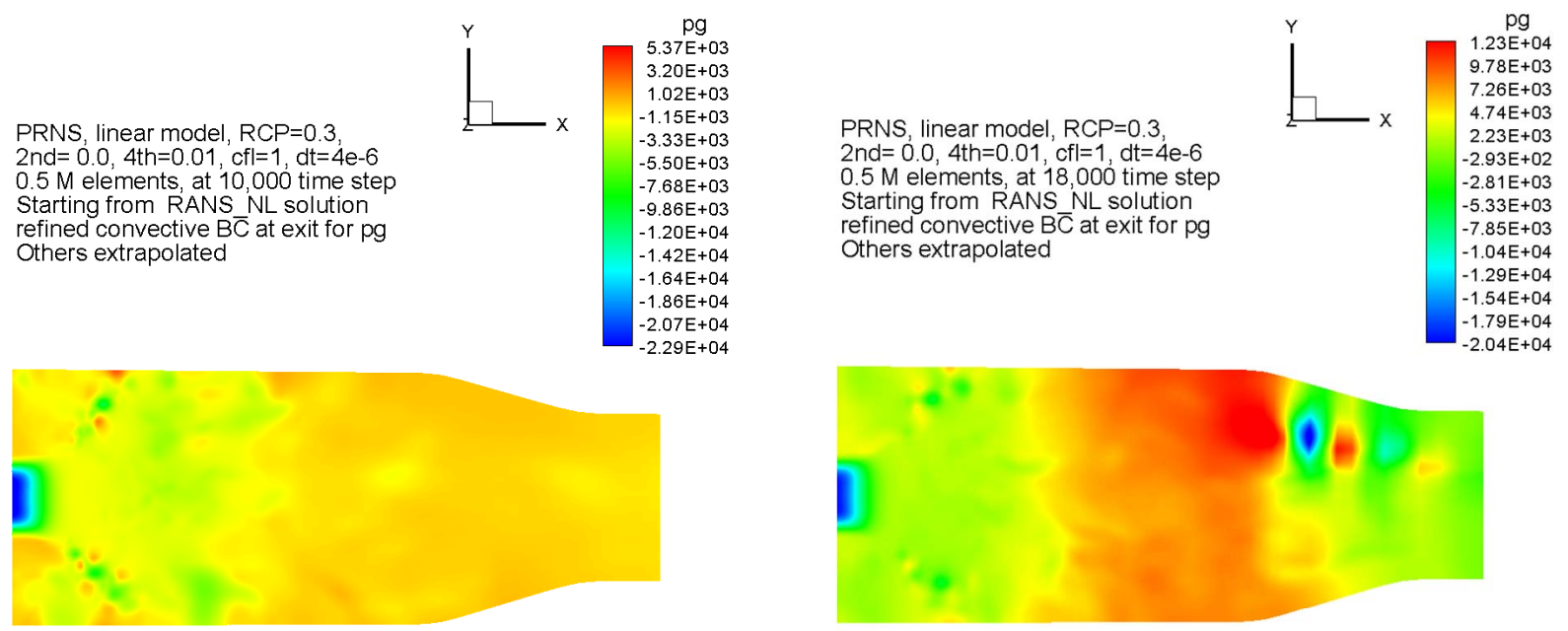

\subsection{Concluding Remarks}

The unsteady pressure convective BC appears to be very suitable for PRNS simulations with nonlinear subscale model. It is also robust with respect to very different initial conditions. It is noticed that the solutions with different initial conditions are different from each other near the inlet region where no or less turbulent fluctuations are observed due to the specified "laminar" inflow condition; however, the solutions become statistically equivalent in regions away from the inlet, where the turbulence becomes fully developed. The solution does sustain itself in a physically meaningful manner over a long period of time.

Both extrapolation BC and fixed pressure at the outlet are not suitable for large or very large eddy simulations. Even though a "reasonable" solution can be established, they can only last over a short period of time. In the long run, the solution will become unphysical.

In addition, the numerical studies indicate that the linear subscale $k-\varepsilon$ model does not work very well for high swirling flows. The subscale eddy viscosity is vanishing towards the value of the laminar viscosity, eventually, the simulation can not survive for long in the high Reynolds number environment. 


\subsection{URANS of LM6000 Single Injector Flame Tube}

In this section, we present the results of unsteady RANS simulations. Two Reynolds stress models (nonlinear and linear) have been applied. Three outlet boundary conditions (i.e., the unsteady convective $\mathrm{BC}$, the extrapolation BC and the fixed pressure BC) have been assessed. Furthermore, three different initial conditions (i.e., the nonlinear RANS solution, the linear RANS solution and the static flow field) have been used

\subsection{Nonlinear Model}

URANS with the nonlinear model is fundamentally different from the standard $k-\varepsilon$ model (Ref. 9). Here, the interactions between the turbulent mean flow and the entire spectrum of the turbulent fluctuations are accounted for not only by the eddy viscosity, but also by the explicit turbulence source terms in the filtered transport equations. These additional source terms are due to the nonlinear part of the model, and they do not originate from the standard $k-\varepsilon$ model.

\subsubsection{Results Using Unsteady Convective BC for Pressure Only}

Similar to the PRNS simulations in Section 3.1.1, the unsteady convective outlet BC is only applied to the gauge pressure. All the other dependent flow variables at the outlet are provided by extrapolating from the interior point.

The results are presented in three parts: the time history of velocity components and gauge pressure at four locations along the centerline; the instantaneous contour plots of flow variables at a center plane; and the instantaneous centerline flow variable profiles.

\subsubsection{Time History}

The time history of velocity components and gauge pressure are recorded at four centerline locations: $x=0.015,0.05,0.10$ and 0.2 . From which we may examine the temporal development of the filtered variables. The results are presented with respect to three different initial conditions: the nonlinear RANS solution, the linear RANS solution, and the static flow field.

\section{Initial condition: Nonlinear RANS solution}
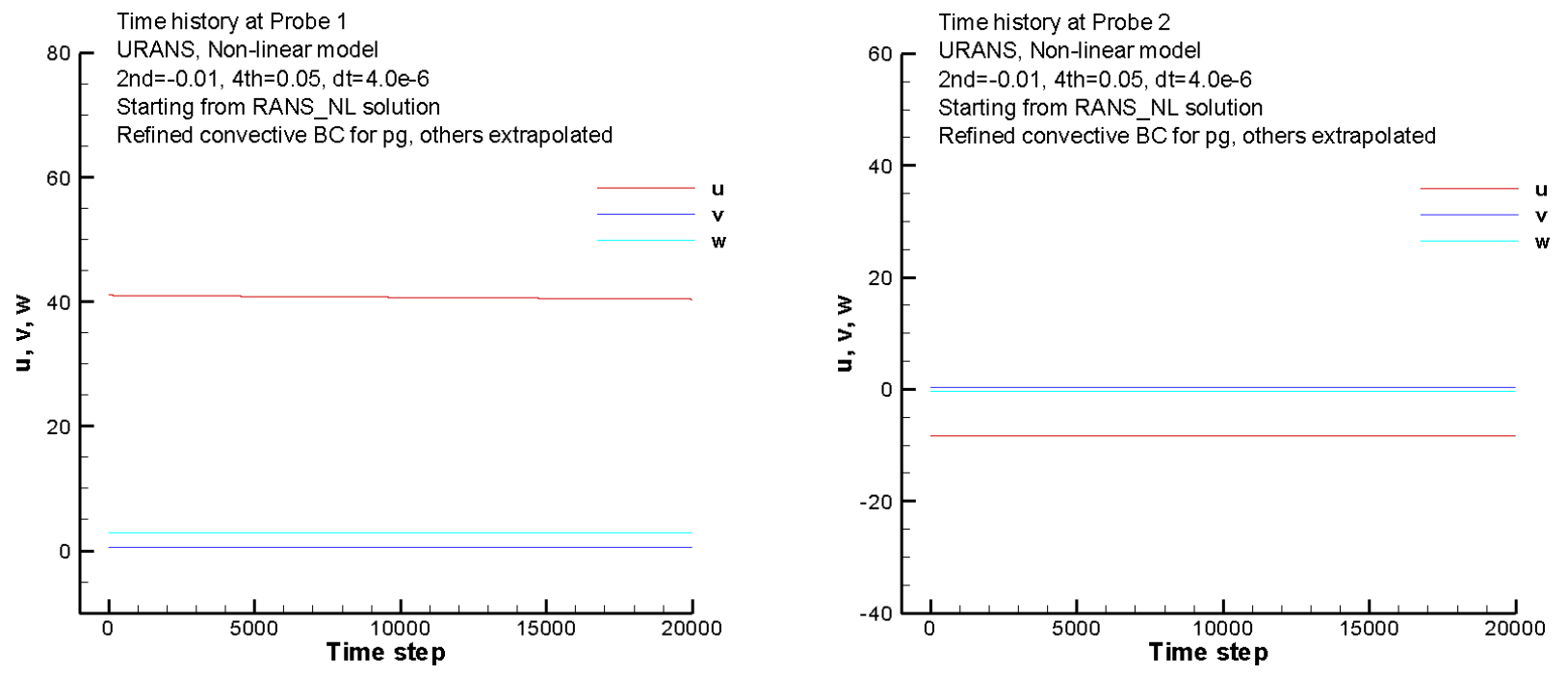

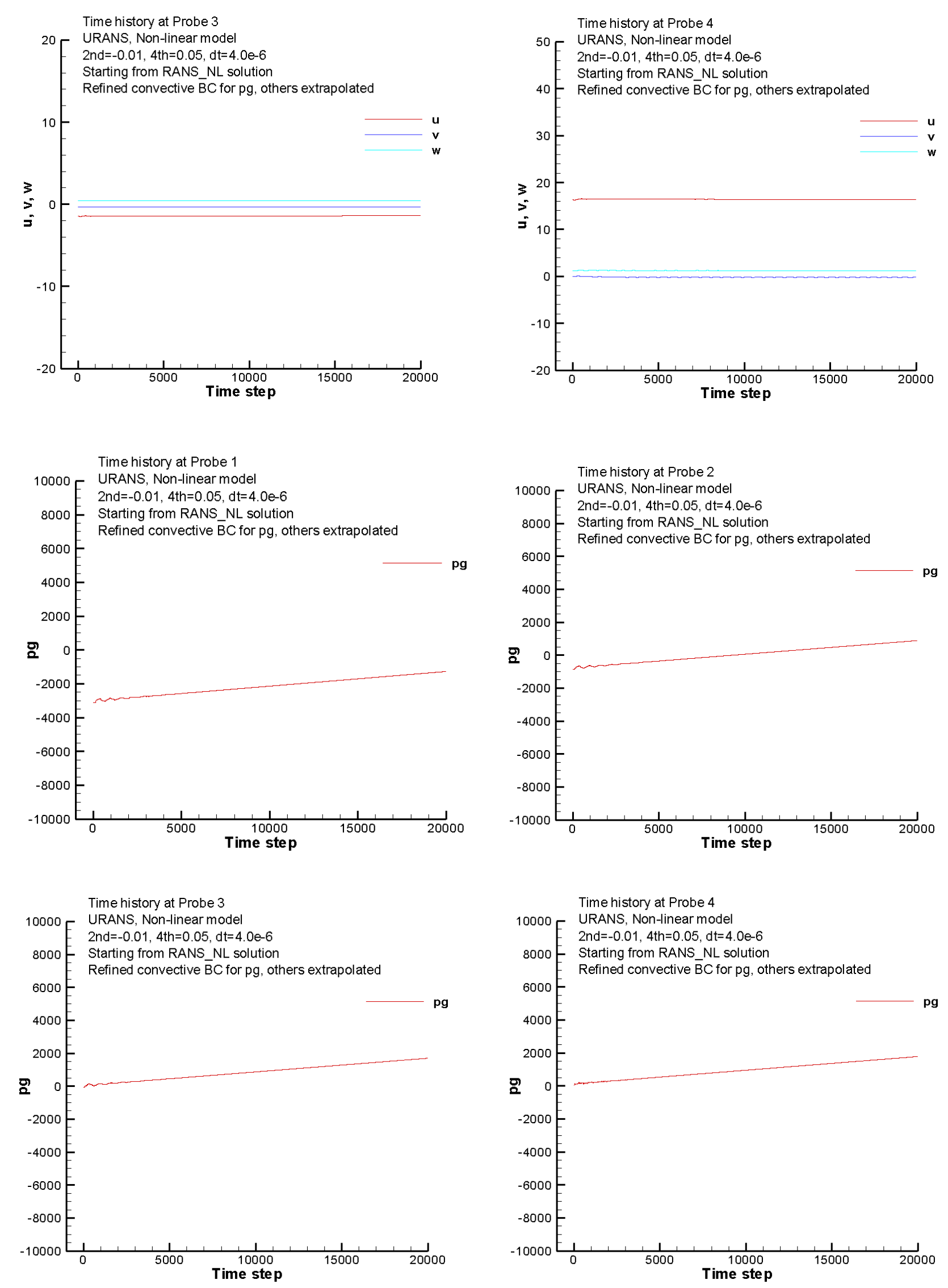


\section{Initial condition: Linear RANS solution}
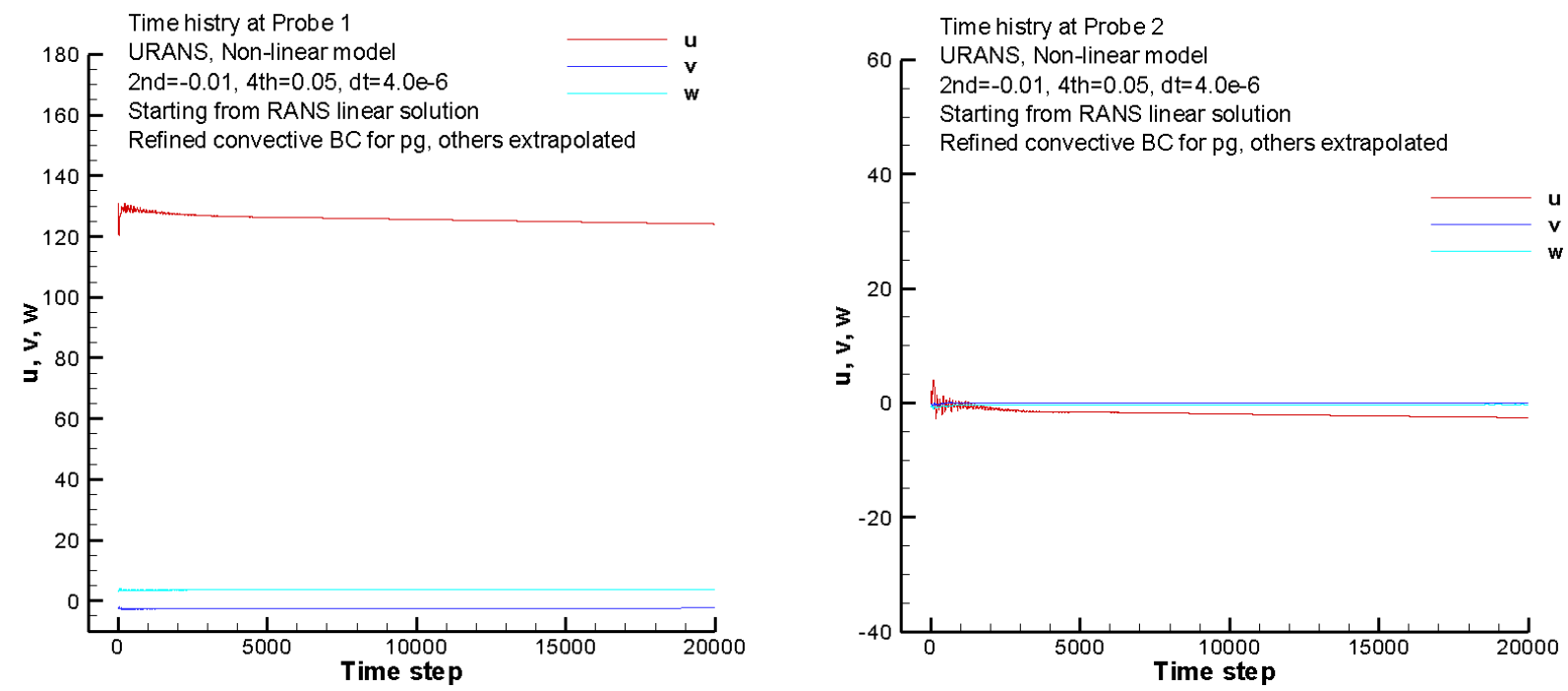

Time histry at Probe 3
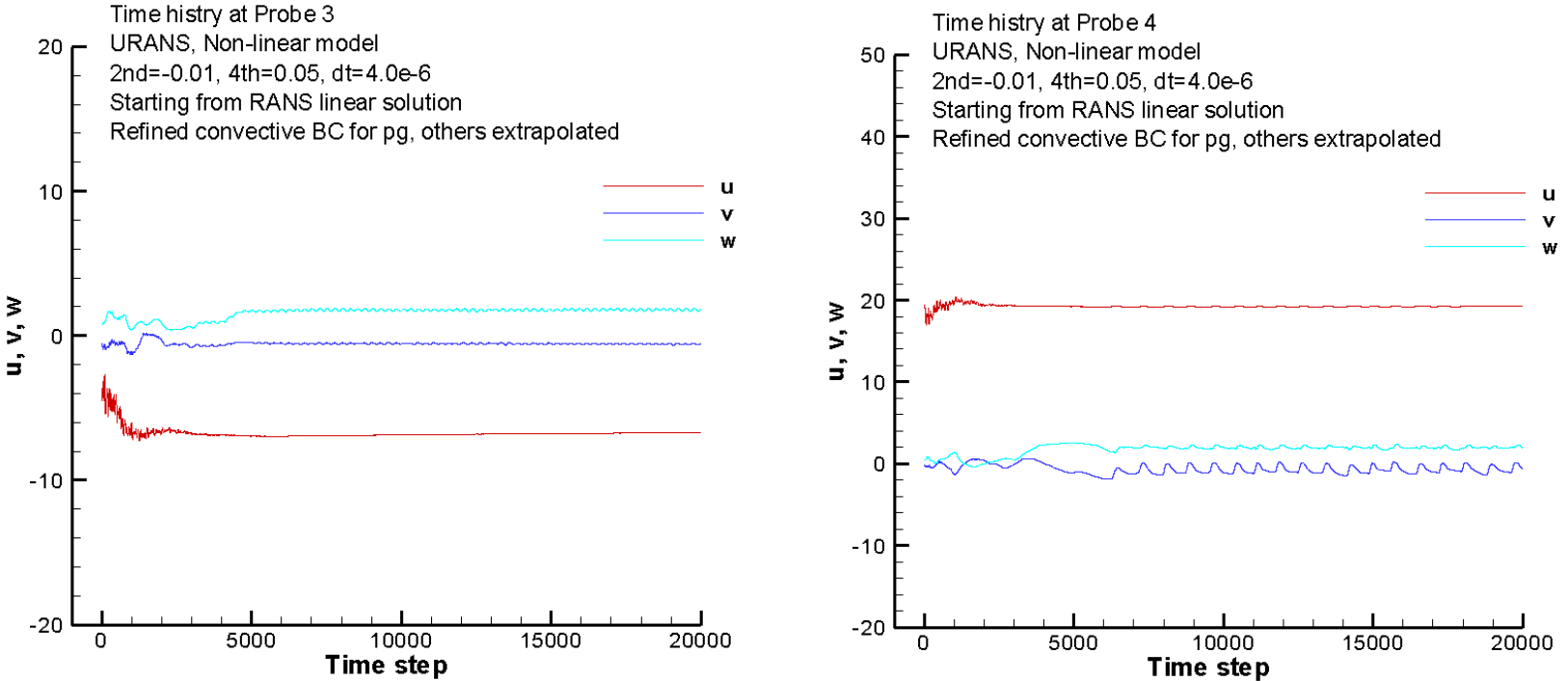
Initial condition: Static flow field
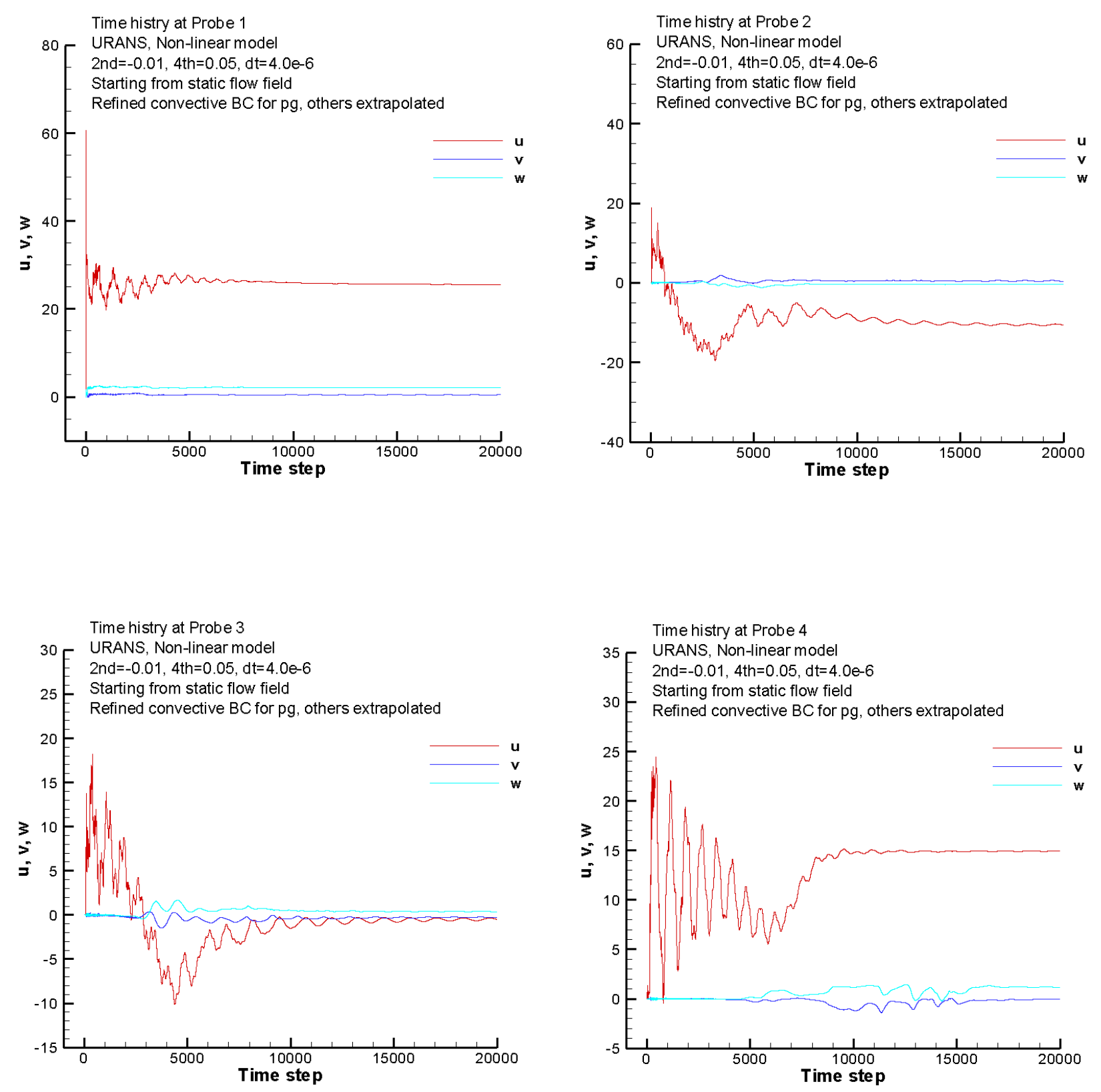


\subsubsection{Contour at Center Plane}

The snapshots of instantaneous contour of flow variables at a center plane are presented for the time step 20,000, which is about 40 through-flow time. From which we may examine the flow structures. The results are presented with respect to three different initial conditions: the nonlinear RANS solution, the linear RANS solution, and the static flow field.

\section{Initial condition: Nonlinear RANS solution}

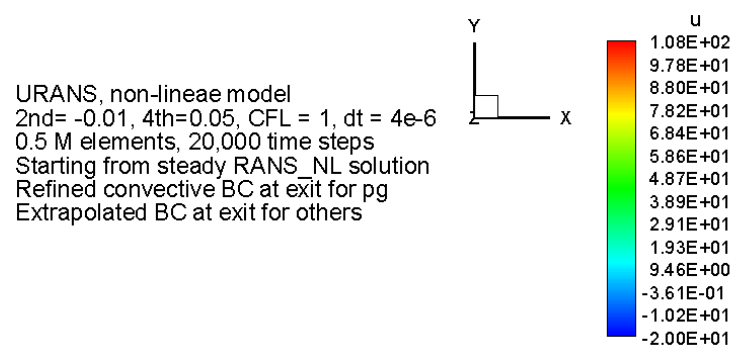

URANS, non-lineae model

2nd $=-0.01,4$ th $=0.05, C F L=1, d t=4 e-6$

$0.5 \mathrm{M}$ elements, 20,000 time steps

Starting from steady RANS_NL solution

Refined convective $\mathrm{BC}$ at exit for $\mathrm{pg}$

Extrapolated $\mathrm{BC}$ at exit for others
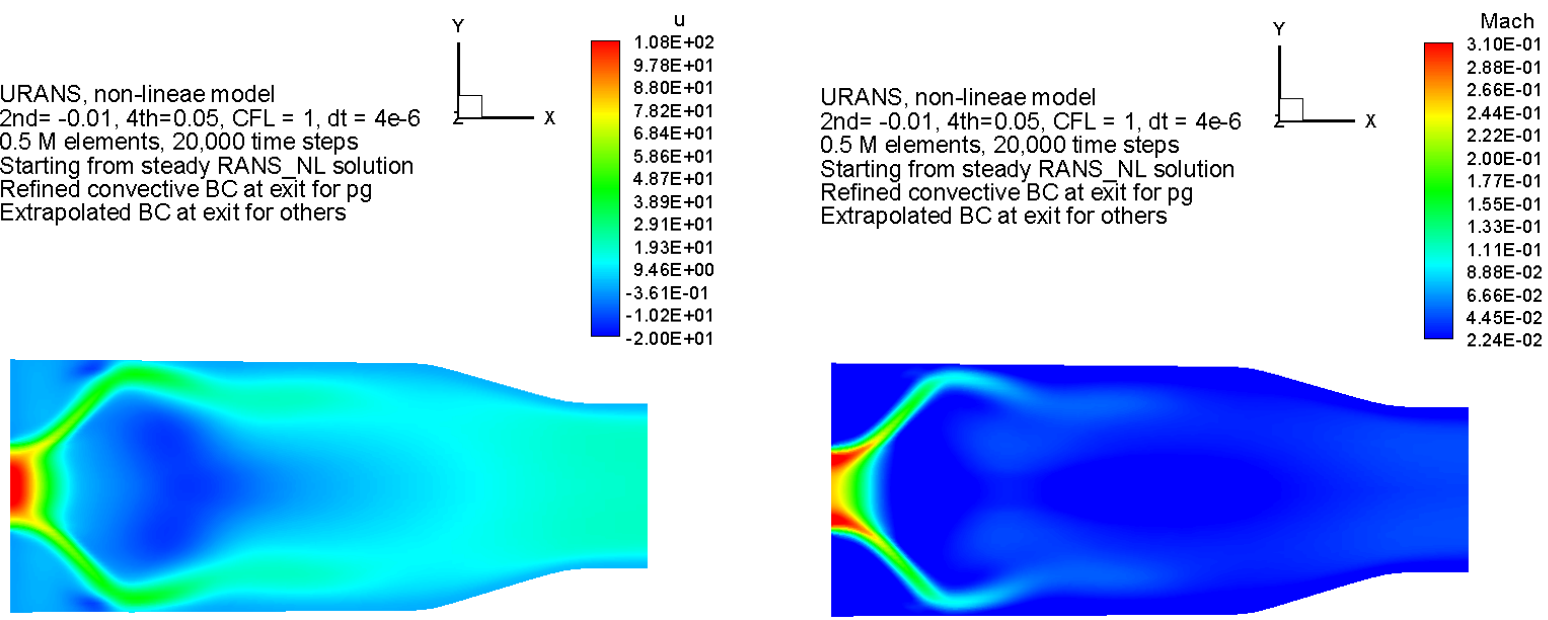

(4) -02
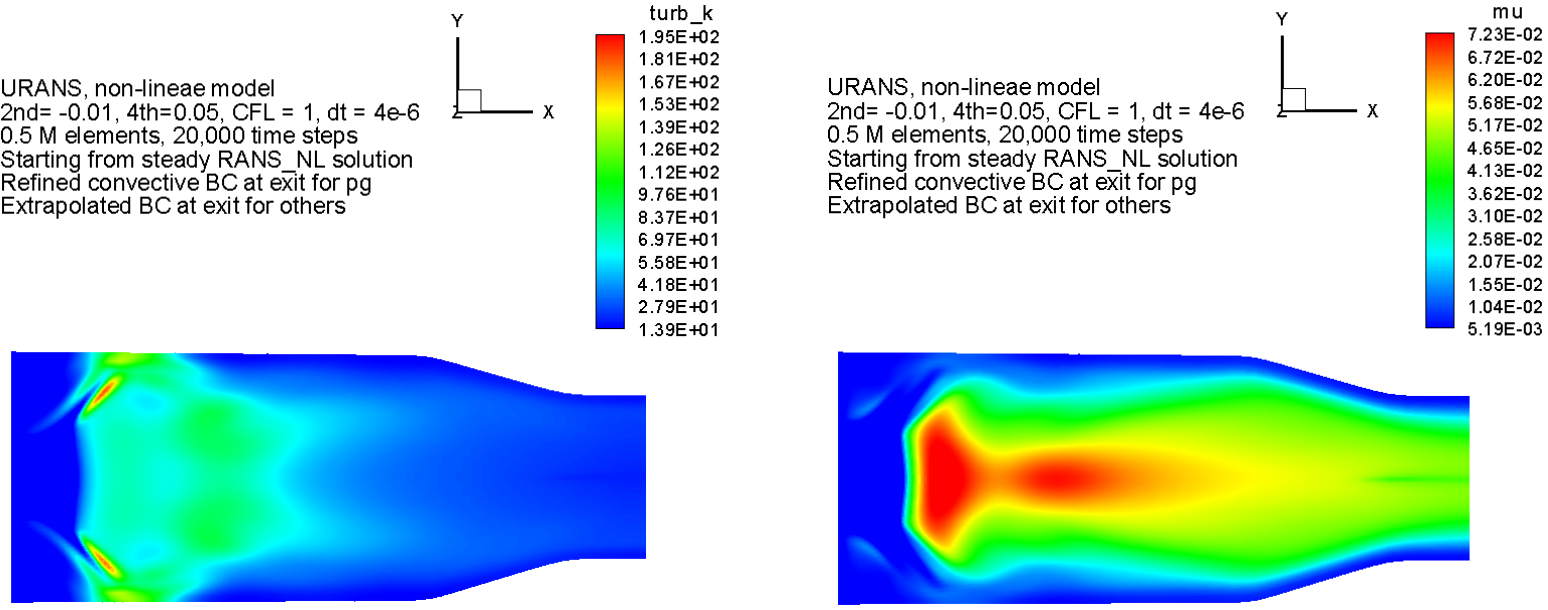

URANS, non-lineae model

nd $=-0.01,4$ th $=0.05, C F L=1, d t=4 e-6$

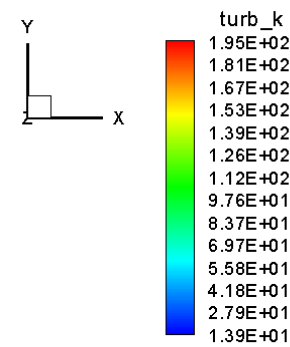

URANS, non-lineae model
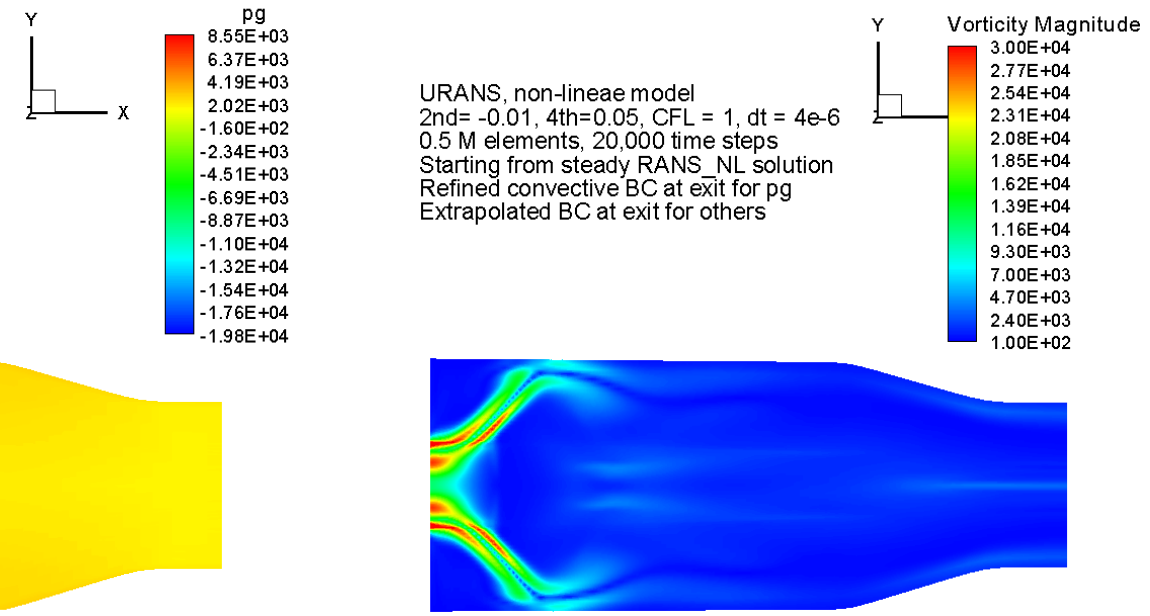


\section{Initial condition: Linear RANS solution}

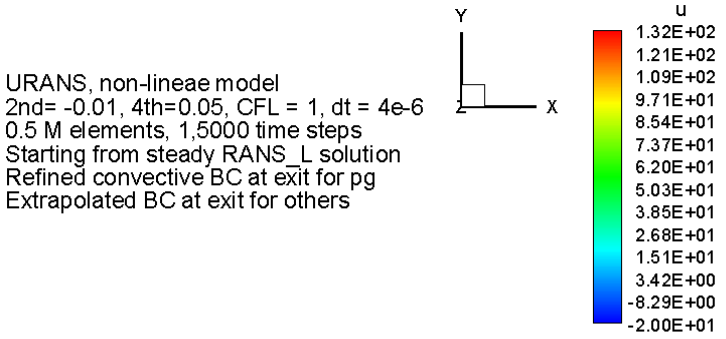

URANS, non-lineae model

2nd $=-0.01,4 \mathrm{th}=0.05, \mathrm{CFL}=1, \mathrm{dt}=4 \mathrm{e}-6$

$0.5 \mathrm{M}$ elements, 1,5000 time steps

Starting from steady RANS L solution

Refined convective BC at exit for pg

Extrapolated $\mathrm{BC}$ at exit for others
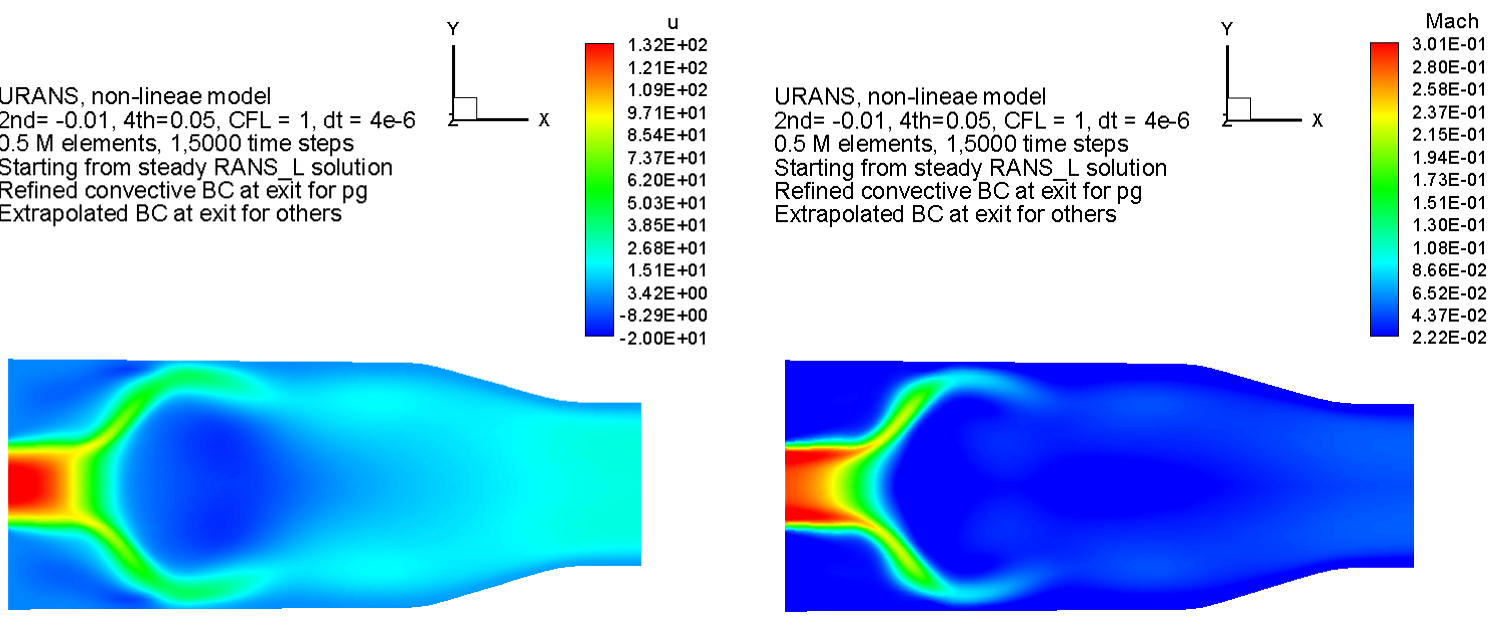

URANS, non-lineae model

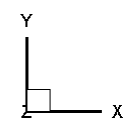

$3.25 \mathrm{E}+02$

2nd $=-0.01,4$ th $=0.05, C F L=1, d t=4 e-$

$2.98 \mathrm{E}+02$

$0.5 \mathrm{M}$ elements, 1,5000 time steps

$2.71 \mathrm{E}+02$

Starting from steady RANS_L solution

$2.44 \mathrm{E}+02$

Refined convective $B C$ at exit for $p$

$2.17 \mathrm{E}+02$

$1.90 \mathrm{E}+02$

$1.63 \mathrm{E}+02$

$1.35 \mathrm{E}+02$

$1.08 \mathrm{E}+02$

$8.13 \mathrm{E}+0$

$5.42 \mathrm{E}+01$

URANS, non-lineae model
2nd $=-0.01,4$ th $=0.05, C F L=1, d t=4 e-6$

$0.5 \mathrm{M}$ elements, 1,5000 time steps

Starting from steady RANS L solution

Refined convective $\mathrm{BC}$ at exit for $\mathrm{Pg}$

Extrapolated $\mathrm{BC}$ at exit for others
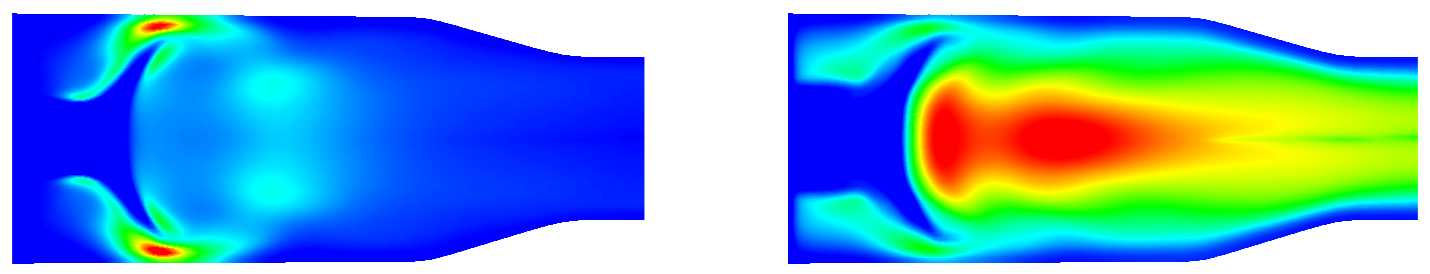

URANS, non-lineae model

2nd $=-0.01,4$ th $=0.05, C F L=1, d t=4 e-6$

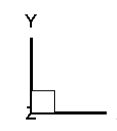

$0.5 \mathrm{M}$ elements, 1,5000 time steps

$1.91 \mathrm{E}+03$

$-5.52 \mathrm{E}+02$

$-3.01 \mathrm{E}+03$

$-5.48 \mathrm{E}+03$

$-7.94 \mathrm{E}+03$

Starting from steady RANS L solution

$-1.04 \mathrm{E}+04$

Refined convective BC at exit for $\mathrm{Pg}$

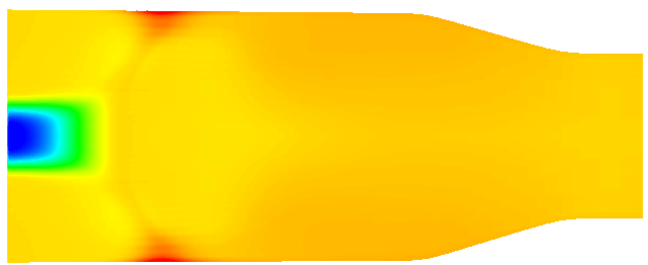

URANS, non-lineae model

$2 \mathrm{nd}=-0.01,4 \mathrm{th}=0.05, \mathrm{CFL}=1, \mathrm{dt}=4 \mathrm{e}-6$

Y Vorticity Magnitude

2nd $=-0.01,4$ th $=0.05, C F L=1, d t$
$0.5 \mathrm{M}$ elements, 1,5000 time step

Starting from steady RANS_L solution

Refined convective BC at exit for $\mathrm{pg}$

Extrapolated $\mathrm{BC}$ at exit for others
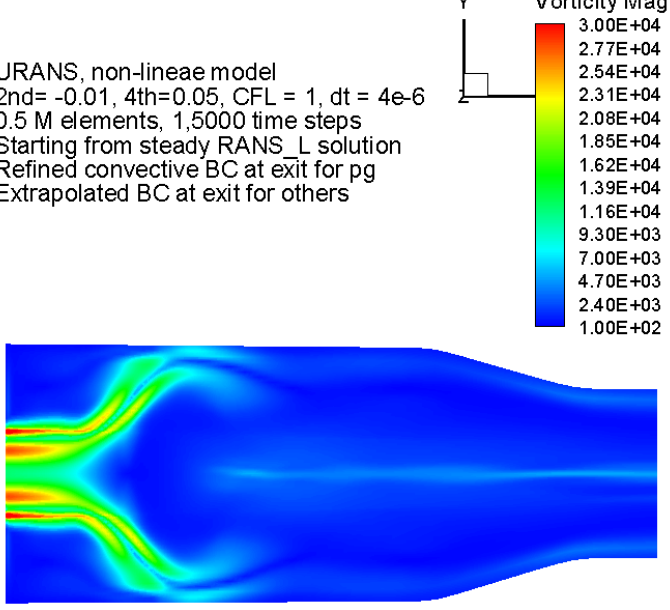
Initial condition: Static flow field

URANS, non-lineae model

2nd $=-0.01,4$ th $=0.05, C F L=1, d t=4 e-6$

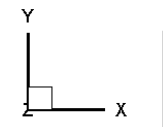

$\mathrm{U}$
$92 \mathrm{E}+0$

$9.00 \mathrm{E}+01$

$8.09 \mathrm{E}+01$

7.17E+01

$6.25 \mathrm{E}+01$

$5.34 \mathrm{E}+01$

$5.34 \mathrm{E}+0$

$4.42 \mathrm{E}+01$

$3.50 \mathrm{E}+01$

$2.58 \mathrm{E}+01$

$1.67 \mathrm{E}+01$

$7.51 \mathrm{E}+00$

$1.66 \mathrm{E}+00$

$-1.08 \mathrm{E}+01$

$2.00 \mathrm{E}+01$

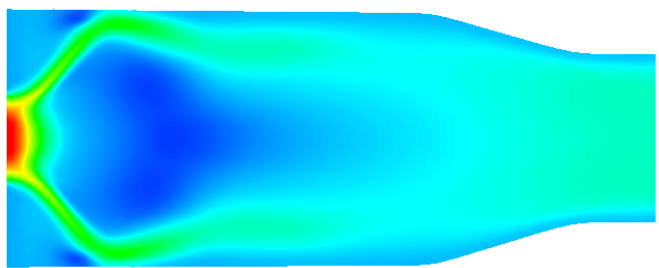

URANS, non-lineae model

$2 \mathrm{nd}=-0.01,4 \mathrm{th}=0.05, \mathrm{CFL}=1, \mathrm{dt}=4 \mathrm{e}-6$

$0.5 \mathrm{M}$ elements, 20,000 time steps

Starting from static flow field

Refined convective BC at exit for pg

Extrapolated $\mathrm{BC}$ at exit for others
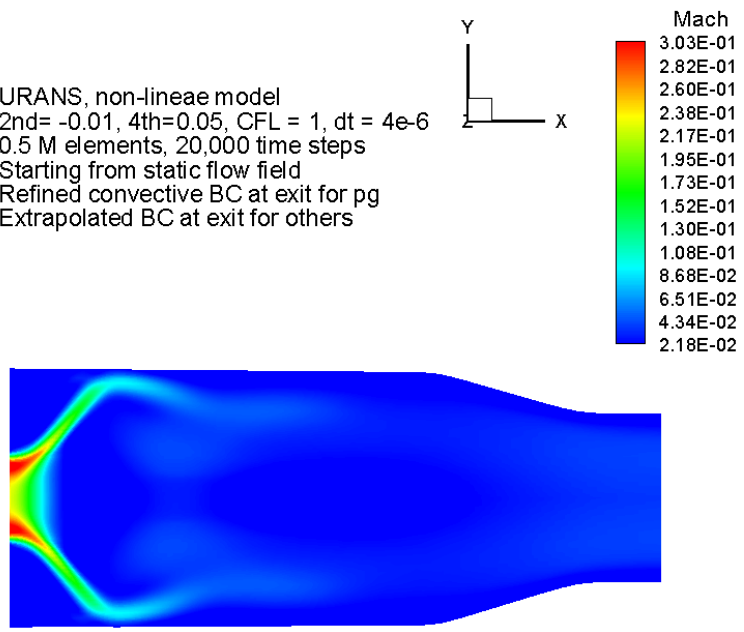

URANS, non-lineae mode
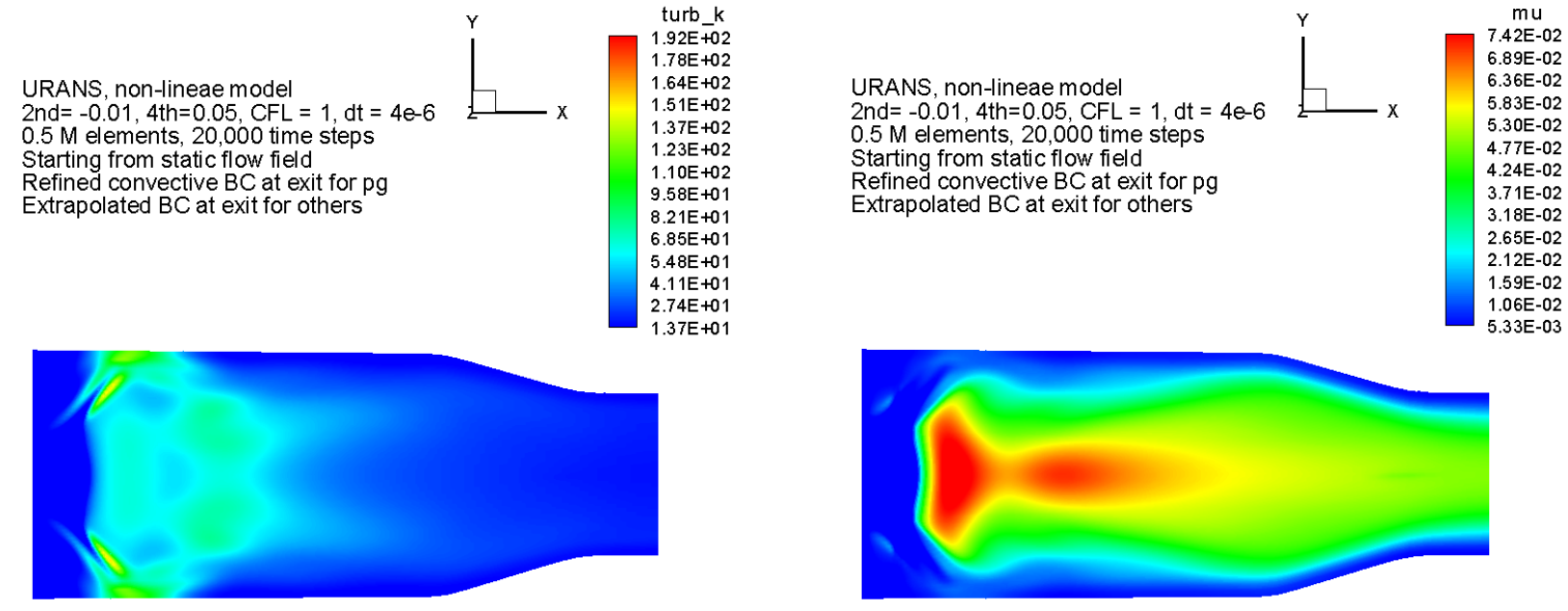

$0.5 \mathrm{M}$ elements, 20,000 time steps

.23E+02

$10 \mathrm{E}+02$

Starting from static flow field

Refined convective BC at exit for pg

$85 \mathrm{E}+0$

(11E+0

$\mathrm{pg}$
$.76 \mathrm{E}+04$

URANS, non-lineae model

2nd $=-0.01,4$ th $=0.05, C F L=1, d t=4 e-6$

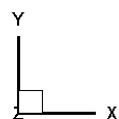

$6.28 \mathrm{E}+04$
$6.04 \mathrm{E}+04$

$0.5 \mathrm{M}$ elements, 20,000 time steps

Starting from static flow field

$5.80 \mathrm{E}+04$

$5.56 \mathrm{E}+04$

$5.33 \mathrm{E}+04$

$5.33 \mathrm{E}+04$

$5.09 E+04$

$4.85 \mathrm{E}+04$

$4.61 \mathrm{E}+04$

4.37E+04

4.13E+04

$3.89 \mathrm{E}+04$

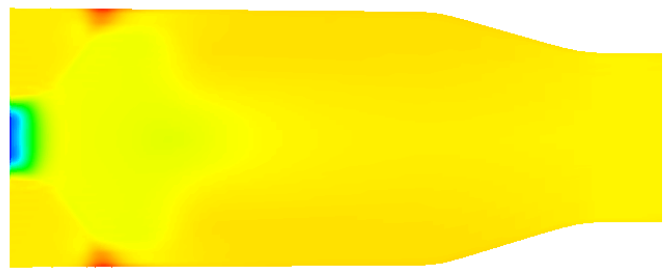

URANS, non-lineae model

2nd $=-0.01,4$ th $=0.05, \mathrm{CFL}=1, \mathrm{dt}=4 \mathrm{e}-6$

$0.5 \mathrm{M}$ elements, 20,000 time steps

Starting from static flow field

Refined convective BC at exit for $p$

Extrapolated $\mathrm{BC}$ at exit for others
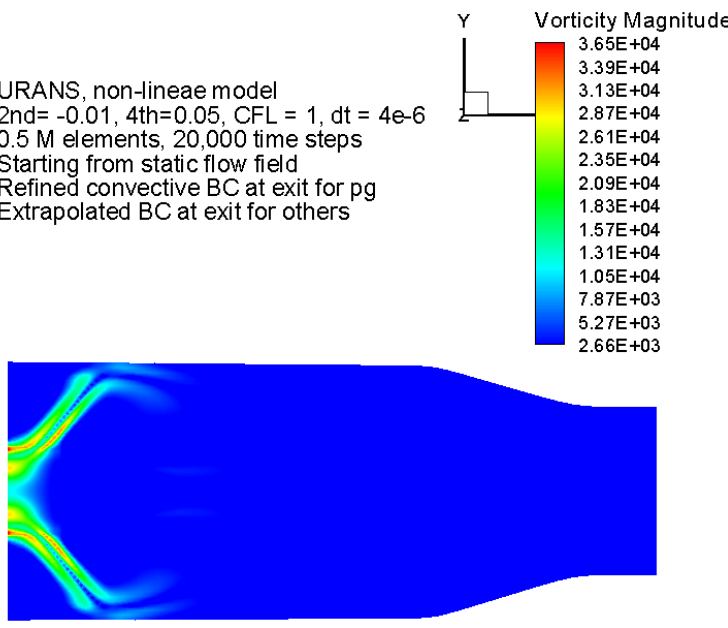


\subsubsection{Centerline Variables}

The instantaneous centerline flow variables (axial velocity $u$, Mach number, subscale turbulent kinetic energy $k$, effective viscosity $\mu_{T}$, gauge pressure and vorticity magnitude) at time step 20,000 are presented here with three different initial conditions. From which we may examine the flow variations along the centerline.
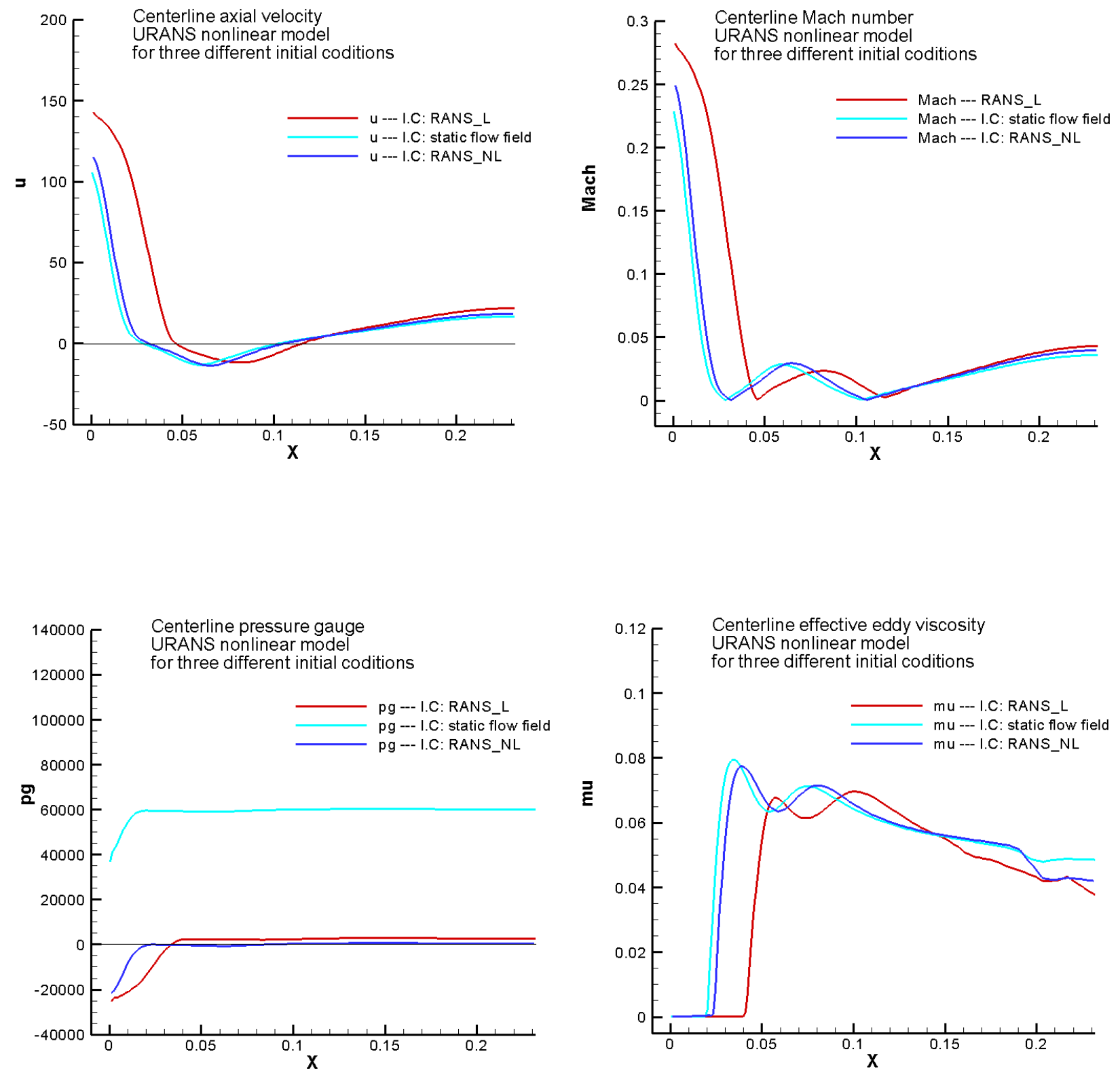


\subsubsection{Convergence History}

In the present case, the time-accurate URANS simulations have reached an asymptotic steady state. Using the simulation in Section 4.1.1 as an example, its convergence history of the residual is given below. As it can be seen, the convergence of the inner (i.e., pseudo time) iteration within a physical time step has reached a steady (i.e., periodic) state.
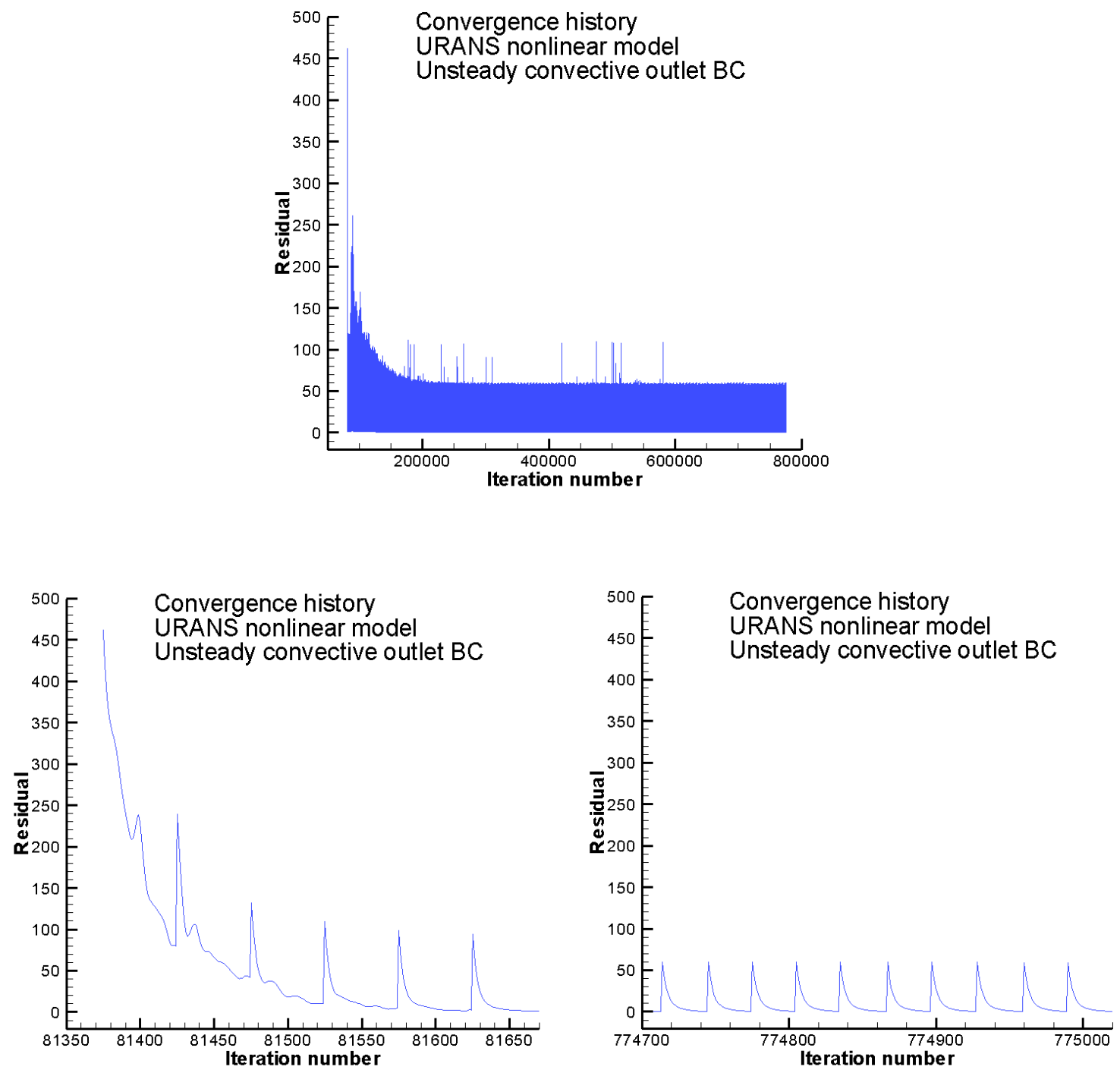


\subsubsection{Results Using Fixed Pressure at the Outlet}

Simulations have been performed using a fixed gauge pressure at the outlet while the rest of the dependent variables are provided by extrapolating from the interior point. The nonlinear RANS solution is used as the initial condition.

The calculations have proceeded over 20,000 time steps (about 40 flow-through time) without difficulty. Apparently, there are very little pressure disturbances existing in the URANS solution.

The results are presented in two parts: the time history of velocity components and gauge pressure at four locations along the centerline; and the instantaneous contour plots of flow variables at a center plane.

\subsubsection{Time History}

The time history of velocity components and gauge pressure are recorded at four centerline locations: $x=0.015,0.05,0.10$ and 0.2 . From which we may examine the temporal development of the filtered variables. The results are presented only for the initial condition using the nonlinear RANS solution.
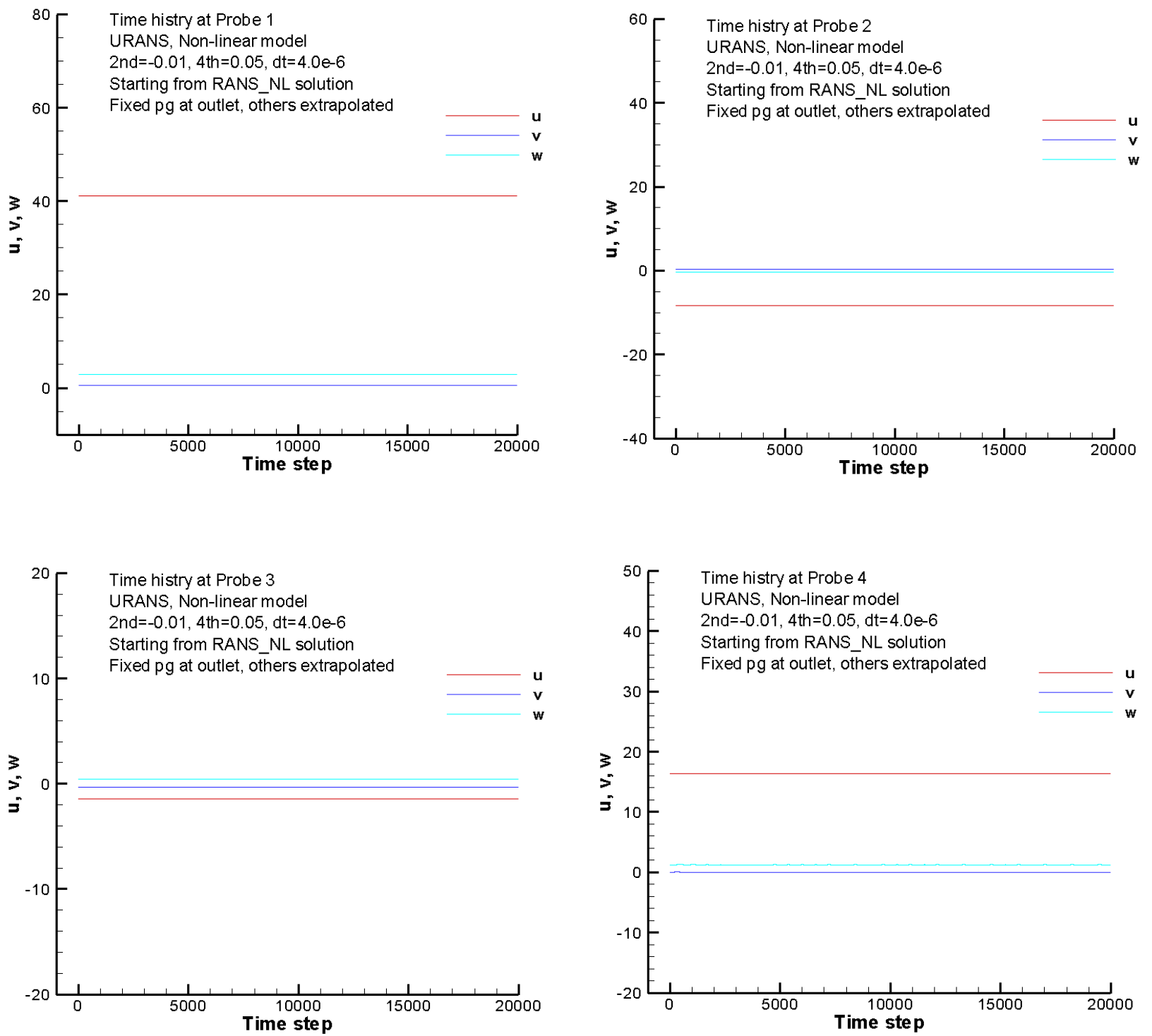

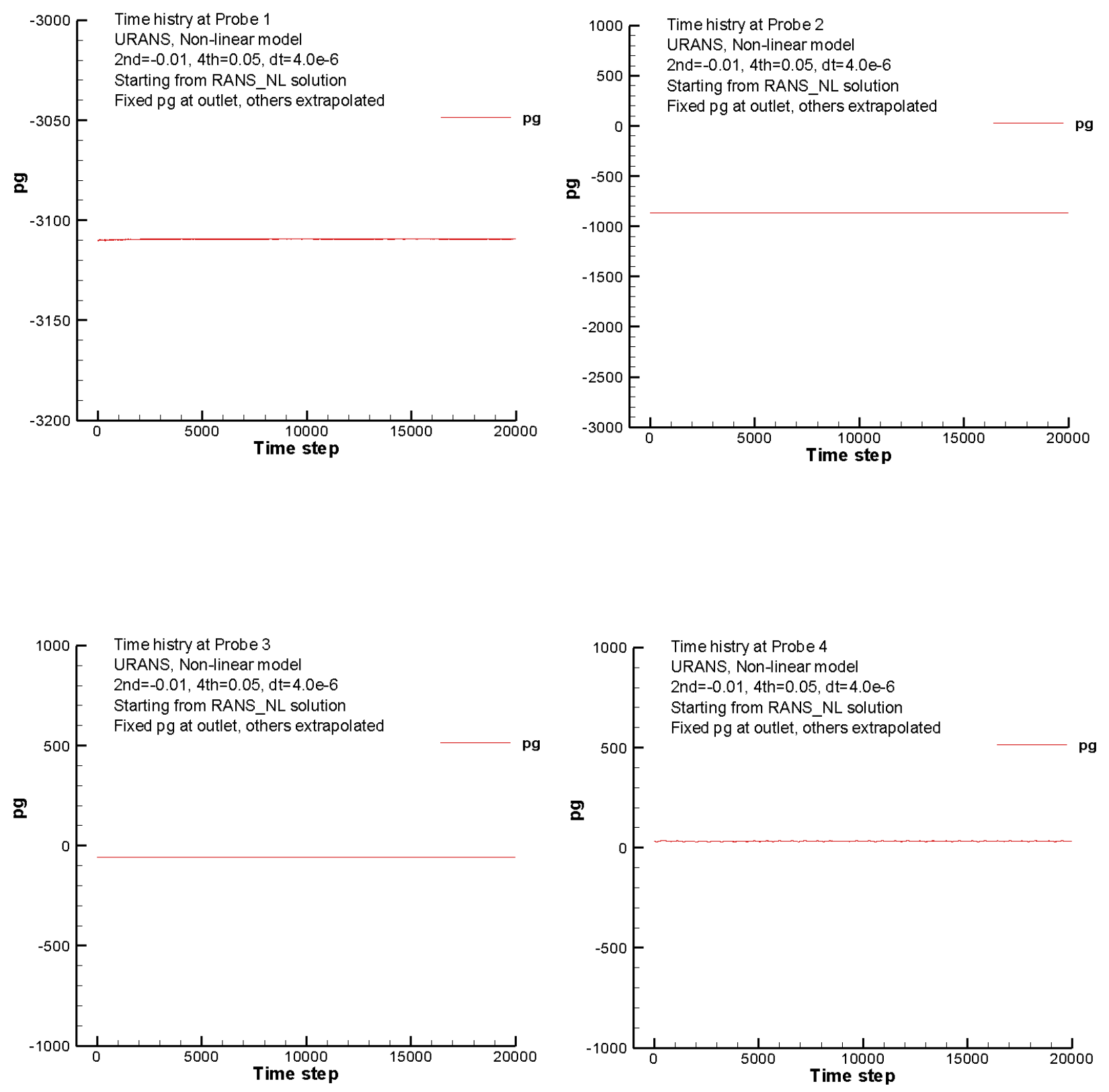


\subsubsection{Contour at Center Plane}

The snapshots of instantaneous contour of flow variables at a center plane are presented for time step 20,000 , which is around 40 flow-through time. From which we may examine the flow structures. The results are presented only for the initial condition using the nonlinear RANS solution.
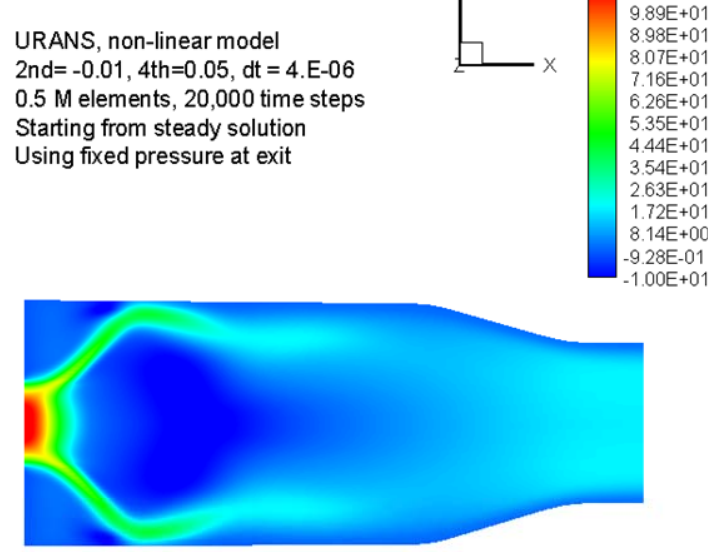

URANS, non-linear model $2 \mathrm{nd}=-0.01,4 \mathrm{th}=0.05, \mathrm{dt}=4 . \mathrm{E}-06$
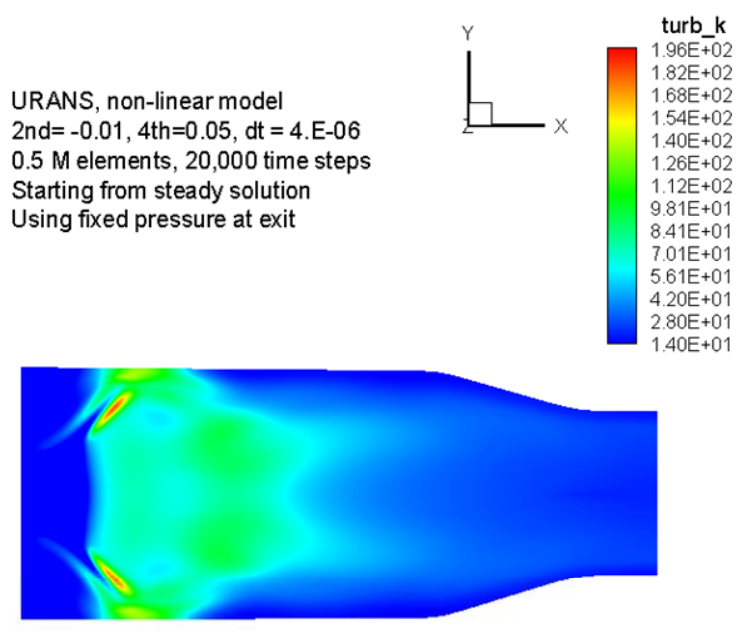

Starting from steady solution

Using fixed pressure at exit

\section{URANS, non-linear model} $2 \mathrm{nd}=-0.01,4 \mathrm{th}=0.05, \mathrm{dt}=4 . \mathrm{E}-06$ 0.5 M elements, 20,000 time steps

Starting from steady solution

Using fixed pressure at exit
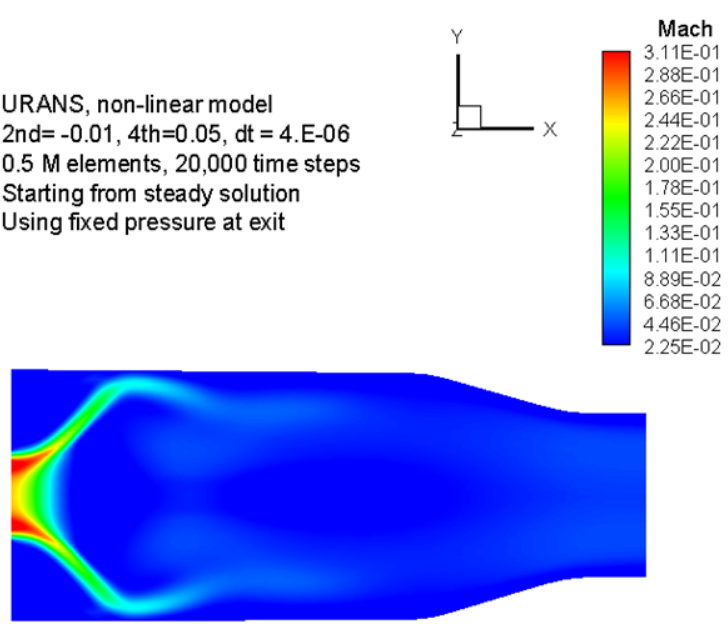

URANS, non-linear model 2nd $=-0.01,4$ th $=0.05, \mathrm{dt}=4$. E- 06 $0.5 \mathrm{M}$ elements, 20,000 time steps Starting from steady solution Using fixed pressure at exit
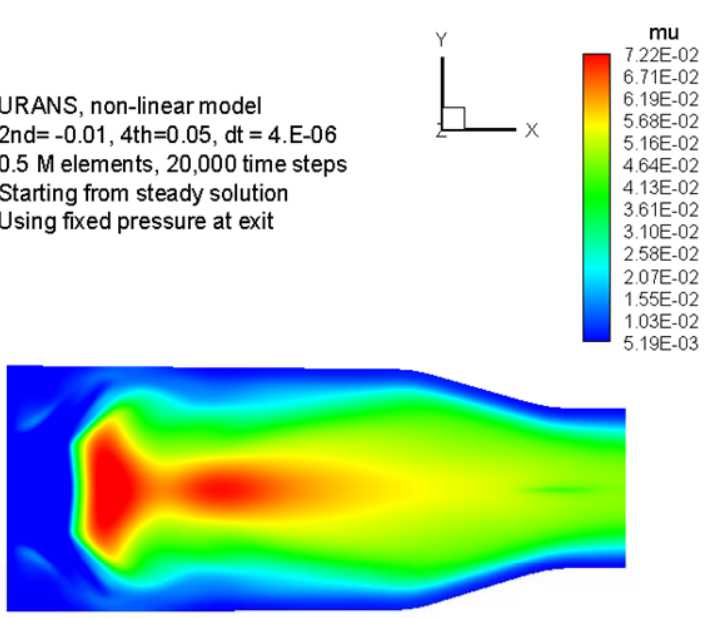

URANS, non-linear mode 2nd $=-0.01,4$ th $=0.05, d t=4 . E-06$ $0.5 \mathrm{M}$ elements, 20,000 time steps Starting from steady solution Using fixed pressure at exit
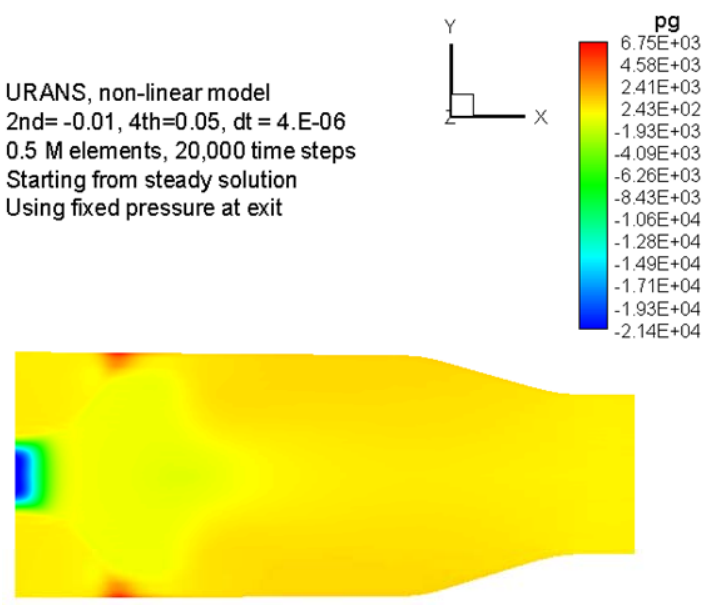

URANS, non-linear model 2nd $=-0.01,4$ th $=0.05, \mathrm{dt}=4 . \mathrm{E}-06$ $0.5 \mathrm{M}$ elements, 20,000 time steps Starting from steady solution Using fixed pressure at exit
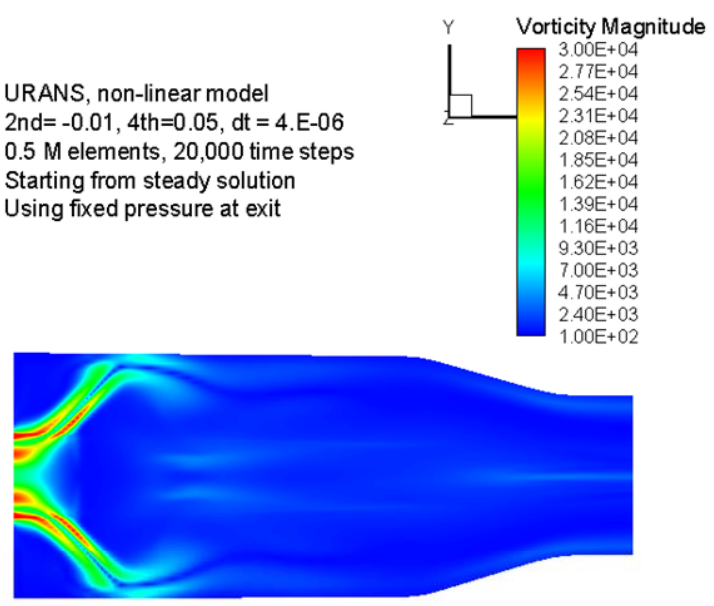


\subsubsection{Results Using Extrapolation BC}

In this case, all dependent flow variables at the outlet are determined by extrapolating from the interior point.

The results are presented in two parts: the time history of velocity components and gauge pressure along four locations of the centerline; and the instantaneous contour plots of flow variables at a center plane.

\subsubsection{Time History}

The time histories of velocity components and gauge pressure are recorded at four centerline locations: $x=0.015,0.05,0.10$ and 0.2 . From which we may examine the temporal development of the filtered variables. The results are presented only for the initial condition using the nonlinear RANS solution.
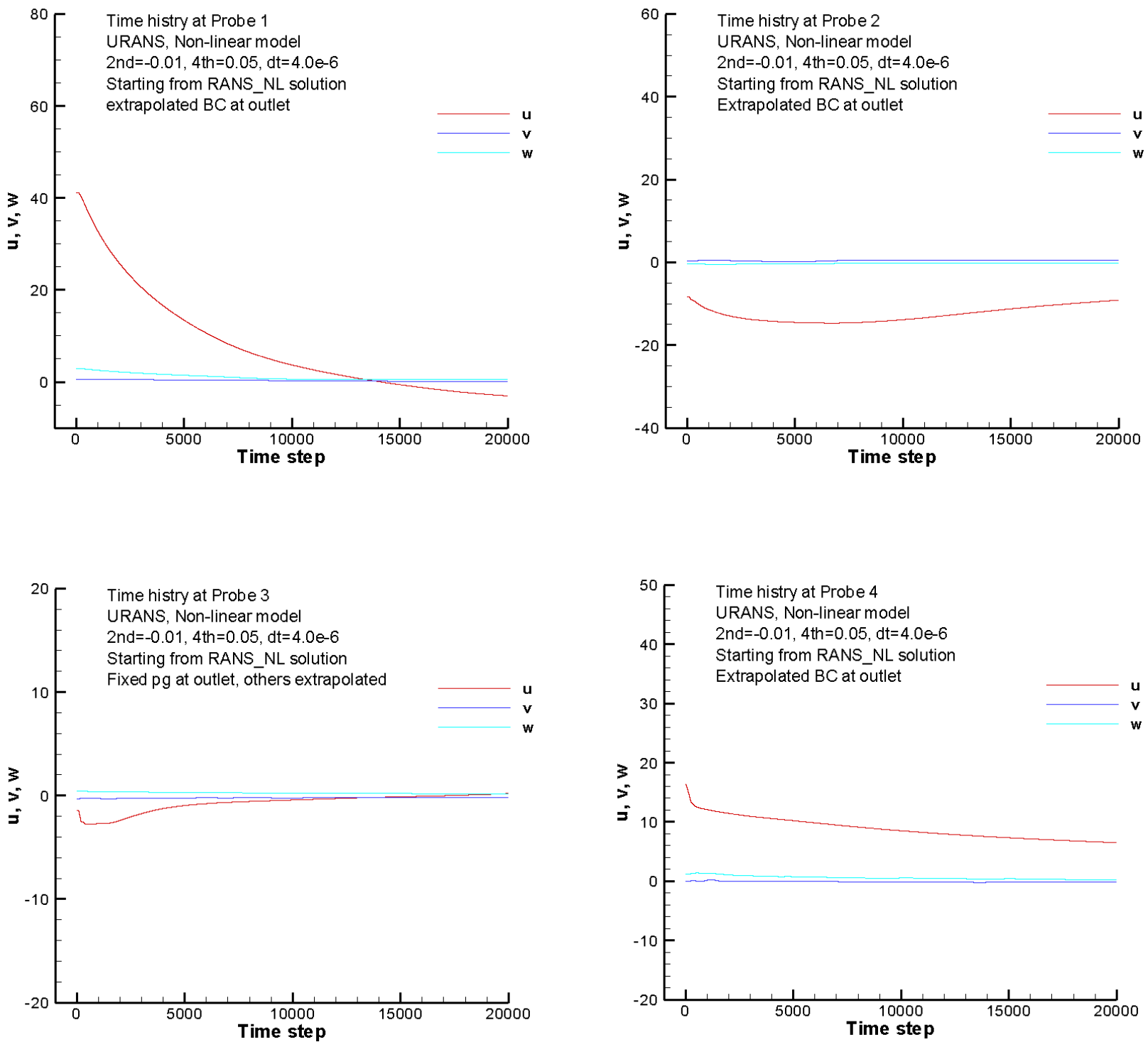

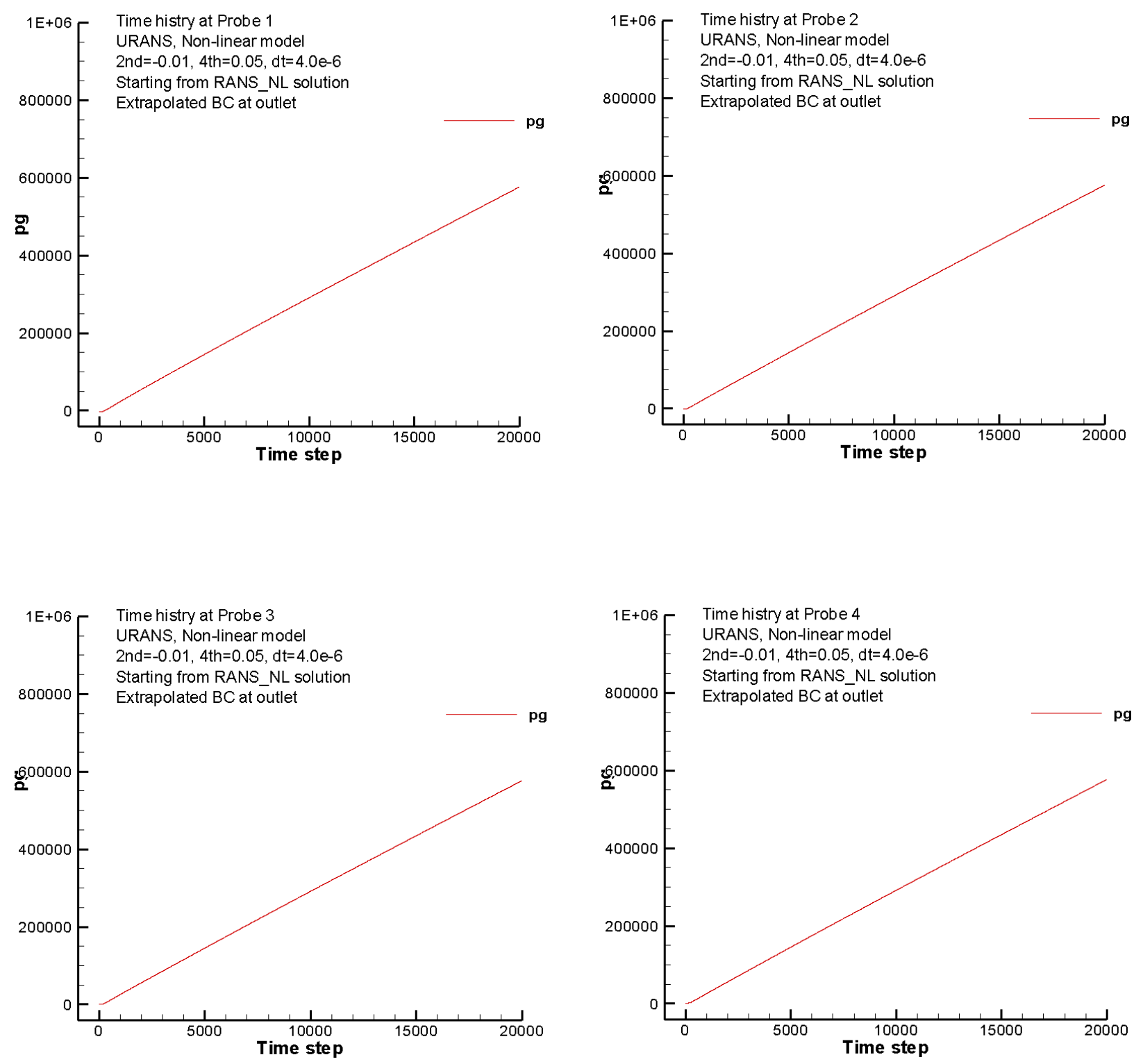

\subsubsection{Contour at Center Plane}

The snapshots of instantaneous contour of flow variables at a center plane are presented for time step of 20,000, which is about 40 flow-through time. From which we may examine the flow structures. The results are presented only for the initial condition using the nonlinear RANS solution. 
URANS, non-linear model

$2 \mathrm{nd}=-0.01,4 \mathrm{th}=0.05, \mathrm{dt}=4 . \mathrm{E}-06$

$0.5 \mathrm{M}$ elements, 20,000 time steps

Starting from RANS_NLsolution

Extrapolated $\mathrm{BC}$ at exit

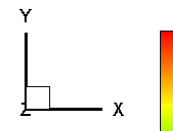

$5.77 \mathrm{E}+01$

$5.24 \mathrm{E}+01$

$4.72 \mathrm{E}+01$

$4.20 \mathrm{E}+01$

$3.68 \mathrm{E}+01$

$3.16 \mathrm{E}+01$

$2.64 \mathrm{E}+01$

$2.12 \mathrm{E}+01$

$1.60 \mathrm{E}+01$

$1.08 \mathrm{E}+01$

$5.61 \mathrm{E}+00$

$4.08 \mathrm{E}-01$

$-4.80 \mathrm{E}+00$

$1.00 \mathrm{E}+01$

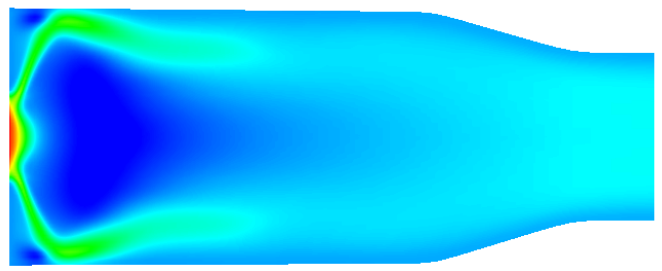

URANS, non-linear model 2nd $=-0.01,4$ th $=0.05, \mathrm{dt}=4 . \mathrm{E}-06$ $0.5 \mathrm{M}$ elements, 20,000 time steps Starting from RANS_NLsolution

Extrapolated $\mathrm{BC}$ at exit
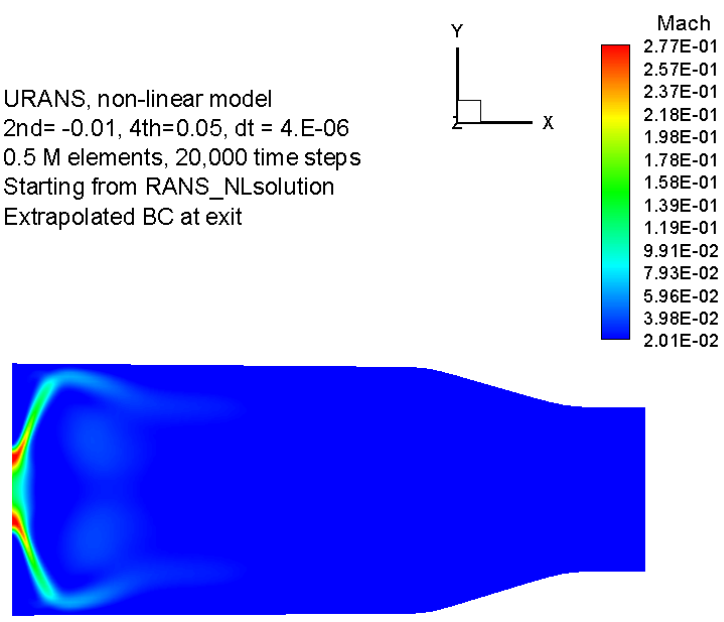

turb_k $2.64 \mathrm{E}+02$ $2.45 \mathrm{E}+02$ $2.26 \mathrm{E}+02$ $2.07 \mathrm{E}+02$ $1.89 \mathrm{E}+02$ $1.70 \mathrm{E}+02$ $1.51 \mathrm{E}+02$ $1.32 \mathrm{E}+02$ $1.13 E+02$ $9.43 \mathrm{E}+01$ $7.54 \mathrm{E}+01$ $5.66 \mathrm{E}+01$ $3.77 \mathrm{E}+01$ $3.77 E+01$ ents, 20,000 time step Starting from RANS_NLsolution

Extrapolated $\mathrm{BC}$ at exit
URANS, non-linear model $2 \mathrm{nd}=-0.01,4 \mathrm{th}=0.05, \mathrm{dt}=4 . \mathrm{E}-06$ $0.5 \mathrm{M}$ elements, 20,000 time steps Starting from RANS_NLsolution Extrapolated $\mathrm{BC}$ at exit
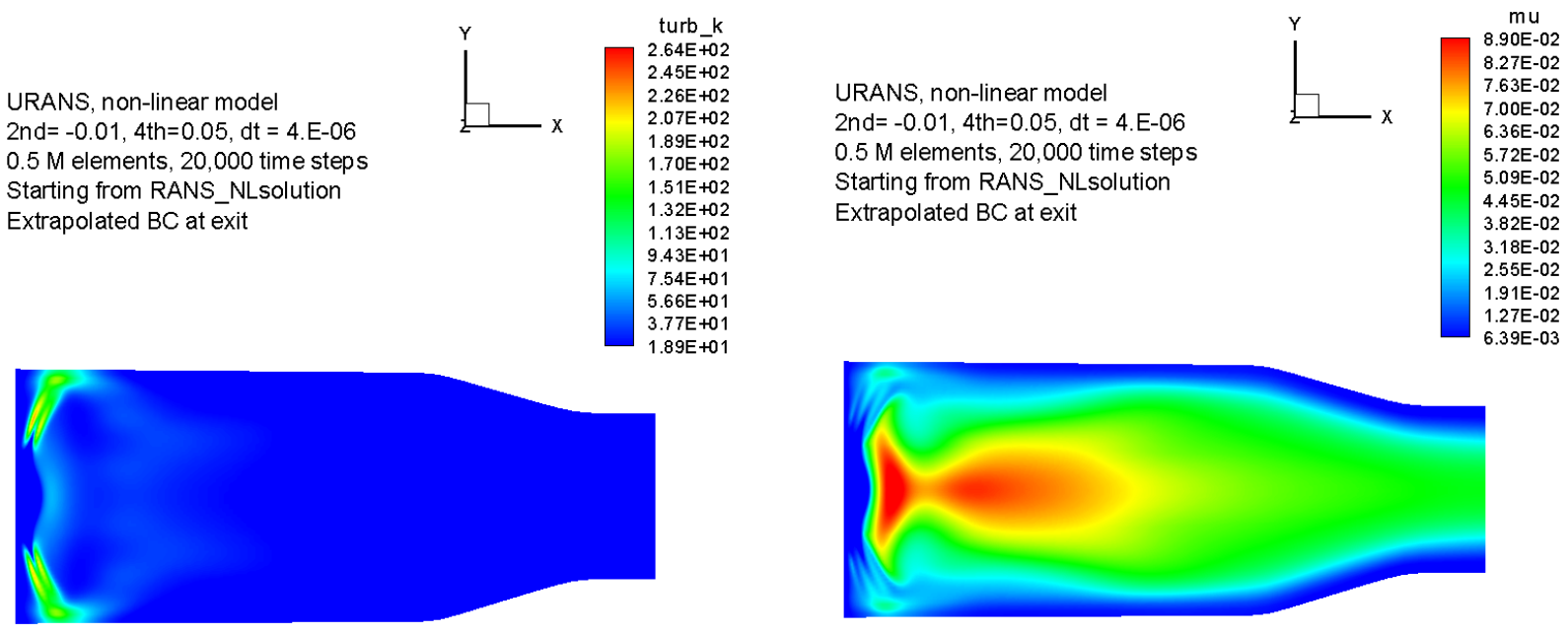

$\mathrm{pg}$ $5.95 \mathrm{E}+05$ $5.91 \mathrm{E}+05$ $5.87 \mathrm{E}+05$ $5.84 \mathrm{E}+05$ $5.80 \mathrm{E}+05$ $5.76 \mathrm{E}+05$ $5.72 \mathrm{E}+05$ $5.68 \mathrm{E}+05$ $5.64 \mathrm{E}+05$ $5.61 \mathrm{E}+05$ $5.61 E+05$ $5.53 \mathrm{E}+05$ 5.53 $5.49 \mathrm{E}+05$

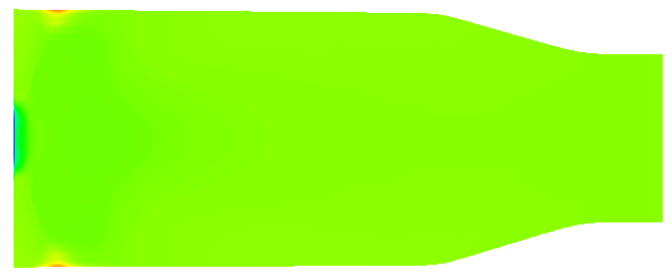

URANS, non-linear model

$2 \mathrm{nd}=-0.01,4 \mathrm{th}=0.05, \mathrm{dt}=4 . \mathrm{E}-06$ $0.5 \mathrm{M}$ elements, 20,000 time steps Starting from RANS_NLsolution Extrapolated $\mathrm{BC}$ at exit
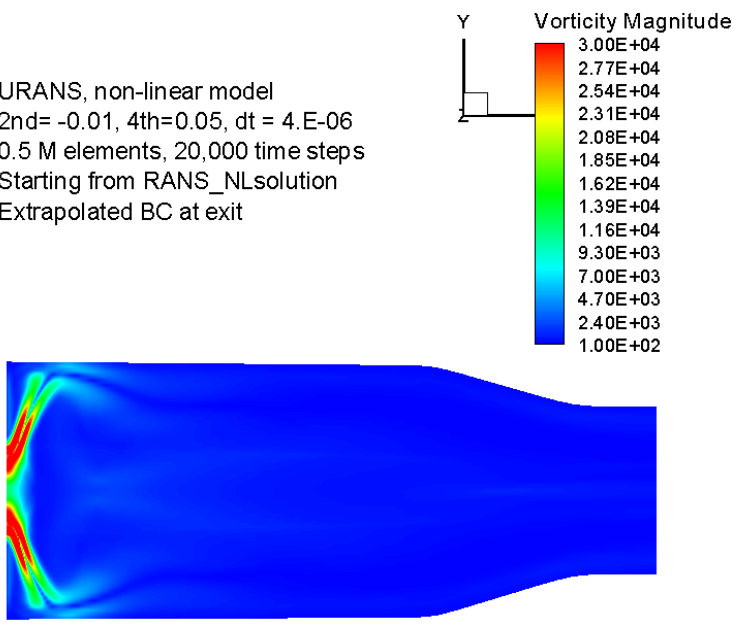


\subsubsection{Effect of the Outlet BC on Centerline Variables}

The above results indicate that the extrapolation boundary condition is not sustaining the dynamically important flow structures in the URANS simulation. This is further illustrated by inspecting the solutions along the centerline (see below). It can be seen that results from the unsteady convective $\mathrm{BC}$ and the fixed gauge pressure $\mathrm{BC}$ are almost identical; however, the results from the extrapolation $\mathrm{BC}$ are significantly different.

Furthermore, the following results show that URANS with the unsteady convective BC (or fixed gauge pressure $\mathrm{BC}$ ) leads to a sustained steady mean flow solution; however, URANS with the extrapolation $\mathrm{BC}$ can not provide a sustained mean flow solution, it keeps evolving towards a physically unreasonable state.
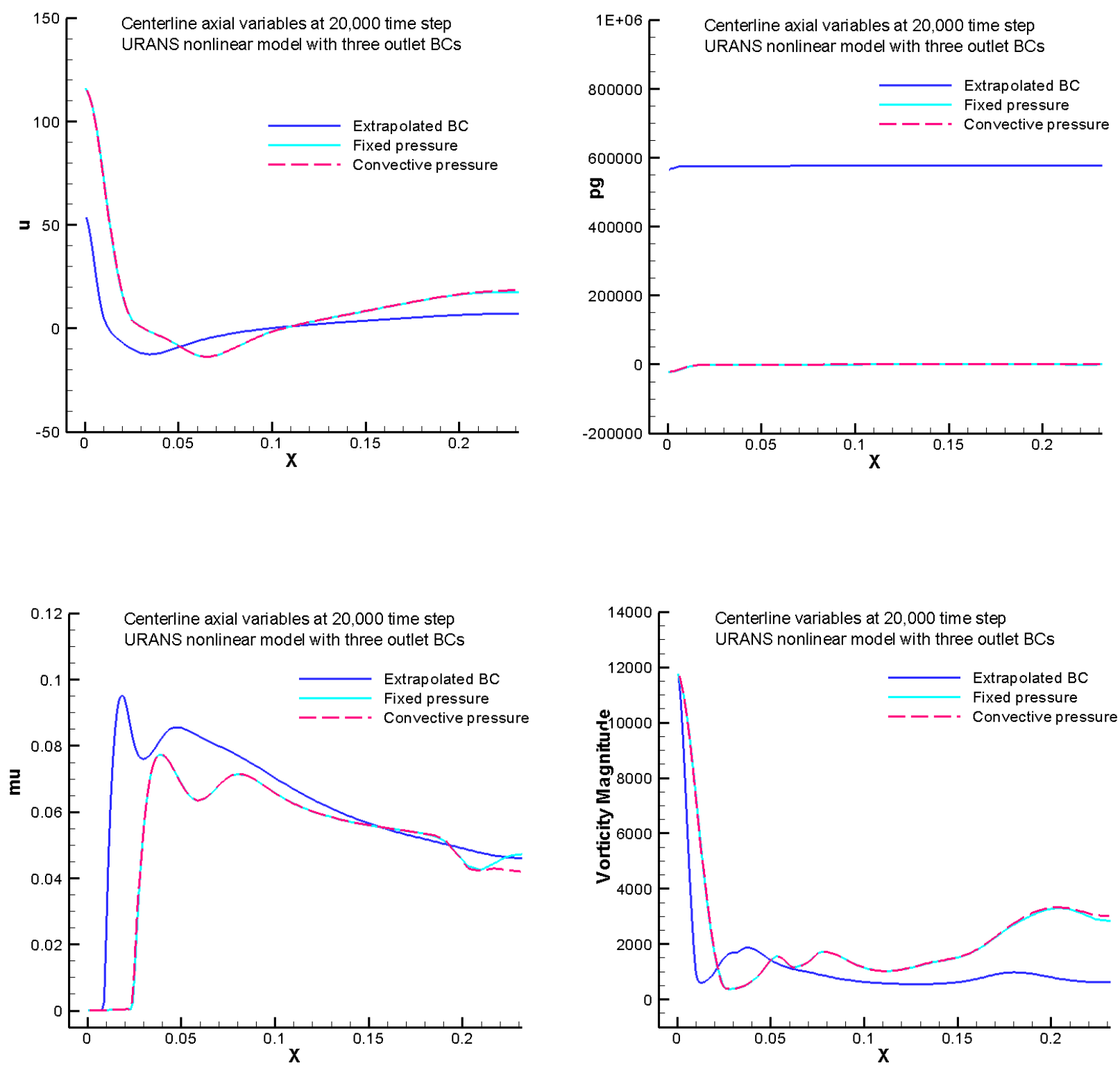

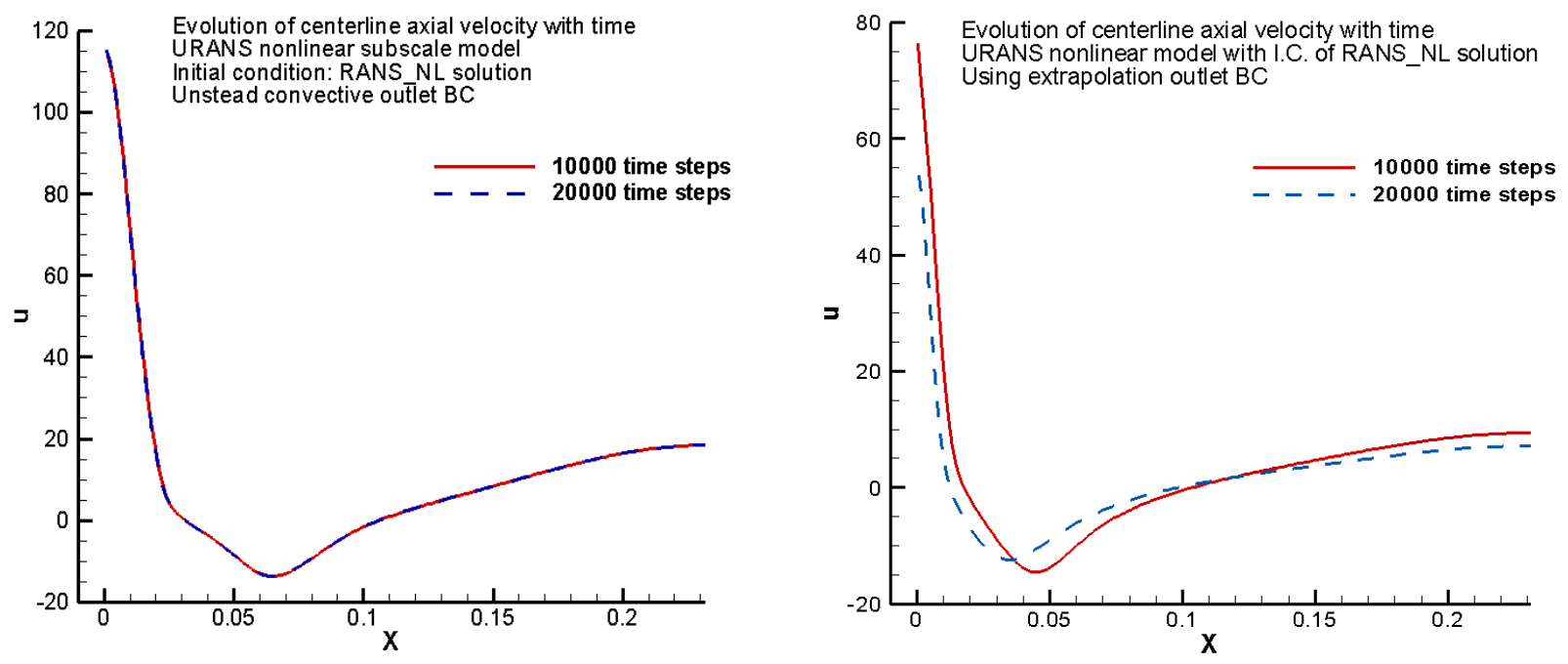

\subsection{Linear Model}

The URANS simulations with the nonlinear subscale model are quite successful using both the unsteady convective outlet boundary condition and the fixed outlet gauge pressure. We have also performed the same simulation with a linear model (the standard $k-\varepsilon$ model) using the unsteady convective outlet BC. The initial condition is the nonlinear RANS solution.

\subsubsection{Results Using Unsteady Convective BC for Pressure Only}

The results are presented in two parts: the instantaneous contour plots of flow variables at a center plane; and the instantaneous flow variable profiles along the centerline.

\subsubsection{Contour at Center Plane}

The snapshots of instantaneous contour of flow variables at a center plane are presented for time step of 20,000, which is about 40 flow-through time. The mean flow structures are quite similar to their counterparts due to the nonlinear model.
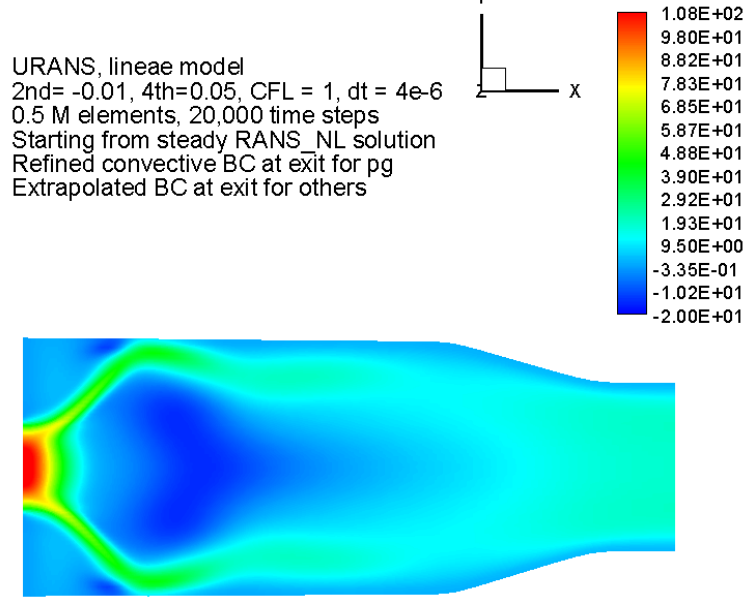

URANS, lineae model

2nd $=-0.01,4$ th $=0.05, C F L=1, d t=4 e-6$

$0.5 \mathrm{M}$ elements, 20,000 time steps

Starting from steady RANS_NL solution

Refined convective BC at exit for $\mathrm{pg}$

Extrapolated $\mathrm{BC}$ at exit for others
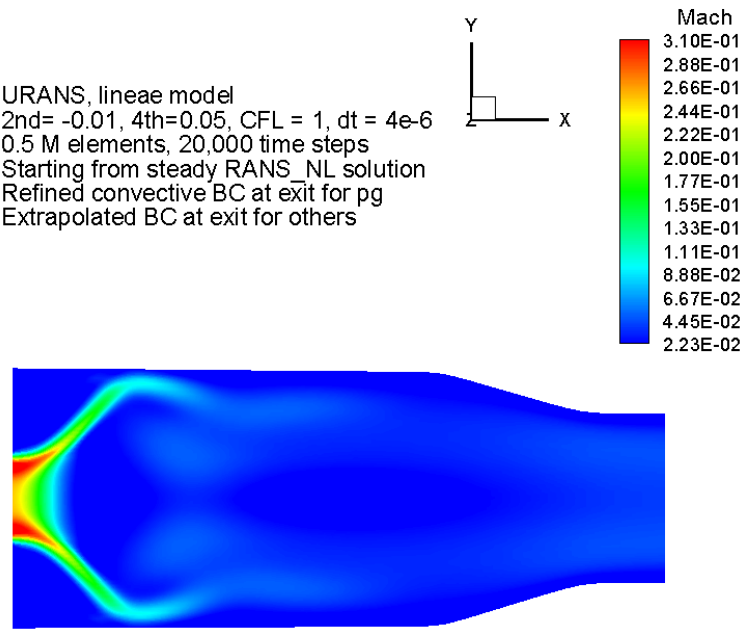


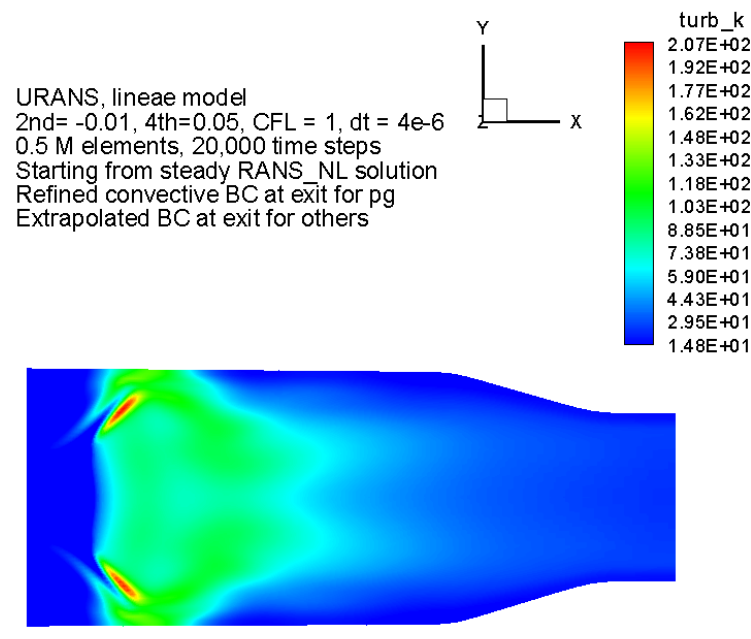

URANS, lineae model
2nd $=-0.01,4$ th $=0.05, C F L=1, d t=4 e-6$

2nd $=-0.01,4$ th $=0.05, C F L=1, \mathrm{dt}=$
$0.5 \mathrm{M}$ elements, 20.000 time steps

Starting from steady RANS NL solution

$\mathrm{mu}$
$\mathrm{Y}$ $7.93 \mathrm{E}-02$
$7.36 \mathrm{E}-02$ $7.36 \mathrm{E}-02$
$6.79 \mathrm{E}-02$ $6.79 \mathrm{E}-02$
$6.23 \mathrm{E}-02$ $3.96 \mathrm{E}-02$
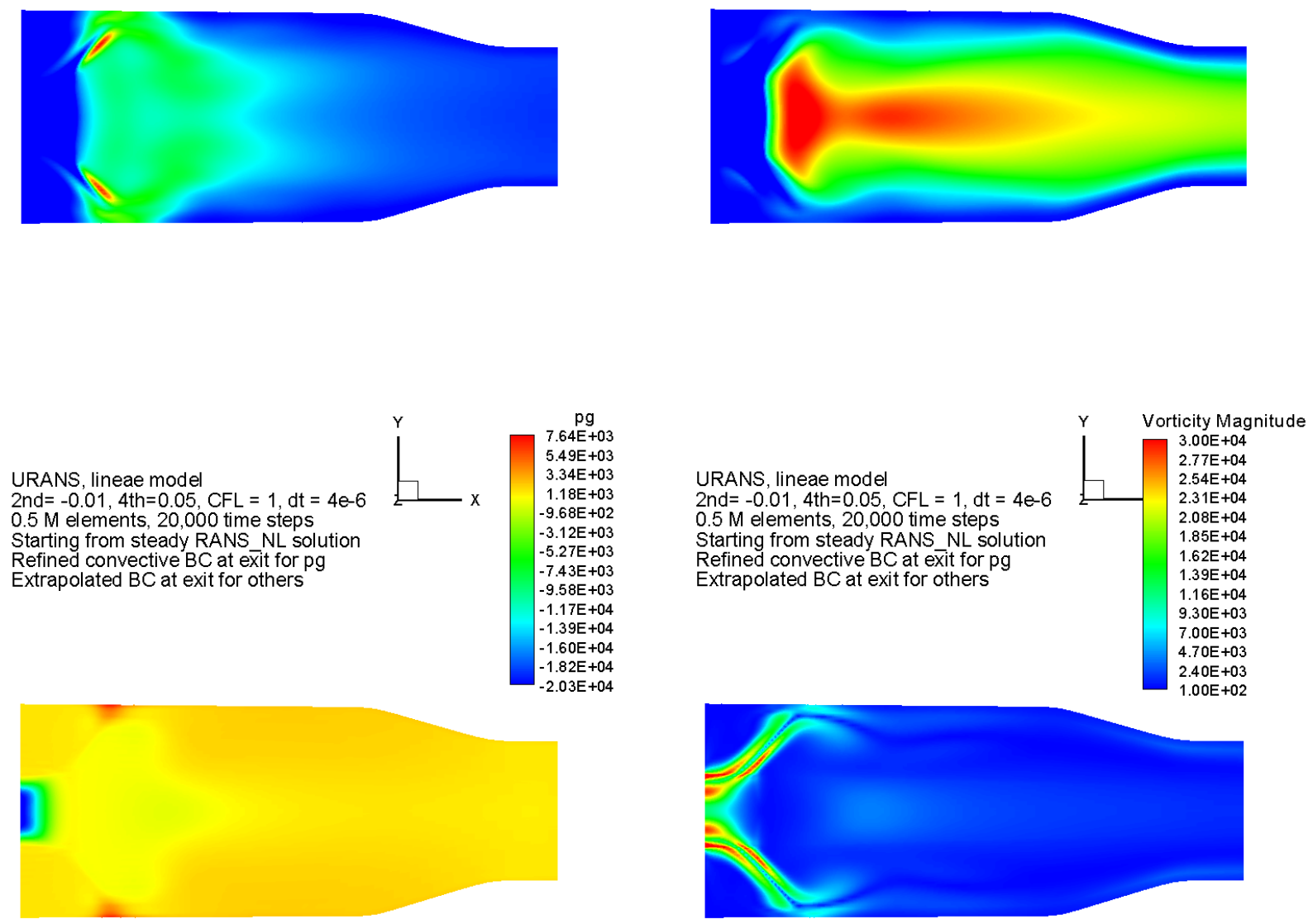

\subsection{Comparison of Centerline Variables Between Linear and Nonlinear Models}

The flowing figures present the comparison of the distributions of the flow variables along the centerline between those from the linear model and those from the nonlinear model under the same initial condition (nonlinear RANS solution) and the same outlet boundary condition (unsteady convective BC). The results indicate that, there are differences in the level of the mean turbulent kinetic energy and in the mean vorticity distribution. 

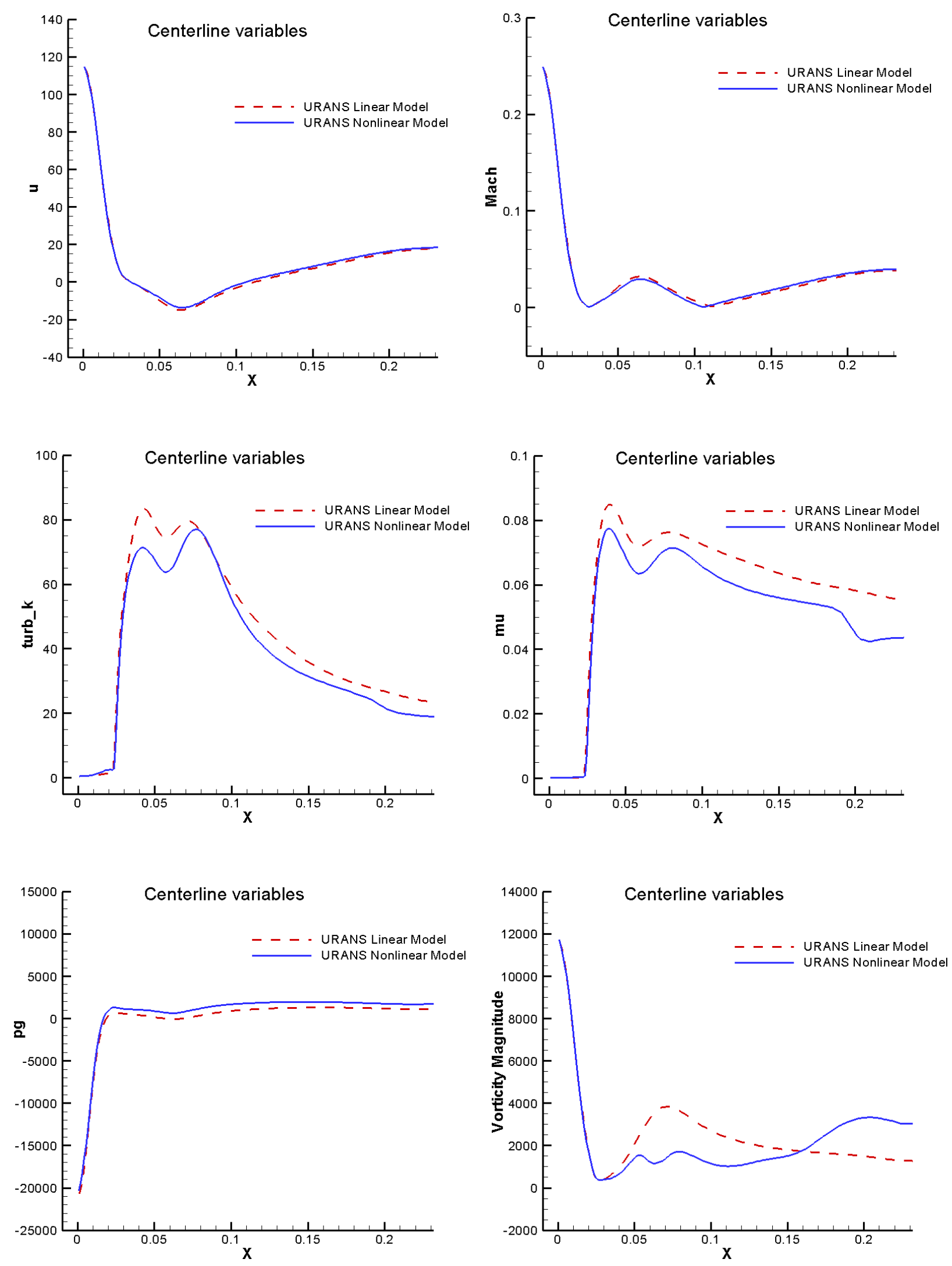


\subsection{Concluding Remarks}

The unsteady pressure convective BC works well for URANS simulations even when the filtered flow is approaching to the steady state. The fixed pressure $\mathrm{BC}$ also works for the time accurate simulation of the LM6000 single injector flame tube, and its result is almost identical to that using the unsteady convective BC. This is not surprising, because, in this particular case, the filtered flow field itself is pretty steady; and there is no significant pressure disturbance near the outlet. The extrapolation BC is not appropriate due to its inability to sustain a physically meaningful solution.

The initial condition has a strong effect on the evolution path of the URANS simulation towards the eventual state. Based on our experiences, we recommend the use of the solution from the nonlinear RANS simulation as the initial condition for the URANS as well as the PRNS/VLES simulations.

Although the numerical results suggest that the URANS of linear and nonlinear $k-\varepsilon$ model seems to predict quite similar mean flow structures for the given initial and boundary conditions, there in deed exist appreciable differences in quantities (such as the vorticity and the turbulent kinetic energy) which are more sensitive to the effects of the rotation and anisotropy.

\subsection{RANS of LM6000 Single Injector Flame Tube}

The basic equations for Steady RANS approach is the Reynolds averaged Navier-Stokes equations. It can relatively quickly provide a global picture of the turbulent mean flow field. If the physically existing turbulent flow is statistically stationary, then the picture may be accurate. It can be used as a starting point for other higher level numerical simulations, for example, the large or the very large eddy simulation to explicitly bring out the unsteady turbulent structures.

Steady RANS simulations using both nonlinear and linear models have been carried out for fixed pressure condition at the outlet. The purpose of these simulations is to provide the initial flow fields for the very large eddy simulation (PRNS/VLES) and the unsteady RANS simulation (URANS).

\section{$5.1 \quad$ Nonlinear Model}

RANS with the nonlinear model is fundamentally different from the standard $k-\varepsilon$ model. Here, the interactions between the turbulent mean flow and the entire spectrum of the turbulent fluctuations are accounted for not just by the eddy viscosity but also the explicit turbulence source terms originated from the nonlinear part of the model that considers the effects of anisotropy and rotation, which are missed by the standard $k-\varepsilon$ model.

The results presented below are the contour plots of the mean flow variables at a center plane. It is a converged (over 5 orders-of-magnitude of the residual) steady solution.

\subsubsection{Contour at Center Plane}

The snapshots of mean flow variables at a center plane are presented here. It is a converged solution after 81374 iterations. 

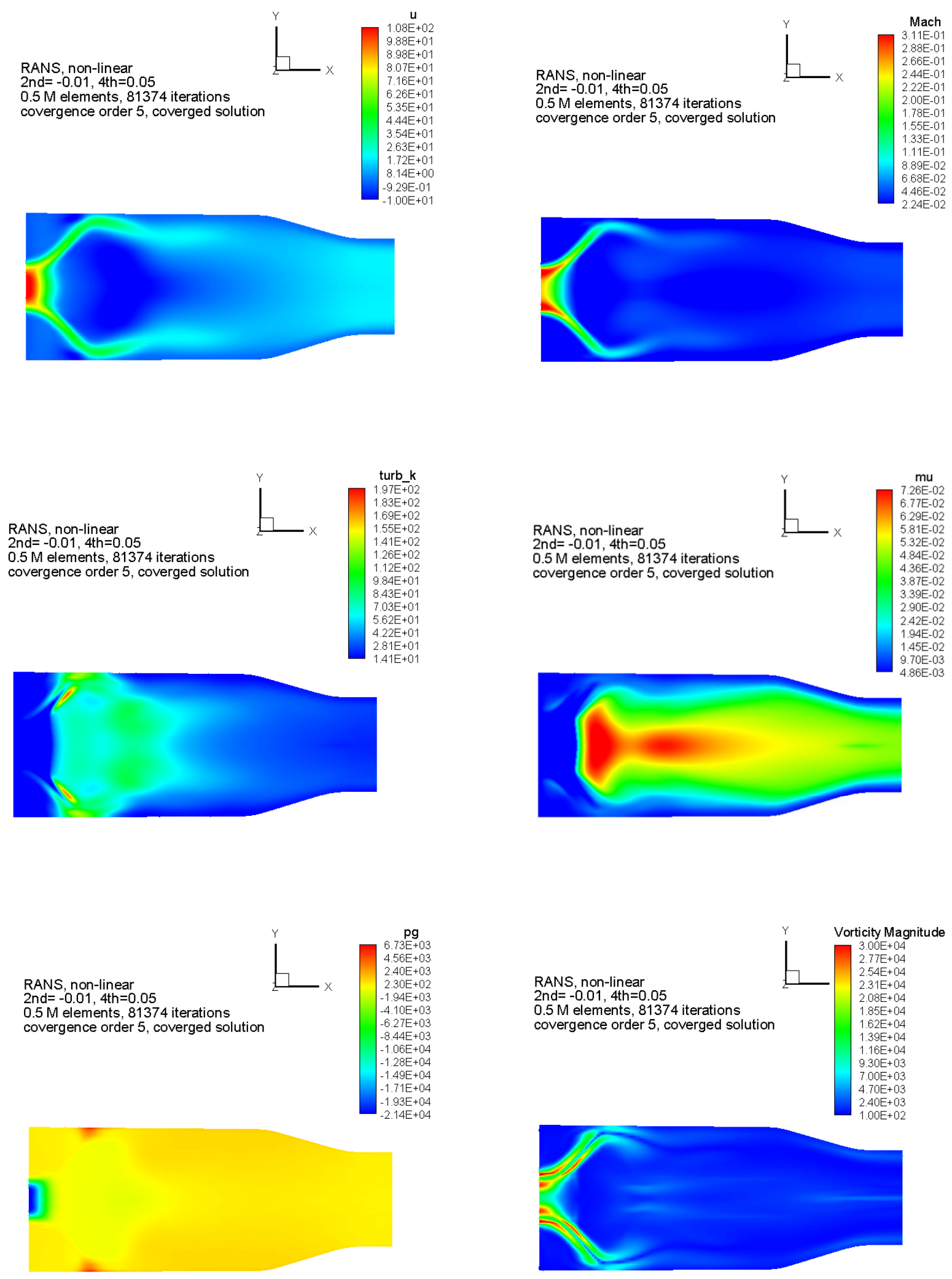


\subsection{Linear Model}

RANS with the linear model is the standard $k-\varepsilon$ model. Here, the interactions between the turbulent mean flow and the entire spectrum of the turbulent fluctuations are accounted for by the eddy viscosity. Therefore, this type of model does not account for the effects of anisotropy and rotation.

The results presented below are the contour plots of mean flow variables at a center plane.

\subsubsection{Contour at Center Plane}

The snapshots of mean flow variables at a center plane are presented here. It is a steady solution plotted at the 620,000 iteration.
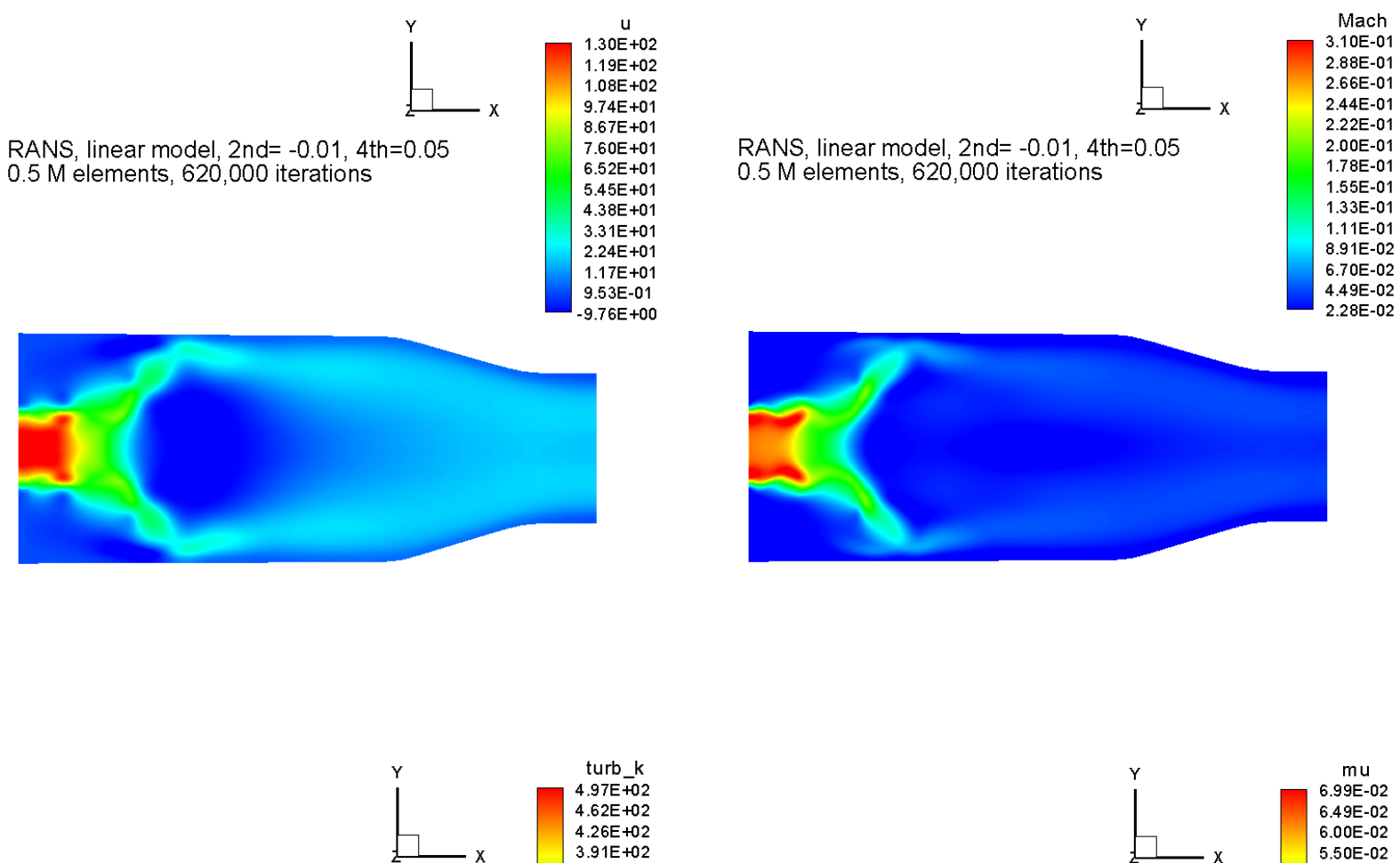

turb_k

$4.97 \mathrm{E}+02$
$4.62 \mathrm{E}+02$

$4.62 \mathrm{E}+02$
$4.26 \mathrm{E}+02$

$3.91 \mathrm{E}+02$

RANS, linear model, $2 \mathrm{nd}=-0.01,4 \mathrm{th}=0.05$

$3.55 \mathrm{E}+02$
$3.20 \mathrm{E}+02$

$0.5 \mathrm{M}$ elements, 620,000 iterations

$2.84 \mathrm{E}+02$

$2.49 \mathrm{E}+02$

$2.13 \mathrm{E}+02$
$1.78 \mathrm{E}+02$
$1.42 \mathrm{E}+02$

$1.78 \mathrm{E}+02$

$1.07 \mathrm{E}+02$

$7.10 \mathrm{E}+0$
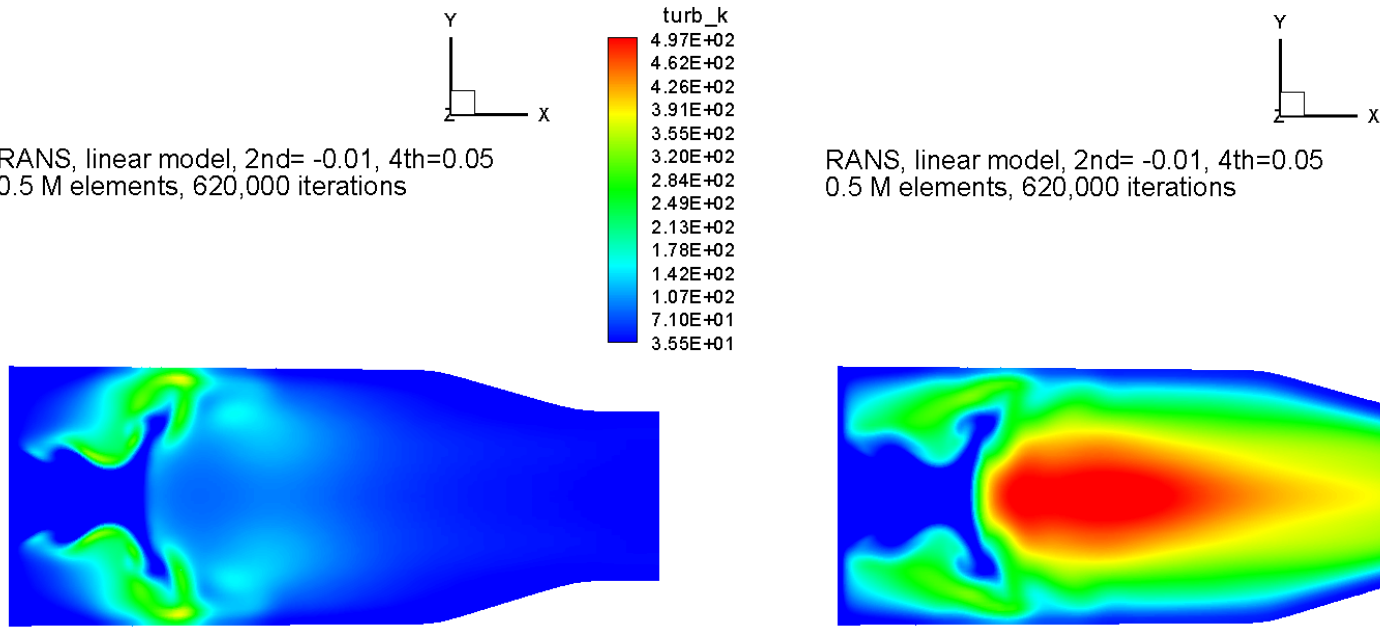

$\mathrm{mu}$

$6.99 \mathrm{E}-02$

$6.49 \mathrm{E}-02$

$6.00 \mathrm{E}-02$ $5.50 \mathrm{E}-02$

RANS, linear model, 2nd $=-0.01,4$ th $=0.05$ $4.50 \mathrm{E}-02$

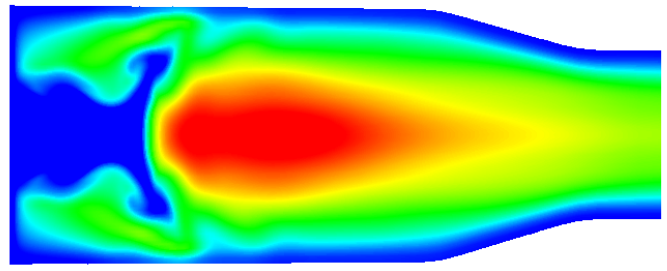



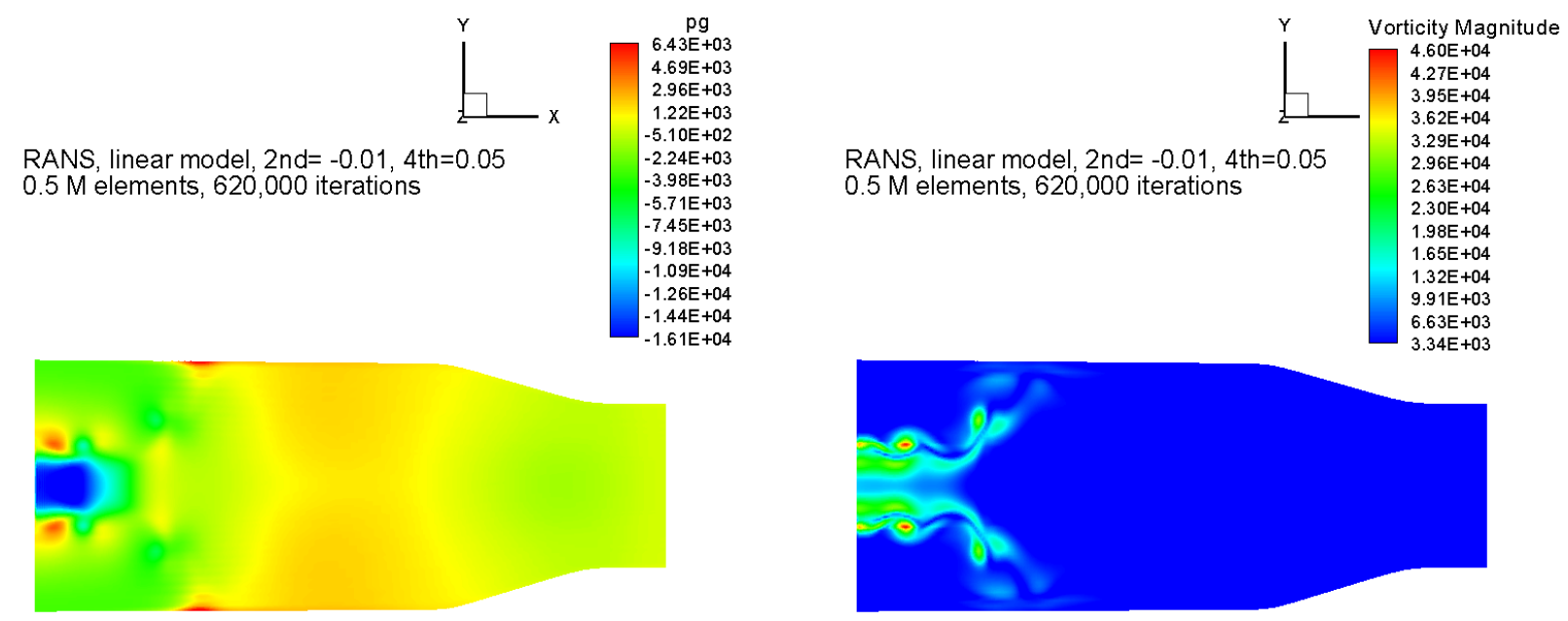

\subsection{Comparison of Centerline Variables Between Nonlinear and Linear Models}

The following figures present the comparison of the solutions along the centerline between those obtained from the linear model and those from the nonlinear model. Both the contour plots and the centerline profiles show that the results from using the linear and the nonlinear models are quite different, especially near the inlet region, where the flow separation and swirling are the strongest.
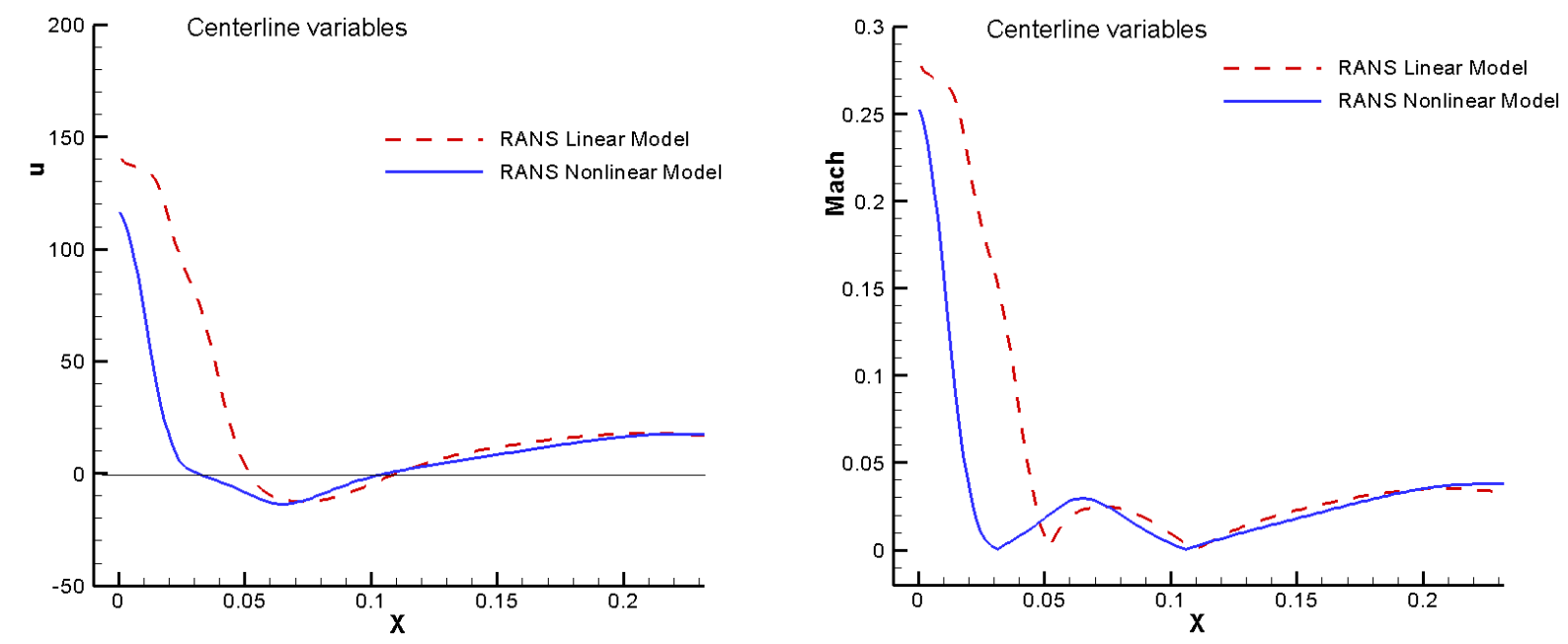

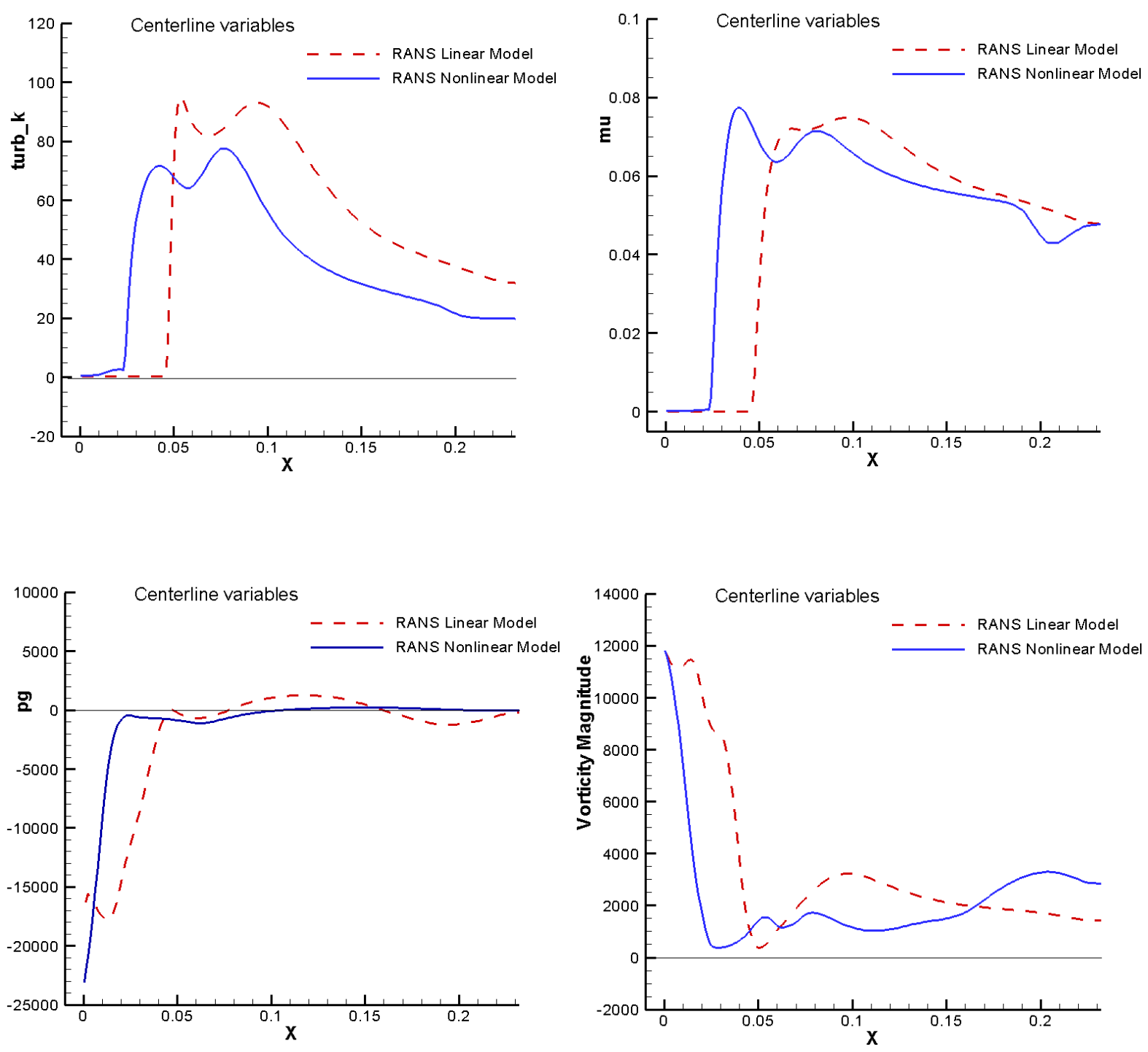

\subsection{Conclusions}

We have performed PRNS/VLES and URANS simulations for a single injector flame tube of the LM6000 gas turbine combustor using the National Combustion Code (NCC). Two subscale models in the PRNS/VLES approach and two Reynolds stress models in the URANS approach have been applied. In addition, in the context of each approach, three different outlet boundary conditions and three different initial conditions have been assessed. The major goal of these extensive numerical studies is to identify a relatively simple and robust outlet boundary condition for simulation approaches aimed at explicitly bringing out the unsteady large scale structures typically occurring in the turbulent flows of the combustors.

Based on these investigations, we recommend the following outlet boundary condition: unsteady convective Equation (1) for the gauge pressure together with the extrapolation Equation (4) for the rest of the dependent variables.

In addition, we believe that the best way to create the initial flow field for PRNS/VLES and URANS simulations is to run a steady RANS simulation using the nonlinear Reynolds stress model. 
The favorite model for PRNS/VLES and URANS simulations is the nonlinear subscale model and the nonlinear Reynolds stress model, respectively, as the nonlinear models can account for the effects of rotation and anisotropy in the swirling flows.

\section{References}

1. Shih, T.-H. and Liu, N.-S., "Assessment of the Partially Resolved Numerical Simulation (PRNS) Approach in the National Combustion Code (NCC) for Turbulent Non-reacting and Reacting Flows," NASA/TM-2008-215418, October 2008.

2. Liu, N.-S. and Shih, T.-H., "Turbulent Modeling for Very Large-Eddy Simulation," AIAA Journal, Vol. 44, No. 4, April 2006.

3. Shih, T.-H., and Liu, N.-S.,"A Strategy for Very Large Eddy Simulation of Complex Turbulent Flows," AIAA-2006-175, $44^{\text {th }}$ AIAA Aerospace Sciences Meeting and Exhibit 9-12 Jan. 2006, Reno, Nevada.

4. Shih, T.-H. and Liu, N.-S., "Modeling of Internal Reacting Flows and External Static Stall flows Using RANS and PRNS," Journal of Flow, Turbulence and Combustion, Springer Netherlands, Published online: July 18, 2007.

5. Ferziger, J. H. and Milovan, P., Computational Methods for Fluid Dynamics. Springer, 1996.

6. Baum, M., Poinsot, T. and Thevenin, D., "Accurate Boundary Conditions for Multicomponent Reactive Flows," J. of Computational Physics, Vol. 116, 247-261, 1994.

7. Ferziger, J. H., "Direct and Large Eddy Simulation of Turbulence: A Short Course Presented at NASA Glenn Research Center," Stanford University CA, July 4, 2001.

8. Moder, J. P., "National Combustion Code: User Guide," NASA Glenn Research Center, March 2001.

9. Shih, T.-H., Zhu, J., Liou, W., Chen, K-H., Liu, N-S., and Lumley, J.L., "Modeling of Turbulent Swirling Flows," NASA/TM-1997-113112, 1997. 


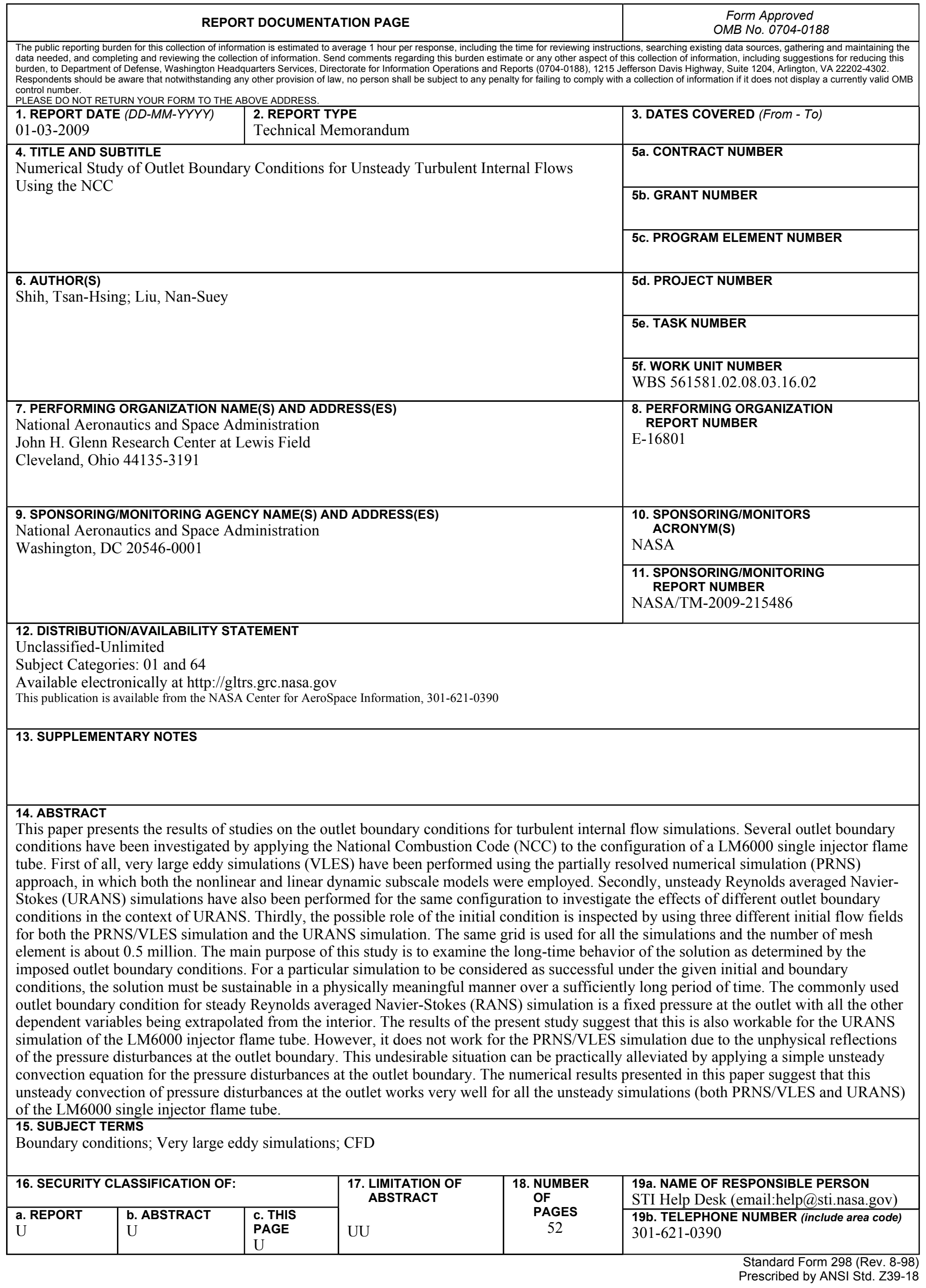



